\title{
A COMPARATIVE ANALYSIS OF RACE AND MATTERING IN LEISURE LITERATURE
}

by

Cassandra Faye Rubinstein

\begin{abstract}
A thesis
Submitted to the faculty of the University Graduate SchoolisEp: in partial fulfillment of the requirements for the degree
\end{abstract}

Masters of Science

in the Department of Public Health

Indiana University, Bloomington

Spring 2020 
A Comparative Analysis of Race and Mattering in Leisure Literature

A Thesis submitted by

Cassandra Faye Rubinstein

Graduate Committee:

Dr. Rasul Mowatt, Chairperson

Dr. William Ramos

Dr. Brian Forist

Date of Defense: May 4, 2020 


\section{TABLE OF CONTENTS}

\section{Page}

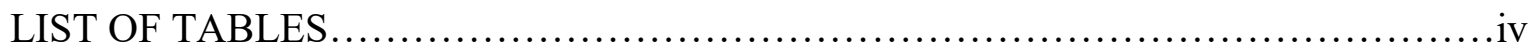

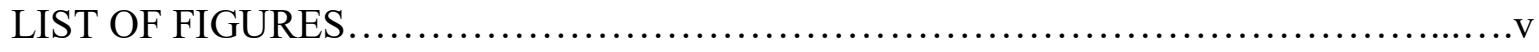

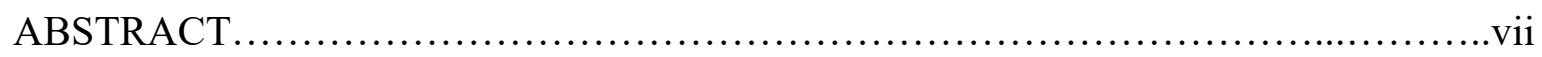

CHAPTER 1: INTRODUCTION..................................................

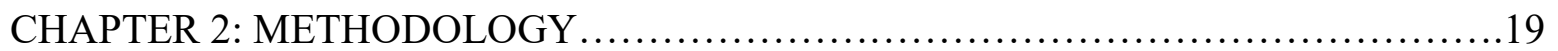

CHAPTER 3: RESULTS.................................................. 32

CHAPTER 4: DISCUSSION ................................................... 72

CHAPTER 5: CONCLUSION .............................................90

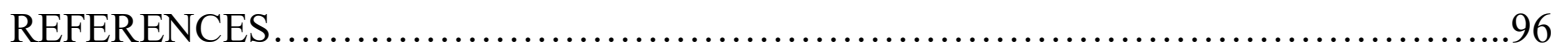

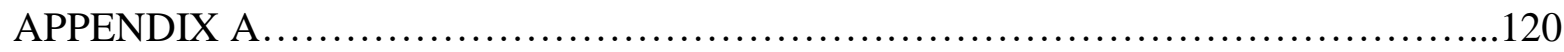

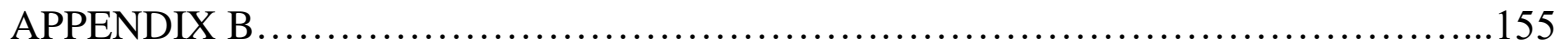




\section{LIST OF TABLES}

TABLE 1: Thematic Descriptions

TABLE 2: Articles on Race Classified as a Faint Mention

TABLE 3: Articles on Race Classified as a Racialization in the Negative

TABLE 4: Articles on Race Classified as an Improper Terminology Use

TABLE 5: Articles on Race Classified on the Intentionality of Race

TABLE 6: Articles on Race Classified as Inadequate Lens of Problem/Solution

TABLE 7: Article Themes Based on Decade 


\section{LIST OF FIGURES}

FIGURE 1: A feminist analysis of selected professional recreation literature about girls/women from $1907-1990$

FIGURE 2: Central Park as a model for social control: urban parks, social class and leisure behavior in nineteenth-century America

FIGURE 3: Role of leisure in meaning-making for community-dwelling adults with mental illness: Inspiration for engaged life

FIGURE 4: Women, wilderness, and everyday life: A documentation of the connection between wilderness recreation and women's everyday lives

FIGURE 5: Ten percent of those we teach and they serve: A case study of incorporating gay and lesbian studies into the curriculum

FIGURE 6: Voluntary participation and parents' reasons for enrollment in after-school programs: Contributions of race/ethnicity, program quality, and program policies

FIGURE 7: Organizational barriers to diversity in the workplace

FIGURE 8: The reemergence and revitalized focus of JLR

FIGURE 9: Rurality in leisure research: A review of four major journals

FIGURE 10: "Embarrassingly White" faculty racial disparities in American recreation, park, and tourism programs

FIGURE 11: Attracting Hispanics to an African American recreation center: Examining attitudes and historical factors

FIGURE 12: Not yet a woman, not yet a mom: The leisure experiences of pregnant adolescents FIGURE 13: Minority youth participation in an organized sport program: Needs, motivations, and facilitators 
FIGURE 14: "I can't have my mom running me everywhere": Adolescents, leisure, and accessibility

FIGURE 15: Multiple dimensions of meaning in the domains of work, family, and leisure FIGURE 16: Young adolescents' shared leisure activities with close friends and dating partners: Associations with supportive communication and relationship satisfaction

FIGURE 17: Just spaces: Urban recreation centers as sites for social justice youth development FIGURE 18: The future of leisure studies

FIGURE 19: Power threats and radical healing in Black youths' leisure FIGURE 20: Increasing diversity among students in recreation, parks, and leisure studies curricula: A case study

FIGURE 21: The relationship between multicultural service-learning and self-reported multicultural competencies in undergraduate students: A qualitative participatory action study FIGURE 22: Notes from a leisure son: Expanding an understanding of whiteness in leisure FIGURE 23: "You have to have some fun to go along with your work": The interplay of race, class, gender, and leisure in the Industrial New South 


\begin{abstract}
The purpose of this thesis was to examine the progression of discourse on race within leisure studies scholarship through the lens of racecraft and the construct of mattering. The Journal of Leisure Research as well as Schole were examined within the periods of the 1990s (1989 - 2000) and the 2010s (2009-2019). Articles were chosen based upon their employment of the keywords of community recreation, youth development, and race within both time periods, yielding a total of 99 articles that were examined. A discourse historical approach (DHA) was utilized in assessment of the impact of the socio-political context on leisure research as well as the development of discourse on race. Through DHA techniques and the concept of racecraft, this project classified articles under five overarching themes: Faint mentions of race, racialization in the negative, improper terminology use, intentionality of race, and inadequate lens of problem/solution. Based upon the findings of this thesis, leisure literature has displayed minimal progression in its conceptualizations of race. Leisure studies scholarship reflects the dominant discourse through its latent ideology of racism that maintains marginalization of various racialized ethnic groups. It is posited that, without institutional examination and targeted mitigation efforts, the field of leisure will continue to uphold a detrimental racial order with an underdeveloped political and historical stance on race.
\end{abstract}




\section{CHAPTER 1}

\section{INTRODUCTION}

Within the history of leisure literature, an individual's freedom to choose experiences had remained an unquestioned part of the leisure process. The notion that equality in choice is inherently provided to all had long been a point of difficulty in expanding the discussion of racism in leisure (Philipp, 2000). Although leisure has historically contributed to reduced racial contact and propagation of discrimination through spatial relations, integration and equity in access to various leisure pursuits have remained beyond the purview of legislature and community priorities (Mowatt, 2018; Philipp, 2000). The proposed neutrality of leisure in which the field is deemed as free from prejudicial behaviors begets continued production of discourse that maintains the "cognitive tyranny of dominant paradigms in leisure research" (West, 1989, p.12). Evolution in knowledge on leisure experiences is constrained by research questions that elucidate era-specific social and political priorities (Floyd, 1998). Therefore, it becomes prudent to "reevaluate this era of literature and how it influenced our contemporary thinking of race" and how this thinking has parceled out power and significance to various racialized ethnicities (Mowatt, 2018, p.665).

In the late 1990's emergence of a more critical view of leisure studies scholarship pertaining to the construct of race by Floyd (1998) revealed propagation of biased ideologies underlying marginality and ethnic hypotheses. Floyd (1998) contextualized these discussions as having failed to recognize the "compelling reasons for a more explicit treatment of race as a major stratifying principle in the study of racial and ethnic factors in leisure research" (p.12). This particular publication becomes a notable divergence from prevailing research in that it specified the problematic manner through which scholars assessed the intersection between 
leisure and race. More so, it exhibited the pivotal need to understand the construction of racial classifications as "the meaning society ascribes to the phenotype and the societal rewards and privileges allocated to persons based on their phenotypic characteristics can have a profound on leisure choices and constraints" (Floyd, 1998, p.11). Almost two decades later, Floyd and Stoldolska (2019) reiterated the need for leisure discourse to progress away from the utilization of race as an explanatory variable in leisure inequity and rather analyze the systems that produce the inequity.

The development seen currently in leisure studies scholarship supports the urgency to expand leisure research to allow for critical thought and inquiry, creating recognition of latent patterns of discrimination that underlie norms in the field (Floyd, 2014). Patterns such as acknowledgement, erasure, marginalization, and mattering within publications serve to "articulate with, reinforce, or resist dominant power relations" (King, 2005, p. 405). Thus, while the amount of research on the topic of race has increased over time, this is not necessarily an indication that the type of research being conducted is useful in dismantling the predominance of adverse paradigms (Floyd \& Stoldolska, 2019).

Based on current and historical criticism, this thesis aims to examine whether leisure studies scholarship has conceded to essential critiques as seen within the field's discourse of race. This study is oriented with particular attunement to the progression in conceptualizations of race as seen through comparative analyses of research produced within two decades. This thesis utilizes the concept of racecraft in assessment of the covert practices within leisure studies publications that reveal the marginalization and/or mattering of racialized ethnicities. Thematic findings from this study will be utilized as a means of appraising the field of leisure's implicit stance on oppression. 


\section{Leisure Publications and Race}

Recognition of patterns of prejudice must be initiated before the process of change in deleterious conditions can be brought about (Mowatt \& Schmalz, 2014). Thus, critical analyses of leisure and its conceptualization of race within literature can further the identification and resolution of harmful discourse in research.

Floyd (2007) observed leisure publications as consisting of waves in thought beginning in the 1970's. At the end of the 20th century, Kivel (2000) becomes a part of the third wave of leisure studies publications on race. Kivel (2000) expounded that the use of false racial categories as a means to explain leisure discrepancies bring about the continuation of detrimental differences. The utilization of such classifications in research thereby served to "reinforce the fact that differences exist rather than examine how differences are constructed within cultural ideologies and institutionalized oppressions" (Kivel, 2000, p.81). Beyond notable and divergent assessments of race and leisure, research during this wave focused on race as an identification marker in studying varying leisure experiences; consequently, failing to acknowledge the racism from which these variances were conceived (Arai \& Kivel, 2009). An additional analysis of leisure literature on race by Philipp (2000) acknowledged that the prevalent and oftentimes unchallenged perception of leisure as supremely beneficial had produced a lack of awareness in researchers of the field's role in producing harmful conditions. In both instances, leisure studies scholarship within that particular time period is viewed as part of persistent discrimination against various racialized ethnicities.

Consistent with Floyd (2007), the field is now approaching what is believed by Arai and Kivel (2009) as the fourth wave of race research in the field. This current formulation in ideas elaborates on how "power, ideology and white hegemony" operate within in leisure studies 
scholarship (Arai \& Kivel, 2009, p.459). Kivel et al. (2009) expanded on the notion that ideologies uphold hegemony in their critique of research's focus of leisure "experiences" of racialized ethnicities without acknowledging the socio-political context and the "leisure experiences of marginalized groups [that] reinscribe their status as "other" (p.475). Thus, there is an appeal to scrutinize race as a construct with which systems and institutions attribute meaning and power (Arai \& Kivel, 2009). Development in analyses in the current decade is further demonstrated by Mowatt (2009) in which the author detailed the influence of Whiteness and racism in the field through their assessment of racial projects as permeating differences in power. While there is a resounding urge in both waves and decades to utilize diversified theories and methods to study race in leisure studies, the current conceptualization shifts the recognition of leisure's contribution to prejudicial outcomes toward "address[ing] racism inherent within policies and practices" (Arai \& Kivel, 2009, p.469) Thus, framing the examination of leisure studies scholarship as being oppressive rather than merely part of the oppression.

Through its utilization theories and models that have been received limited application within the field, this thesis adds to the growing literature within the current wave of research by providing a varying perspective on the prejudicial nature of leisure research.

\section{The Concept of Racecraft}

Conceptualizations of race, although scrutinized and reimagined over time, remain fundamental to the producing the social change that is sought after within the fourth wave of leisure publications (Arai \& Kivel, 2009). Emphasis on illusory differences based upon racialized ascriptions is indicative of more than the shortsighted practices in leisure research but rather it "obscure[s] the insidiousness of complex issues of power at the root of racism" (Kivel 2005, p.22). The relationship between race and racism is understood through the process of 
racecrafting in which race is utilized as a "ceremonial expression of super- and subordination which is regularly enacted" in preserving racism (Guess, 2006, p.671). Racecraft "disguise[s] collective social practice as inborn individual traits"; thereby, utilizing characteristics of racialized groups as a means to justify racism (Fields \& Fields, 2012, p. 261).

The illusion of racecraft makes the use of race in research appear as "a guiltless word, a neutral term for an empirical fact" (Fields \& Fields, 2012, p. 95). Race as descriptive grouping is not a fact but rather a circumvention around the acknowledgment and actuality of racism in its systemic perpetuation. The perceived impartiality and innocence of race thereby concealing the pernicious outcomes that occur as a result of it's use. While there is an effort to understand constituents and ultimately bolster leisure services, leisure researchers have unwittingly used race as a categorical or explanatory variable that is fraught with hegemony and racialized inferiority (McDonald, 2009). The use of racialized classifications allows for "immoral acts of discrimination disappear, and then reappear camouflaged as the victim's alleged difference" (Fields \& Fields, 2012, p. 95). In operating from this point of view, explanations for inequity become a matter of divergences in 'racial preferences and experiences' (aspects of the victim) rather than a function of oppression that differentially affects groups of rationalized ethniticites (actions of the perpetrator). Whereas the intent may be to recognize the complexity of leisure behavior and constraints along "racial and ethnic lines" (Shinew et al., 2006), leisure studies scholarship revitalizes the deception of race and become complicit actors in the preservation of racist ideology.

As conveyed by Kivel (2005), “in an attempt to understand differences in leisure behavior and participation rates, we will forever be tied to seemingly essential categories of race and, subsequently, we will be tied to reinforcing racism" (p.25). The collective understanding of 
race as is represented in literature exemplifies a system of racialized identification without evaluation of the social and ideological foundations that both produce and rationalize discrimination as a result of its use (Fields \& Fields, 2012). Whether through blatant means or otherwise, production of knowledge can be set within the "mental terrain" of racecrafting (Fields \& Fields, 2012, p.25); thereby, demonstrating the "discursive power of language to produce and reproduce differences" and injustices in leisure research (Kivel, 2000, p.80).

\section{Critiques of Racecraft}

Fields and Fields conception of racecraft has been critiqued as patronizing, overly grounded in biology, and ambiguous in their assessment of present-day bearing of historical occurrences such as slavery (Morning, 2013). In scrutinizing the utilization of race within the linguistic repertoire and research categories of scholars, Fields and Fields (2012) do not deduce that these scholars have the "emotion or state of mind, such as intolerance, bigotry, hatred, or malevolence" that would precede overt or violent displays with racism (p.17). Nor do the authors found their examination of racecraft under the misinterpretation that many scholars that study race are not forthright in their endeavor to bring about equity or awareness despite their involvement in racecraft (Fields \& Fields, 2012). However, Fields and Fields approach to uncovering oppression is based on the knowledge that "the first principle of racism is belief in race, even if the believer does not deduce from that belief that the member of a race should be enslaved or disfranchised or shot" (Fields \& Fields, 2012, p.110). Thus, while scholars may not intend to regenerate hegemony and prejudice in their practices, a worldview that presumes "differences between racial groups are determined by a fixed and uniform essence that resides within and defines all members of each racial group" (i.e., biological essentialism) sustains racialized social order (Soylu Yalcinkaya et al., 2017, p.2). More so, it exhibits that racecrafting 
remains entrenched within collective consciousness and customs so far as to be repeated and unexamined by even those that attempt to bring about justice and equitable conditions through their research.

While denounced for its perceived weakened applicability based upon referencing "the historical study of slavery" and "a historical, black and white vision of the United States" (Morning, 2013, p. 530), the chronicle of persistent oppression is a foundational aspect in understanding its current translation to additional racialized ethnic groups. As is seen, "the various forms of racial oppression in the United States have drawn heavily on the white-racist framework created for black Americans", placing groups on the " 'black end' of the society's racist continuum" based upon their various migratory patterns, visible characteristics and perceived traditions (Feagin, 2010, p. 257). Thus, the marginalization of groups based upon their racialization, although derived from a long historical lineage, illustrates that "most forms of white-racist attitudes and practices directed against the numerous groups of color reproduce and reinforce each another" (Feagin, 2010, p. 257). While indoctrinated into America's social order, racism does not rely on solely black identifications to make it a pervasive aspect of current society. Rather it relies on the continued consumption of racecraft to confirm the existence of race; accordingly, "race then ceases to be a historical phenomenon and becomes instead an external motor of history" (Fields \& Fields, 2012, p.120). Overall, "racial ideology in its radical American form is the ideology to be expected in a society in which enslavement stands as an exception to a radically defined liberty so commonplace that no great effort of imagination is required to take it for granted" (Fields \& Fields, 2012, p.142). Accordingly, while the concept of racecraft was defined through a black-white historical lens that included slavery, its application only provides further depth to the selective withholding of basic human rights based upon 
racialized ascriptions.

In addition to the abovementioned critiques, Morning (2013) claimed that the fundamental ideas presented by Fields and Fields are no longer an innovative concept and have been preceded by scholars in fields such as sociology. However, this particular critic's later claim that "race notion remains comfortably ensconced in the most cutting-edge realms of the natural sciences" lays a foundation of support for the present day utilization and effects of racecraft despite previous scholarly acknowledgement as well as their own attempts at scrutiny (Morning, 2013, p.529). While academic fields may neither discredit the existence of racism nor have overlooked the maintained inferiority of racialized ethnicities (Morning, 2013), the preservation of race within scientific reasoning despite previous biological dismantling exhibits the endurance of racecraft at the crux of collective beliefs. As it is seen, "when virtually the whole of society ... commits itself to belief in propositions that collapse into absurdity upon the slightest examination, the reason is not hallucination or delusion or even simple hypocrisy; rather it is ideology" (Fields \& Fields, 2012, p. 118).

\section{Application of Racecraft}

Leisure studies scholars have explained moral implications that come about when scholars are unwilling to challenge the injustices that have been revealed within research (Floyd, 2014). However, the field is wholly unprepared for such movements toward social justice and advocacy against inequality if positioned within the unstable ideological grounds of racecraft (Field \& Fields, 2012). Thus, the literary analysis conducted within this study is centered on observing racecraft with the intent to "reorient analysis and activism" within leisure studies scholarship (Benjamin, 2014, p.688).

The power of language is specifically noted in the actualized deception of race as it is 
through discourse and thought that it is conceived and reconceived through time (Field \& Fields, 2012). Therefore, the term racialized ethnicities is utilized within this thesis to place greater emphasis on the process of racialization as opposed to the illusion of differing races.

Consequently, averting attention away from the supremacy given to various racialized ethnicities and toward the differential application of racism (Wiegman, 1995).

Additionally, while race is noted as a topical area of interest within this paper, it is taken through an incongruent conceptual lens than what may be noted in leisure studies scholarship. It is neither in confirmation of its pseudo-biological actuality nor in validation of the cultural and biological essentialism of race. Rather, it is viewed as a marker that racism is in operation in production of leisure differences. It is through this incongruence that the ideological underpinnings of the field and subsequent research are noted as it relates to leisure's position in matters of power and prejudice.

\section{Ahistorical and Apolitical Lens of Leisure}

The power inherent in discourse is that it exists as one of the "structural dimensions of a racialised social system" (Mowatt, 2019, p.2). In disengaging from the predominant mental grounds from which misinformation and inequity are advanced, discourse surrounding race requires a historical and political lenses to accurately evaluate the foundation from which they were formed (Kivel, 2005). Thus, without an astute awareness of oppressive patterns that have formulated and become increasingly systematized over time, it becomes easy to miss the progression of racism that continues in the present (Guess, 2006). Racism is not an antiquated fact nor is it obsolete in it's bearing on the knowledge and practices on the field as it currently exists (Glover, 2007). However, it is difficult to appropriately challenge racism in the present when constrained by a "lack of an accurate contextual memory and understanding [that] is 
central to the dominant white framing of society" (Feagin, 2014, p.60).

Race and, by extension, racial prejudice is created through history and political patterns that, despite shifts, continue to establish and re-establish inequality in power in leisure (Mowatt, 2018). Floyd and Stodolska (2019) scrutinized the field's limited engagement and response to racialized issues in leisure in research. If fostered from the prevailing orientation of racialization that has endured for centuries within America, it is unsurprising that, without critical questioning, publications are able to engage from this detrimental viewpoint (Feagin, 2014). It is denoted in the chronicle of leisure policies that have been and continue to be driven by racialized ethnicities in power; thus, historically legitimatizing and maintaining inferiority of those that are oppressed (Floyd \& Johnson, 2002). It is additionally exemplified in the utilization of terminology such as "difference and diversity [which] replace words like slavery, injustice, oppression, and exploitation, diverting attention from the anything - but - neutral history these words denote" (Fields \& Fields, 2012, p. 147). Commonplace rhetoric, which outwardly emerges as unbiased and even benevolent in its use, effectively detaches discourse from historical accounts that demonstrate matters of racialized "difference" to be constructed as a means to authorize discrimination (Fields \& Fields, 2012). Thus, when our contemporary reality is positioned within the unexamined political and historical roots of oppression, leisure studies scholarship is "unwittingly re-catalyzing a distillate ideology produced out of the very history they sought to escape" (Johnson, 2014, p. 132).

While the utilization of race may appear inconsequential, the reproductions of race and racialized distinctions as a social fact as seen in leisure research "define real issues in American society... [and] issue into real social consequences" (Guess, 2006, p.654). Although acts such as segregation in leisure settings appear as a function of the past, manifestations of injustice 
function as signals for the pervasive beliefs and thoughts that are indoctrinated as commonplace (Mowatt, 2009). It is epitomized in a letter to the editor in response to an article regarding equity within a leisure publication:

...Our parks are overcrowded now. Whether Goldsmith wishes to be realistic or not, bringing in blacks and Latinos from the ghettos will only contribute disproportionately to vandalism and other criminal activities, including robbery, murder, drug trafficking and gang activity... By publishing the article, national parks does current visitors a disservice. (Lange, 1994)

It occurs in the current decade as is seen in "modern race play" in which individual performances are created by White teens with black face make up in ridicule the death of a young Black teen and later broadcasted through digitalized leisure spaces (Durham, 2015, p.255). Thereby, making light that "White pleasure can trump Black pain" (Durham, 2015, p.256). Despite that over two decades passed between both instances, the prevailing supremacy that is afforded to some based upon racialized ascriptions in leisure remains. Over time, the existence of prejudice has not changed from its historical roots but the performance has been altered to fit the landscape of the time periods from which they occurred. Additionally, while both can be seen as individual acts of willful discrimination, they depict the manners by which historically and currently "leisure has always been political and malignant" (Mowatt, 2018, p.672).

Rose et al. (2018) contend that "every aspect about leisure, from its management to its implementation to its funding to its identities, is political" and with that includes leisure studies scholarship and the information that is formulated (p. 651). If politics is recognized as resource allocation based on power, then the field engages in politics when engaging in racecrafting that 
perpetuates beliefs and actions to help justify prejudicial allocation of commodities, including leisure consumption (Rose et al., 2018). There is a participation in politics as researchers examine race by focusing on racialized ascriptions, "placing them in a world exclusively theirs and outside history — a form of intellectual apartheid no less ugly or oppressive, despite its righteous (not to say self - righteous) trappings, than that practiced by the bio - and theo racists" (Fields \& Fields, 2012, p.146). It is shown in the lack of literature on sociopolitical issues that impact leisure services, where silence in the name of apolitical positions becomes political in nature and in defense of hegemony (Rose et al., 2018).

When viewing the aforementioned waves of leisure studies scholarship on race, they become exhibitions of the changing nature of conceptualizations of race. Segmented into periods of time, these waves reflect the ways in which understanding of race is reinvented to adapt to the changing political and historical periods at which research is produced. However, the field of leisure in the current decade continues to be criticized as lacking scholarship that recognizes the ways both race and leisure are politicized (Rose et al., 2018). This thesis is seen as complementary to the progression of leisure research by questioning what is viewed as conventional practice and positions. Can the field critically engage in topics of race and racism in leisure without historical and political knowledge of racialization and prejudice? Can publications produce change in leisure's contribution to such topics if there is a disregard for how the field continues to sustain racial order through apolitical and ahistorical stances (Mowatt, 2018)? Can oppression in leisure be thwarted without discourse that assumes responsibility for the ways in which it has and continues to be systemically prejudicial and problematic? 
Classifications can prove to be divisive agents in facets of belonging (Schlossberg, 1989). While there is an expectation for various racialized ethnicities to thrive in similar ways as those who are recognized and promoted, it is difficult to ignore the endurance of systemic inequity. The presence of such diminishes and even expunges the reality of racialized ethnicities from contexts including leisure spaces and research produced by the field. Diverse paradigms that can be used to remediate injustices thereby become fundamental agents in producing change. Marginalization is proposed to exist on a polarized scale by which the construct of mattering is situated on the opposing end (Schlossberg, 1989). In this regard, mattering provides an approach to reduce marginalization of racialized ethnicities (Johnson, 2012).

Based upon the biological and psychological needs in humans, mattering has been understood as a fundamental aspect of this hierarchy of necessities (Tucker et al., 2010). Mattering is one's perception of personal significance to not only the individuals with whom one interacts with but also the environments that one occupies (France \& Finney, 2009). While a sense of belonging is correlated with mattering, mattering goes beyond mere awareness and relies on the additional components of importance, reliance, and ego-extension (France \& Finney, 2009). In connection to the aforementioned patterns in leisure research, acknowledgement is understood as a demonstration of mattering with both concepts positioned in stark contrast to erasure and marginalization.

While race is regarded as a falsified social construct, identity has been found to be influenced by racial distinctions (Steck et al., 2003). This finding is especially noted in the identity of racialized ethnic groups (Steck et al., 2003). Through the lens of racecraft, this ascribed identification does not pertain to an individual's "sense of self, but identification by others, peremptory and binding" (Fields \& Fields, 2012, p. 128); consequently, racialization 
allows some to be "readily perceived as inferior by nature when they are already seen as oppressed" (Fields \& Fields, 2012, p.158). Thus, the effects of oppression latent within various racialized identities can be seen in the formation of a "stigmatized self-concept" (Wright et al., 2000, p. 71). However, mattering is an element of self-concept that can positively aid in personal identity formation (Josselin, 1994). Perceptions of acknowledgement can additionally attenuate marginalization in social spaces and is related to decreased perceptions of stigma (Marshall, 2001). The affect that both racialization and mattering have on identity provides an opportunity to reduce discriminatory patterns in leisure research. Reinforcement of mattering in methodologies and scholarship texts may reduce the permeation of the falsity of race as an identity symbol of power and towards the way in which the environment (racist discourse and practices) propagates racecrafting.

Furthermore, mattering is influenced by not only the quantity but also the quality of behaviors of others (Dixon et al., 2009). These behaviors are viewed as indicators of one's personal significance (Dixon et al., 2009). In this respect, the frequency that the field of leisure produces scholarship on the topic of race is not sufficient in fulfilling the need to matter. While there has been a call to attenuate the issue of relevancy and impact of leisure research, permeating topics such as race for the sake of increasing content on social matters can push scholarship closer on the scale to marginalization (Glover, 2015). In this line of thought, frequency of recognition does not indicate a sense of concern regarding the injustices noted in leisure (importance). It additionally does not denote that racialized ethnicities are acknowledged as an asset rather than a deterrent to leisure spaces (reliance). More importantly, recognition does not convey the sense that those performing the research are invested in dismantling the injustices seen in leisure as those on the receiving end of discrimination (ego-extension). The moral 
implications of such injustices merit critical research examinations that go beyond production and toward an urgent desire to bring about social justice (Floyd, 2014).

Mattering additionally includes perceptions of significance in the world in that the presence of the individual makes a positive influence (Watson, 2017; Conrad-Garrisi \& PerniceDuca, 2013). Societal norms likely influence general mattering as the enactments of customs can indicate an individual's significance (Mashall, 2001). However, these customs and ideas of worldly significance are impacted by another dominant norm of racecrafting that is part of collective social belief. In this view, racialization negates attempts to matter due to the "social de-valuation imposed on non-white peoples" based upon ascriptions (Guess, 2006, p. 651). The significance of some are thwarted by the norms attached to their racialized category; thus, “dividing society into persons entitled to claim respect as a right and persons obliged to beg tolerance as a favor" (Fields \& Fields, 2012, p.105). Racecrafting will always be divisive in its nature; however, on which side of the dividing line that an individual falls can result in drastically different consequences. As so, the destructive price of a racialization falls upon those who have been dehumanized by their outward characteristics, whose presupposed inferiority denies them of the societal license to assert their rights in their totality (Fields \& Fields, 2012). Cultural injunctions saturated in racism may prescribe the societal mattering of groups of individuals. Leisure studies scholarship "with a racialized worldview imbedded in cultural consciousness" upholds hegemony that leaves mattering in the hands of those that have the power to determine the cultural playing field to begin with (Guess, 2006, p.666).

In considering the use of mattering as a means of abating marginalization, this study seeks to consider to what degree this construct is reflected in research and service deliverables in leisure. How does written word or action in the field portray which racialized ethnicities are held 
in the periphery and which are important? What is the quality of attention given and what does this type of quality represent in terms of the field's stance on leisure inequality?

\section{Leisure and Systematic Contribution to Inequality}

If "prejudice is only an echo or evidence marker that injustice has occurred", then the persistent focus on race over time without ideological evaluation becomes indicative of overlooked oppressive systems at work (Mowatt \&Schlmaltz, 2014, p.353). While it is unclear whether practitioners employ the information supplemented by research publications (Stodolska, 2000), leisure studies scholarship is reflective of the institutions from which it is produced (Stewart et al., 2008). Institutionalization of oppression occurs through a process of structuration whereby racism is adopted into systems in part through discourse or signification (Giddens, 1984; Guess, 2006). Therefore, while the practical application of research may not be seen through obvious translations in leisure settings, there exists a general concession of institutional patterns of thought, "where problems of power and socially constructed categories of race are created, normalized and maintained" (Kivel, 2005, p.26). Even more so, prejudice has become an unquestioned axiom "institutionalized in time and space by the concrete acts of men in power" and effectively distanced from the individual (Lyman, 1990, p.140). Thus, while individual thought behind research may not indicate intentional propagation of racism, scholars are not exempt from examining the ideologies and institutions from which their beliefs and knowledge is constructed upon (Stewart et al., 2008).

As expressed by Stodolska (2000) at the end of the 20th century and restated in the current decade by Schmalz and Mowatt (2014), there has been very little if any current and historical deviation from the effective and pernicious patterns of racial discrimination, although perhaps more nuanced. Consequently, what has taken the place of "racism by intent" is "racism 
by consequence", which manifests away from the immediate awareness and lives within "social practices that are essentially depersonalized through institutionalization" (Guess, 2006, p. 651). The knowledge that underscores research production is impacted by covert prejudice, influencing the viewpoint of researchers on the inequality of power latent within systems (Schmalz \& Mowatt, 2014). Thus, to assume that the field of leisure is operating within a post-racial society is to ignore the ways that 'neutrality' conceals continued prejudice by ignoring structural aspects of oppression (Durham, 2015). Neither leisure nor knowledge is neutral and operating from this belief effectively removes the opportunity for critical commentary from the forefront of discourse despite obvious relevancy (Stewart et al., 2008; Glover, 2007).

The impact of leisure publications remains that it has the power to create and conventionalize discourse and practices that reinstate power and identity (Hall \& DuGay, 1996). Without acknowledgement and awareness of the manner through which racism and oppression proliferates, it is difficult to take a stance of active resistance (Floyd \& Stoldolska, 2019). More so, it becomes increasingly evident when researchers are unacquainted with the ways that they are impacted by dominant discourses and practices based upon which sociopolitical issues of leisure are erased or acknowledged from the forefront of the field (Rose et al., 2018). A systemic appraisal of injustice in leisure would reveal greater production of scholarship around assessment of "environmental justice, institutional bias and discrimination, program/agency nonresponsiveness, and violence" (Allison, 2000, p.4). It would yield greater critical engagement in matters of politics, power, and history of leisure and race (Rose et al., 2018). Therefore, evaluation of leisure studies scholarship fosters understanding of the ways that power is proliferated through knowledge production and with this knowledge, the demarcation of which individuals are continuously held in the periphery. 


\section{Conclusion}

While inequities are erected systematically, they are illuminated and perpetuated on individual levels including those found in research. In light of this, the purpose of this paper is to investigate the pertinent question if the field has used the power that is inherently intertwined with linguistics and discourse to bring leisure professionals in line with agendas of social justice or closer to the dominant yet detrimental narratives that have endured thus far. 


\section{CHAPTER 2}

\section{METHODOLOGY}

There is influence inherent in the use of linguistics as "the language use of those in power who have the means and opportunities to improve conditions" reveals "ideologies that establish, perpetuate or fight dominance” (Reisigl \& Wodak, 2017, p.88). Reisigl and Wodak (2017) demonstrated the importance of deconstructing how "power is discursively exerted" by those that possess control over texts (p.89). A discourse-historical approach (DHA) allows for a multifaceted examination of text in publications that takes into account not only the written text but also the societal context during the time that the text was produced (Reisigl \& Wodak, 2017). This lends to a greater critique of consistencies and discrepancies found within leisure research as well as the influence of socially constructed narratives that occur outside of the field (Reisigl \& Wodak, 2017).

DHA is a form of Critical Discourse Analysis (CDA), which differs from linguistic evaluations in that it takes into account "the broader historical, social and cultural frame of activities, practices and ideologies" (Le et al., 2009, p.67). Thereby, allowing for greater scrutiny of the social power, ideology, and social practices that are established within discourse and remain a fundamental part of the chosen methodology (Le et al., 2009). Stewart et al. (2008) have noted that ideology and power are inescapable and many times overlooked aspects of leisure research, oftentimes creating limitations and guidelines for how to assess various topics. It becomes imperative that critical inquiry be employed to assess these latent nuances of values and boundaries within leisure studies scholarship (Stewart et al., 2008) The CDA and more specifically DHA heeds upon this essential critique in order to “ 'demystify' discourses by deciphering ideologies" (Wodak, 2009, p.312); consequently, creating awareness around 
otherwise conspicuous aspects of discourse that can detract from objectives of equity in leisure.

\section{Social Power, Ideology, and Social Practices}

The utilization of DHA within this study is reinforced in its foundation of three principle elements that support its overall methodological goals: social power, ideology, and social practices.

\section{Social Power}

There exists a compelling relationship between discourse and social power in that discourse can function in construction of social power but also can be influenced by its utilization (Le et al., 2009). Therefore, those that occupy a powerful social position are able to control the rhetoric and, by extension, the beliefs and commonplace practices of those on the receiving end of discursive practices (Le et al., 2009). DHA explores the covert indications of social power within texts or discourses as is exhibited by the signaling of power differentials. Social power is additionally displayed in the level of concern given to those that do possess the same amount of power, which can be revealed within the grammar, vocabulary, and overall production of texts (Wodak, 2009; Le et al., 2009). When viewing leisure studies scholarship, the authors' utilization of race (i.e., categorically or critically) can illustrate their understanding of hegemony as well as their own possession of power. Moreover, the author's engagement in racecraft can be exhibitory of their position in reproducing social power and also potentially reveals their own heedless consumption of discourse that serves the supremacy of those that benefit from its creation.

\section{Ideology}

Power differentials adduce ideologies that intervene in the research process in leisure studies scholarship (Stewart et al., 2008). Endurance of oppression is upheld by the combination 
of ideology and beliefs that permit it (Van Dijk, 1992). Discourse becomes an important mediating component as it functions to erect ideologies that meet the needs of those that employ it (Stewart et al., 2008). An obvious proclamation of ideological underpinnings within research would thereby influence researchers to acknowledge their values and positions on topics they seek to investigate, which is a practice that is not currently seen in leisure studies scholarship (Stewart et al., 2008). Thus, the use of DHA is substantiated due to its inextricable link to ideology in that its investigation is predicated on the ways ideology is "encoded in texts, often manifested in lexical choice, cliché, presuppositions and implicatures" (Le et al., 2009, p.12).

\section{Social Practices}

Discourse is seen as a social practice in that it is a process and activity of communication (Le et al., 2009). While this type of activity is viewed as customary, especially within academic fields and institutions, social practices are integrated in ideology and inequity of power that allow the oppressive nature of discourse to remain inconspicuous precisely because it is widely accepted (Le et al., 2009). The social action of language use has the faculty to control and produce base knowledge and, in doing so, can have a profound effect on the fields and institutions in which they operate (Fairclough, 2003). Considering the "social injustice which is manifested in various social practices", examination of actions within the field of leisure that are considered commonplace is a pivotal component of utilizing DHA (Le et al., 2009, p.4).

\section{Social Justice}

Based upon Philip (2000) and Floyd (2014), agendas of social justice are advanced through research that capitalizes on varied methodologies and theories as a more deliberate address of oppression. DHA permits such interdisciplinary analyses as it amalgamates diverse models, practices, and applications to create a comprehensive analysis of the topic, immediate 
text and socio-political and historical context (Reisigl \& Wodak, 2017; Le et al., 2009). The use of mattering as a construct within this evaluation serves to further expand the paradigmatic explanations of inequality in leisure research while also being applied as an explanatory tool of DHA in looking at discourse and the conditions that discourse production is embedded (Wodak, 2009).

Additionally, while there is an employment of multiple analytical and disciplinary approaches within the DHA, they are incorporated under "a problem-focused approach, a particular theoretical preoccupation with, and orientation to, power, and a transformative agenda flowing from that orientation" (Le et al., 2009, p.66). In view of the advancement of social justice in leisure studies scholarship, this methodological orientation can be seen as complimentary to the foundation of equity that should be instilled within the research process (Floyd, 2007). Through its attunement to the nature of hegemony in discourse, DHA is able to “take a stance against social abuse, racism, social prejudice and discrimination against dominated or maginalised people with less power" (Le et al., 2009, p.4), which is notably absent within leisure research (Floyd, 2007).

\section{DHA and Racecraft}

Discourse is a fundamental component of racecraft in that text and rhetoric is able to "revivify belief through incessant ritualization" (Johnson, 2014, p.129). Wodak and Reisigl (2003) call attention to discourse's ability to "construct collective subjects" as well as “perpetuate, reproduce, or justify a certain social status quo" (p.385); hence, establishing it's function in the preservation of "differing races" and racialization. This may be brought forth in leisure study publications based upon the referencing of racialized ethnicities, assigned characteristics given to persons based upon their racialized category, and the conduct prescribed 
based upon the naming and associated qualities given to the subjects based on racialization (Wodak \& Reisigl, 2003)

Alternatively, reconstruction and dissolution of the existing patterns of racecraft can be brought about through discourse (Wodak \& Reisigl, 2003). Such outcomes require recognition that the power of language is contingent upon the persons that utilize it (Wodak, 2009).

Individuals with "access to important institutions and public spheres" augment the outcomes brought about through language use due to their advantageous power (Wodak, 2009, p.312). By utilizing DHA, this study places significance on the nature of language use of those with power, converging attention on those producing scholarship within leisure studies. This emphasis undermines the cognitive space of racecrafting that typically misplaces focus away from rather than onto the complicit actors and creators of prejudice. Consequentially, the purview of this project is guided toward "distinguish[ing] between constructive, perpetuating, transformational, and destructive social macrofunctions of discourses" (Wodak \& Reisigl, 2003, p.385). In appraising discursive patterns through DHA, this study can be seen as in line with the primary mode prescribed by Fields and Fields toward comprehension and ultimate elimination of racecraft from the leisure studies scholarship in that it "observe[s] racecraft in action, study its moves, listen to its language" (Fields \& Fields, 2012, p.261).

\section{Contextual Analysis}

History and historical materials are a source of great reflection through which we are able to analyze the indoctrination of attitudes and beliefs presented in society in various ways. Effective analysis of the construction and power of race in leisure is contingent upon recognition of context in which it is embedded (Floyd, 2014). DHA differs from other analyses of discourse in that it is critical; thus, its appraisal takes into account the influence of socio-political and 
historical principles and occurrences on discourse production (Le et al., 2009). It is noted by Sing (2011) that "current discourse conditions and their prevalence for specific discursive formations are an inevitable product of past power struggles and can only be understood when these are uncovered" (p.148). As follows, DHA within this study prompts deductions of "social change and identity politics" within discourse in leisure studies publications (Wodak, 2009, p.311), as well as the connection between the field's discourse production and society (Van Dijk, 2011). Whether through journal publications or media, chronicle of thought both written and displayed persists and over time one is able to detect progression or lack thereof; acknowledgement and erasure; marginalization and mattering. Therefore, a discourse-historical examination was performed for comparison of the decade of the 1990s $(1989-2000)$ and the current decade beginning in 2009 (2009 - 2019). These time frames coincide with the varying conceptualizations of race within leisure studies publications based upon the abovementioned waves of thought. The 1990s are understood as a reflection of the third wave where as the current decade is the approach and ultimate adoption of the field's fourth wave of leisure research on race. Therefore, evaluation of the topic of race within these time periods yields analyses of critical junctures in leisure publications where previous research has noted changes in developments of thought around race (Floyd, 2007; Arai \& Kivel, 2009). Additionally, the 1990s have been noted as the historical period of the preliminary emergence of knowledge around the social construction of race and of whiteness as a mark of power and advantage in scholarship (King, 2005; McDonald, 2009). Therefore, it serves as the point of initiation in significant awareness from which to base progression.

\section{Thematic Concentrations}

Published articles on studies that utilized race within themes of community recreation and 
youth development were chosen. These keywords were intentionally applied based upon literature on the importance of mattering, justice, and racialization in their effects both in youth and community outcomes. The construct of mattering has been shown to have particular importance in youth (Dixon et al., 2009; Rayle, 2005; Marshall, 2001). Additionally, the racialized ascriptions of youth of color being synonymous with "at-risk" and a threat as seen in both leisure spaces and in research allows for greater examination of the field's engagement in racecrafting and the ideology latent within publications on youth development (Mowatt \& Schmalz, 2014).

Community recreation is seen as an additional area of focus within this study as a sense of belonging within a community does not only promote mattering but can also bolster community improvement, with the opposite undermining effects observed in cases of marginalization (Conrad-Garrisi \& Pernice-Duca, 2013; Johnson, 2012; Stebleton et al., 2014). Leisure within racialized populations can be representative of inequity in power in that values impact views of community priorities (Stewart et al., 2008). Community recreation sites have been a historical location of violence and a manifestation of 'othering' of racialized ethnicities with less power (Mowatt, 2018; Mowatt, 2019). Communities being studied are additionally influenced by the manner through which leisure research is conducted (Floyd, 2007). Consequently, advocacy in leisure studies scholarship can support communities where inequity affects not only recreation but also the overall conditions of oppression (Mowatt \& Schmalz, 2014).

\section{Methods}

An initial query was run within the six major journal publications within the field of leisure (i.e., Leisure Sciences, Journal of Leisure Research, Annals of Leisure Research, Leisure 
Studies, Loisir, and Journal of Park and Recreation Administration) in order to identify the publication containing the greatest production of research on the topics of race, community recreation, and youth development. The Journal of Leisure Research was selected as it contains the largest volume of articles published within the three respective topics, having produced 1,154 articles alone on the community recreation and youth development. Additionally, it currently celebrated its 50 th year in publication; therefore, demonstrating the longevity of research from which can be assessed. The journal entitled Schole was also chosen due to its focus on leisure education. Academia is situated at the juncture of knowledge and practice. It is where the field is able to produce professionals and individuals in society with critical thought and understanding of the variables that affect leisure experiences and outcomes. Thus, the utilization of Schole as an additional publication for review serves to highlight what is deemed as "best practices" and approaches to teaching race within the field. More importantly, it allows for examination of the institutional and practical applications pertaining to the intersection of community recreation, youth development, and race. Combined, both journals may be regarded as comprising a large portion of the academic narrative that surrounds the aforementioned topics.

The joint production of publications that included all three areas of interest within the two time frames revealed a total of 99 articles. This analysis is regarded as the first phase of discourse examination; consequently, there will be exclusion of other journals and texts in the field at this particular time. Both journals were evaluated for (a) progression in discourse that promotes mattering in racialized ethnicities within two distinct decades, (b) continuation of discourse that upholds marginalization in racialized ethnicities within two distinct three focuses decades, and (c) societal narratives that are acknowledged or erased from leisure publications. These examination focal points permit systemic analysis in its consideration of continued 
patterns in discourse, historical aspects of texts, as well as contextual framing of the topic within various time periods (Wodak, 2009).

\section{Analytic Approach}

This study began with an "activation and consultation of preceding theoretical knowledge" whereby foundational comprehension of the field's view of race was reviewed as is documented in the first chapter. The subsequent analyses were conducted to reveal patterns within leisure studies scholarship through various genres and texts that join to form a discourse (Wodak, 2009). In order to understand the conceptualization of race within leisure research, Reisigl and Wodak (2017) propose a "triangularity approach" to effectively view the macro and micro aspects of discourse which includes examination of the text (i.e., journal articles) (p.93); “intertertextual and interdiscursive relationship" of texts (i.e., similar language or topic use within and between decades); "institutional frames" (i.e, institutional background that exists outside of the immediate text); and "broader sociopolitical and historical context" (i.e., macro occurrences outside of field and institutions that are associated or affect view of race).

\section{Immediate textual analysis}

The first step of this approach led to an evaluation of the immediate 99 articles based upon strategies that establish "persuasive rhetoric" and rationalize deductions made from the presented information within publications (Wodak, 2009, p.320). These discursive devices serve as an approach in uncovering the embedded ideology of the texts and overall discourse on race within the field of leisure (Reisigl \& Wodak, 2017).

Referential/nomination strategies. In analysis of texts, this device was assessed to understand how the author(s) categorized and exemplified the subjects/experiences/practices being studied (Reisigl \& Wodak, 2017). This was noted in the researcher(s)' use of "the form of 
a part standing for the whole or a whole standing for the part', the representation of the subjects' actions, and the manner in which the subject is referenced (Wodak, 2009, p.320). This may be noted in texts in which small samples are utilized to make assessments of a racialized ethnic group. It may also be demonstrated through techniques of out-grouping such as the use of "minority" status when regarding racialized group with less auspicious societal statuses as well as the applying a normative lens of whiteness to evaluate leisure behavior and preferences.

Predicational strategies. Evaluation of the author(s)' use of this approach provided information on the label placed on the subjects as seen through adjective or noun use, comparisons, and overall "evaluative attributions of negative and positive traits in the linguistic form" (Wodak, 2009, p.320). Recognition of the authors' employment of "collocations", "stereotypes", and "presuppostions" regarding the subjects/experiences/practices in question were dichotomized into positive and negative characterizations (Reisigl \& Wodak, 2017, p. 95). In application of this strategy, articles that display this devise would portray various racialized ethnic groups negatively utilizing words such as "at-risk" of "deviant" to denote an inherent adverse quality.

Argumentation strategies. In appraisal of the researcher(s)' use of this strategy, this study viewed the process of legitimization of positive and negative characterizations given to subjects/experiences/practices within the text (Wodak, 2009). In this case, the author(s) may justify an action or label when utilizing this approach (Reisigl \& Wodak, 2017). The employment of discursive devise would substantiate an out-group status by providing evidence for the implied negative/positive traits associated with a racialized ethnic group. As an example, this could translate into results that display differences between groups based upon their racialized ascription that would justify presuppositions. 
Perspectivation/framing/discourse representation. The researcher(s)' stance on the topic/subject of research is expressed in the reporting, description, narration, or quotation of relevant events or utterances" (Wodak, 2009, p.320). Thus, an assessment of this discourse device is denoted in the authors' engagement or disassociation from the topic/subject as can be seen through what is brought to the forefront, omitted, or minimized within the text (Reisigl \& Wodak, 2017). When comparing outer-field discourse, texts utilizing this representation could denote similar and/or diverging approaches to speaking about race/racism such as a minimizing systemic oppression in leisure or strengthening arguments for diversity appreciation.

In this study, these strategies were additionally referenced during analyses of publications utilizing five guiding questions provided by Wodak and Reisigl (2003):

(1) How are persons named and referred to linguistically? (2) Which traits, characteristics, qualities, and features are attributed to them? (3) By means of which arguments and argumentation schemes do specific persons or social groups try to justify and legitimate the exclusion, discrimination, suppression, and exploitation of others? (4) From which perspective or point of view are these nominations, attributions, and arguments expressed?

(5) Are the respective discriminating utterances articulated overtly, are they even intensified, or are they mitigated? (p.385)

\section{Intertextuality and Interdiscursivity}

Emergence of themes was based upon the demonstration of such strategies and recurring lines of reasoning within research texts between and within the decade of the 1990's and the 2010's. Intertextuality and interdiscursivity can function as a way to elicit reliability and authority in certain developments of thought/ideology on race within the field of leisure (Koller, 
2011). However, the reproduction of various arguments can strengthen knowledge on race within the field regardless of if they are appropriate or correct in their assessments (Koller, 2011).

Intertextuality between leisure studies publications would arise from continued examination of a topic or subject utilizing a particular strategy and/or repeated use of a particular argument or event (Reisigl \& Wodak, 2017). Intertextuality was also denoted in publications when aspects of research are reproduced within other articles and obtain new meaning as a result

of recontextualization between and within the decades presented in this study (Reisigl \& Wodak, 2017). Interdiscursivity was observed through repeated reference to outer-field discourse as a way to support the author's reasoning (Reisigl \& Wodak, 2017). Evaluations of intertextuality and interdiscursivity formed the basis to understand the field's progression in their conceptualization of race as it pertains to mattering of racialized ethnicities. The permeation or discontinued use of aforementioned rhetorical devices function in support of ideology and can promote marginalization or acknowledgement of racialized ethnicities when viewed along historical periods.

\section{Contextual Framing}

In order to obtain a contextual view within this study, information was gathered on the overall conditions and circumstances within the time period of society that the research was situated in and affected by (Wodak \& Reisigl, 2003). Outer field discourse was reviewed in this study based upon the repetition of key words or concepts exhibited within each decade. Repetition was regarded as indicative of intertextuality and/or interdiscursivity that may demonstrate the reciprocal affect of sociopolitical and historical background on discourse produced in leisure studies scholarship (Wodak, 2009). Additionally, notable occurrences both currently and historically were viewed as "important discursive events" (Reisigl \& Wodak, 2017, 
p.98). Therefore, content within texts were reviewed for relevant analyses, recurring points of view, or erasure of the event(s) altogether from the field.

\section{Mattering}

It is with these strategies and subsequent thematic groupings that mattering was assessed within this study. Mattering was seen through themes centered on characterizations of racialized ethnicities, omitted/highlighted content, ideological underpinnings, suggested courses of action based upon research findings. Thematic results were additionally oriented within the view that race and thus racism permeate through racecrafting. Therefore, if racecraft is established within the collective consciousness of both the field and society, then what and who is highlighted or omitted and the manner that they are regarded within discourse demonstrates a conscious or unconscious choice to marginalize or bring forth equity. Cognitive domains will persevere or diminish in part due to discourse with progression in mattering in race within the field being in direct extension. 


\section{CHAPTER 3}

\section{RESULTS}

Of the selected 99 articles, 14 were removed from the analysis due to the article's content being predicated on a physical running race. This was often noted in texts regarding marathon races or within recreation events that included running components. Additional removals were due to a failure to include any information pertaining to race or racialization within the article. Based upon reoccurring patterns in discourse, the remaining 85 articles were classified into five thematic categories: (a) Faint mentions of race, (b) racialization in the negative, (c) improper terminology use, (d) intentionality of race, and (e) inadequate lens of problem/solution. A descriptive overview of these thematic categories can be found in Table 1. Classification was not mutually exclusive in that one article could be included in multiple thematic categories as well as within multiple subcategories under a single theme.

\section{Faint Mentions of Race}

The category of faint mentions of race included articles in which race was neither a central component of the text nor were attempts made by the author(s) to elaborate extensively on how race functioned within the scope of their study. Forty-four classifications were made under the three subcategories of this theme comprised of periphery mentions, inclusion of demographic variables with no assessment, and mentions in relationship to stigma comparison as is seen in Table 2.

\section{Periphery Mentions}

Eighteen articles fell within the subcategory of periphery mentions, which included literature where race was only cited in mentioned sources or utilized within a minimal amount of text within the article. This was frequently seen as one or two sentences on race within the article 
with no additional mentions made. In a study performed by Henderson (1993), the author

performed a content analysis of literature from 1907 to 1990 in examination of their portrayal of

women. The single utilization of race was seen in the following sentence:

The role of people of color in the recreation movement was largely invisible in literature and little could be determined about the role of women of color based on the material reviewed. (p.168)

The research was further delimited to addressing what the literature suggested about women and did not address women in comparison to changes occurring in the editorial and organizational philosophies of the National Recreation Association and its predecessor and successor organizations. In addition, the description of social roles was primarily about Euro-American women. The role of people of color in the recreation movement was largely invisible in the literature and little could be determined about the role of women of color based on the material reviewed. Class issues were more apparent in the analysis because the early focus of the playground and recreation movement was on bringing a quality of life to working class adults and their families (Sessoms, 1984). Class distinctions were not necessarily specified in the literature, but latent meanings concerning class status were noted in the interpretation of the analysis when possible.

Figure 1. A feminist analysis of selected professional recreation literature about girls/women from 1907-1990 (Henderson, 1993).

Race was a variable noted in passing as it was not within the scope of the article's study (See

Figure 1). Periphery mentions were additionally observed within studies where utilized sources contained race as a focus and/or component as was seen within the study performed by Ito et al. (2014):

In an analogous study on race and ethnicity in leisure studies, Floyd, Bocarro, and Thompson (2008, pp. 3-4) proposed that undertaking such a review could lead to a more objective statement on the state of a literature on three levels. (p. 227-228)

While the study performed by Ito et al. (2014) was on research of non-Western and cross-cultural leisure, the authors utilized an article on race and ethnicity in verification of their methodology 
use. Thus, race was not emphasized in their assessment and received no additional mention beyond this. A similar pattern was noted in the studies included in this subcategory in which mentions of race were presented within a citation or in temporary departure from the overall research focus.

However, in various instances, these references were made when additional assessments could have elaborated and created more critical discussion. Shown in a study on the expansion of parks as a way to diminish class conflicts, Taylor (1999) explored the utilizations of Central Park in the nineteenth century:

Parks like Central Park were not built in uninhabited open space. Often unemployed and working class whites and blacks lived in spaces chosen for these parks. (p.439)

attempts to develop the parks. For example, the following issues and constraints had to be addressed in the process of designing and developing the urban parks: (a) land use conflicts, (b) traffic, noise, congestion, (c) large numbers of users, (d) incompatibility of working class and middle class values and behavior, (e) labor relations, (f) city politics, (g) economic conditions, and (h) social lifestyles. Parks like Central Park were not built in uninhabited open space. Often unemployed and working class whites and blacks lived in spaces chosen for these parks. Notwithstanding, these areas were perceived as urban wastelands standing in the way of efforts to "improve" and develop the city. Differing land use perspectives between the middle and working class resulted in poor people being evicted as their Communities were cleared to make way for the parks. For example, DownFigure 2. Central Park as a model for social control: urban parks, social class and leisure

behavior in nineteenth-century America (Taylor, 1999).

In such exemplars, although in the periphery of the articles' purview, many articles overlooked extensions that could have added depth to the analyses (See Figure 2). Passive remarks erased important current and historical realities of racialized ethnic groups; thus, diminishing a complex issue with silence and glossed over references.

\section{Demographic Variable with no Assessment}


Demographic variables are understood as sample descriptors perceived as indicative of key characteristics and variations between the participants (Salkind, 2010). Demographics are often collected as a way to group participants and ultimately allude to representation of the study's population of interest (Salkind, 2010). Within 21 articles, race was included as a demographic variable although race and/or racialization were not within the study's aim. As an example, in a study in assessment of leisure's role in producing meaning in life among adults with mental illness, Iwasaki et al. (2015) denoted the steps of participant recruitment taken within the study:

First, cultural backgrounds were considered; thus, we attempted to recruit ten adults (five men, five women) from each of four ethnic/racial subsets (i.e., African American, Asian American, Latino, and Caucasian). (p.542)

\section{Data Collection}

From a pool of 101 Phase I participants recruited from five mental health agencies in a northeastern Unites States city, 40 individuals were invited to a Phase II qualitative study, which this current paper is based on. A purposeful sampling was used to ensure the diversity of participants. First, cultural backgrounds were considered; thus, we attempted to recruit ten adults (five men, five women) from each of four ethnic/racial subsets (i.e., African American, Asian American, Latino, and Caucasian). Second, we considered other personal variables (e.g., age, types of mental illness) and responses to standardized measures (e.g., active living, leisure) during Phase I to recruit as diverse participants as possible (e.g., those with low to high leisure participation levels).

Figure 3. Role of leisure in meaning-making for community-dwelling adults with mental illness: Inspiration for engaged life (Iwasaki et al., 2015).

While racialized ethnicities were intentionally enlisted to participate within the study, the authors made no additional attempt to elaborate as to why the subjects' racialized identifications were pertinent in studying meaning-making experiences within this population (See Figure 3).

Within this particular subcategory, the authors appeared to intentionally collect information and report on their participants' racialized ascriptions. Obtaining a wide variety of 
participants that were identified or self-identified under a racialized category was often seen as a goal within studies:

Stratification of this pool aimed for diversity (racial, sexual orientation, age, ability level, marital and family status, and socioeconomic status) and women who have a moderate to great amount of wilderness experience (self-defined by interviewee, but at least one year). (Pohl et al., 2000, p.419)

\section{Study Participants}

A pool of potential interviewees was generated through posting a call for subjects using recommendations from members of the field of recreation management, from women who recreated in wilderness, from acquaintances of the interviewer, and from responses to posters placed at local outfitting organizations, outdoor equipment shops, and recreation facilities (e.g. climbing walls). Aiming for a stratified and diverse sample of women, the original pool of approximately 45 women was reduced to 24 . Stratification of this pool aimed for diversity (racial, sexual orientation, age, ability level, marital and family status, and socioeconomic status) and women who have a moderate to great amount of wilderness experience (self-defined by the interviewee, but at least one year). While it was important to the researchers to attain a diverse sample, the only sociodemographic characteristic that was asked of the interviewees was age. Paramount to this study was refraining

Figure 4. Women, wilderness, and everyday life: A documentation of the connection between wilderness recreation and women's everyday lives (Pohl et al., 2000).

Though Pohl et al. (2000) conducted their study to examine the relationship between women's participation in wilderness recreation and aspects of social change, diversity of racialized ethnicities was placed at the forefront in their assembly of participants (See Figure 4). As was seen in other studies within this subcategory, authors cited sampling diversity as an important component of the recruitment process while making little to no connection between race and the study's central topic of interest.

\section{Stigma Comparison}


Stigma is viewed as the result of collective condemnation of a quality of an individual that is deemed as a mark of indignity or degradation (Link \& Phelan, 2001). The consequences of societal stigmatization of characteristics or conditions are observed in the ensuing prejudice and inequality of individuals and groups (Link \& Phelan, 2001). The four articles classified under this subcategory mentioned race in order to compare the experience of stigma among groups. Grossman (1993) used racialized identifications as a means to contrast prejudice as a part of curriculum for gay and lesbian studies:

Most of the major differences between gay and lesbian people and member of other minority groups, i.e., ethnic and racial groups, arise from the fact that the gay or lesbian person becomes aware of being a member of the group during adolescence rather than at birth. (p.54)

According to Allport (1958), a minority group is one which suffers from unjustified negative attitudes and actions from the dominant group, ranging from mild denigration to scapegoating. Most of the major differences between gay and lesbian people and members of other minority groups, i.e., ethnic and racial groups, arise from the fact that the gay or lesbian person becomes aware of being a member of the group during adolescence rather than at birth. Most gay and lesbian people, however, demonstrate characteristics that have been identified in other minority groups such as obsessive concern with stigma, denial of membership in the minority group,withdrawal, and passivity (Martin, 1982a).

Figure 5. Ten percent of those we teach and they serve: A case study of incorporating gay and lesbian studies into the curriculum (Grossman, 1993).

This was also seen in Tirone and Goodberry (2011) study of leisure experience in second generations immigrants:

However, the situation is different for racial minority ethnics, who cannot shed skin color or for those who wear traditional clothing. For them, ethnic group membership involves immersion in traditional cultural practices and creates conditions that readily identify 
them as members of ethnic groups. This may result in situations that disadvantage or even discriminate against these individuals (Reitz \& Banerjee, 2007; Waters). (p.431) In both exemplars, the authors utilized race as a means of developing their respective topics. Race within this subtheme was not the preliminary focus of the examinations but rather mentioned in elaboration on the diverging experiences of populations that experience oppression (See Figure 5).

\section{Racialization in the Negative}

Racialized ethnicities that were regarded in a negative manner were cataloged within subthemes based upon their utilization of key descriptive words or phrases. Shown in Table 3, these texts include use of "minority", texts that created a condition of othering, linguistics that conveyed engagement in dangerous activities, and/or created condition of deprivation and persecution. These descriptors were often presented as permanent as opposed to conditional; therefore, making the following labels synonymous with various racialized groups rather than the conditions seen as a result of their racialization.

\section{"Minority"}

A little less than one-third of the articles (i.e., 25 articles) deemed racialized ethnicities as a minority. Minority is utilized as a replacement term for all people of color, designating a chronic societal position as a marginal out-group for individuals based upon racialization. This positioning can be seen regardless of if racialized ethnic groups are the majority within their area of residence; thus, alluding that a "minority" position is about one's enduring place in society rather than the result of population composition. The utilization of a minority status can be found in the examination of after-school programming differences between racialized ethnic groups in a study performed by $\mathrm{Wu}$ and Van Egeren (2010): 
However, most studies examining ASP participation have concluded that low-income minority youth have lower participation rates than their white counterparts and that their time outside of school is often highly unproductive (e.g., Fulbright-Anderson,Lawrence, Sutton, Susi, \& Kubisch, 2005; Harvard Family Research Project, 2007; Pedersen \& Seidman, 2005; Rothstein, 2004; Shann, 2002), indicating a need to identify pathways to enrollment in ASPs for these groups. (p.592)

The literature suggests ASPs have their greatest impacts on low-income youth, who tend to be disproportionately low-achieving and from racial/ethnic minority groups (Marsh, 1992; Marsh \& Kleitman, 2002). The impact of ASP involvement may be stronger on low-income youth because their home and neighborhood environments are often less enriching and more dangerous than those of middle-income youth (Robinson \& Fenwick, 2007; Simpkins, 2003). However, most studies examining ASP participation have concluded that low-income minority youth have lower participation rates than their white counterparts and that their time outside of school is often highly unproductive (e.g., Fulbright-Anderson, Lawrence, Sutton, Susi, \& Kubisch, 2005; Harvard Family Research Project, 2007; Pedersen \& Seidman, 2005; Rothstein, 2004; Shann, 2002), indicating a need to identify pathways to enrollment in ASPs for these groups.

Figure 6. Voluntary participation and parents' reasons for enrollment in after-school programs:

Contributions of race/ethnicity, program quality, and program policies (Wu \& Van Egeren, 2010).

Oftentimes, the placement within a minority status was shown in multiple cited articles as is seen in the abovementioned quote, alluding to the widespread propagation of this terminology.

Additionally, distinctions between various racialized ethnicities were not made clear, as many racialized groups were ascribed under the blanket term "minority" (See Figure 6).

Assignment as a minority was often used in comparison to groups of racialized White individuals as is seen in Simpkins et al. (2012):

Hypothesis 4. The association between friends' and adolescents' activity participation 
would be stronger for White adolescents compared to racial/ethnic minority adolescents. (p.337)

While the assessment by Simpkins et al. (2012) was centered on the predictive value of adolescents' activities among varying racialized ethnicities and age groups, the authors only distinguished participants as White and minorities. Therefore, in line with additional articles in this category, the minority status can be seen as a signification as being anything but White. Ultimately, creating a clear distinction between those that have power and those that do not due to their racialized identification.

\section{Condition of Othering}

Three of the articles examined placed racialized ethnicities within a condition of othering through various words and phrases. A racialized "other" is comprehended as an expression that distinguishes people of color from the supposed White norm of America, constructing a category of difference and underlying inferiority based upon racialized ascriptions (McDonald, 2009). This was noted in a book and resource review by Freysinger et al. (1994) in which the author explicitly named racialized ethnicities as an "other":

Karen Fox writes that the books she reviewed takes us into the everyday lives of the 'other' - in this case, individuals who are African American and Mexican American - in the contemporary United States. (p.80)

As can be seen, the authors combined two individual books under the umbrella term of "other"; thus, designating both books as being exemplary of a status of separation rather than accounts of individual experiences.

Divisive positioning of racialized ethnicities was also shown in Allison (1999) in their examination of diversity in the workplace of parks and recreation agencies: 
Terms and phrases such as 'political correctness', 'quotas', 'reverse discrimination', and 'affirmative action programs' take on levels of symbolic and political meaning in the workplace that can, by their very nature, create barriers in the form of resentment and non-responsiveness toward 'people of difference.' (p.79)

The political potency and controversy surrounding diversity issues in today's society makes it difficult for agencies to know how to create appropriate and meaningful responses to diversity. Social and political discussions of diversity efforts and programs have become increasingly value-loaded and value-laden. Terms and phrases such as "political correctness," "quotas," "reverse discrimination," and "affirmative action programs" take on levels of symbolic and political meaning in the workplace that can, by their very nature, create barriers in the form of resentment and non-responsiveness toward "people of difference." Individuals who are thought to benefit from such programs are frequently stereotyped and diminished in capability. This leads to increased resentment at all levels of the organization.

Figure 7. Organizational barriers to diversity in the workplace (Allison, 1999).

Similar to what was observed in other articles of this subcategory, Allison (1999) grouped

persons as dissimilar; thereby, creating a collective status for varying groups that is held in stark contrast to those that possess power to create barriers for those deemed as "other" (See Figure 7).

\section{Engagement in Dangerous Activities}

Racialized ethnicities were given a quality of deviance within two assessed articles.

Deviance typically underscores the myth of increased criminality in racialized ethnic groups, where the perception of threat and engagement of unlawful behavior becomes synonymous with a racialized identification (Mowatt \& Schmalz, 2014). This was portrayed within Stodolska et al. (2014) examination of after-school sport involvement among racialized ethnic groups:

However, in recent years, professional sport leagues such as Major League Baseball

(MLB) have begun to organize programs to involve disadvantaged youth in sport while, at the same time, providing them the opportunity to engage in positive, team-oriented 
activities that keep them "off the streets," teach community responsibility, and increase academic achievement (Major League Baseball, 2012a). (p. 613)

Along with this exemplar, Wu and Van Egeren (2010) provided models for after school programming for "at-risk" racialized ethnic groups to bring knowledge about differences in programming needs:

However, researchers have also noted the possibility of "deviant training" among youth participating in ASPs; without sufficient high-quality adult supervision to provide structure and promote positive social norms, they may use the program time to learn about risky behaviors from peers (Dishion, McCord, \& Poulin, 1999;

Gottfredson et al., 2007). (p. 594)

The assumption of risk was solely applied to people of color, connecting threatening qualities and conditions with select racialized ethnic groups. In both cases, groups of racialized ethnicities were portrayed as engaging in activities that were unsafe; therefore, eliciting a requirement for additional structure to be able to prevent them from "dangerous" leisure associated with their racialized ascription.

\section{Condition of Deprivation and Persecution}

A permanent condition of deprivation and persecution of racialized ethnicities were noted in 9 articles. These articles conveyed a status of "vulnerable", "at-risk", "marginalized", “oppressed”, “disadvantaged”, or “underprivileged”. Racialized ascriptions were depicted as being a variable associated with vulnerability such as was noted in the article by Payne et al. (2018): 
Mair, Arai, and Reid (2011) advocate for populations that are more vulnerable and lack access and ability to engage in leisure and recreation due to a number of factors such as incarceration, income distress, illness/disease, ethnicity/race, culture, and so on. (p.3)

Alternatively, it is important to note that there are some segments of the population that experience vulnerability beyond that of time famine and busyness. These individuals and families are economically distressed, chronically ill, or otherwise disadvantaged, and leisure is often a luxury they cannot afford (in terms of both time and financial resources). They may face a double- or triple-jeopardy situation in that they have limited access to health care, employment, and leisure. This can create a cycle of family distress, and one that Moore and Henderson (this issue) examined in their article on recreation among low-income couples. In their book, Decentring Work: Critical Perspectives on Leisure, Social Policy, and Human Development, Mair, Arai, and Reid (2011) advocate for populations that are more vulnerable and lack access and ability to engage in leisure and receation due to a number of factors such as incarceration, income distress, illness/disease, ethnicity/race, culture, and so on.

Figure 8. The reemergence and revitalized focus of JLR (Payne et al., 2018).

While in reference to a cited article, the authors frame the findings as being exemplary of racialized ethnicities being in a perpetual state of lack and destitution because of their ascription (See Figure 8). The inability for racialized ethnicities to gain a favorable positioning in society is represented as a stable status:

Open Space parks tried to take a stand against racial discrimination and provide services for underprivileged racial minorities living in the inner cities. Despite these efforts, Cranz points out parks were and often remain racially divided. (Shores, 2010, p.179)

Therefore, literature in this category, marginalization and oppression were framed as a quality of the groups rather than an attribute of their societal environments; thus, perpetuating a status that these groups are unable to remove. This can be viewed within the study performed by Edwards and Matarrita-Cascante (2011) focused on leisure research's conceptualization of rurality:

As indicated by the few articles that examined rural women, racial and ethnic minorities, low-income populations, and other marginalized groups, there seemed to be significant 
differences in the experiences of members of these groups compared to those from majority populations. (p.462)

Specifically, articles found in this review demonstrated the tendency to generalize from largely White male population samples. One problematic aspect of the lack of attention to representation across a population is the implied assumption that a universal rural condition exists across sociodemographic groups. Therefore, we cannot be sure that conclusions related to the perceived benefits of rural residence and rural population preferences for leisure activities, particularly outdoor recreation, were not biased by samples that were overrepresented by White males. Considering theoretical developments and practice recommendations within the leisure and recreation field that may have resulted from these generalizations, this oversight is not minor. As indicated by the few articles that examined rural women, racial and ethnic minorities, low-income populations, and other marginalized groups, there seemed to be significant differences in the experiences of members of these groups compared to those from majority populations. To provide a deeper understanding of rurality, future research should appropriately consider the different social conditions experienced by different sociodemographic groups and the effect of these conditions on leisure and recreation.

Figure 9. Rurality in leisure research: A review of four major journals (Edwards \& Matarrita-

Cascante, 2011).

Articles in this subcategory were found to view racialized ethnicities as being in a societal standing that is less beneficial without context as to why they are recipients of prejudicial outcomes (See Figure 9).

In opposition to all 3 sub-themes within this category, there were 8 classifications made by articles that denoted the harm and/or emphasized the circumstances that place racialized groups in stable rather than unfixed negative statuses. Contrasting explanations of these labels are exemplified in the following:

One can ask, "When is the minority ever the majority in the U.S.?" Throughout this manuscript the term "faculty of color" is used instead of "minority" as it might be more 
empowering and inclusive of both racial and ethnic classifications. (Mowatt et al., 2016,

A counter-narrative noted discussions that included young people as being enriched with backgrounds and perspectives needing to be tapped. The use of the term "minority" could be linked with her assessment of linguistics, as it has less quantifiable representation, rather a position of perpetual inferiority. One can ask, "When is the minority ever the majority in the U.S.?" Throughout this manuscript the term "faculty of color" is used instead of "minority" as it might be more empowering and inclusive of both racial and ethnic classifications.| Stanley's (2007) research is remarkable as it actually uses the feedback from reviewers responsible for manuscripts submitted by faculty of color to highlight Figure 10. "Embarrassingly White" faculty racial disparities in American recreation, park, and

tourism programs (Mowatt et al., 2016).

As is seen, these articles diverge from the literature of this theme in exposing the flaws in both logic and inclusivity that is created through the use of insufficiently substantiated descriptors (See Figure 10).

\section{Improper Terminology Use}

Shown in Table 4, Sixty-five classifications under the subcategories of the theme of improper terminology use were documented in this study. Improper terminology can be seen in authors' conceptualization of race as being correspondent with ethnicity and culture or as a byproduct of race purity.

\section{Race, Ethnicity, and Culture Used Interchangeably}

Race was portrayed as being equivalent to ethnicity and/or culture in 35 articles reviewed in this paper. Within this subtheme, articles viewed race and ethnicity to be synonymous variables as opposed to separate:

Findings suggested that race/ethnicity, age, place of residence, and education level were significant predictors of visitation to local parks, playgrounds, or other open spaces.

(Powers et al., 2019, p.12) 
Within this particular article, Powers et al. (2019) sought to examine the additive access effects of advantageous statuses on the access and use of parks and recreation. In combining race and ethnicity, the valuation of statuses through the process of racialization and ethnic identity are no longer distinguished as singular and divergent.

This was additionally illustrated within articles that confounded race with ethnic groups and country of origins such as was seen in Fernandez and Witt (2013):

Although several parents reflected this view point, other parents made a distinction between the negative behaviors and the African American race. (p.433)

any problems." Other parents enrolled their children at the MRC, but not without some reservations. Laura, a Hispanic mother, shared the apprehension she felt at the beginning,

I'd never feel comfortable to take my kids there because of all the Black people. And they are probably like "who are you?" I don't know how they are going to treat me, really. And I don't know them. I guess I just don't want to have to deal with it.

Although several parents reflected this view point, other parents made a distinction between the negative behaviors and the African American race. Carolina, the Hispanic mother

Figure 11. Attracting Hispanics to an African American recreation center: Examining attitudes and historical factors (Fernandez \& Witt, 2013).

While the study utilized historical accounts in America dating back to the early 20 th century in partial explanation of Hispanic underrepresentation in a recreation center, the authors lack historical/policitical recognition of African American as denoting an ethnicity bound to a place of birth that cannot be synonymous with race (See Figure 11).

The use of synonymous terminology is shown in Clark and Anderson (2014) study of leisure in pregnant adolescents:

While Wiemann et al. did not examine why White girls felt more stigmatized than Black and Mexican-American girls, one may speculate this is the case due to research finding 
that teen pregnancy is a greater cultural norm in low socioeconomic Black communities (Mollborn, 2010). (p.510)

marginalization of pregnant adolescents (Wiemann, Rickert, Berenson, \& Volk, 2005). Interestingly, of the 925 low-income African-American, Mexican-American, and Caucasian pregnant adolescents aged 18 years or younger Wiemann et al. interviewed regarding feelings of stigma during pregnancy, more Caucasian participants $(45.3 \%)$ reported being stigmatized compared to $41 \%$ of African-Americans and $32.7 \%$ of Mexican-Americans. While Wiemann et al. did not examine why White girls felt more stigmatized than Black and Mexican-American girls, one may speculate this is the case due to research finding that teen pregnancy is a greater cultural norm in low socioeconomic Black communities (Mollborn, 2010). Regardless of race, there is no denying pregnant teens have the potential to be forced to the margins as research has found pregnant adolescents lack social interaction with peers and often are not involved in extracurricular activities (Whitehead, 2001).

Figure 12. Not yet a woman, not yet a mom: The leisure experiences of pregnant adolescents

(Clark \& Anderson, 2014).

As is demonstrated by Clark and Anderson (2014), authors of articles in this subcategory

additionally confounded culture with the effects of racialization; thereby, viewing differences to be a function of dissimilar value systems and norms associated with racialized ascriptions (See Figure 12). Whether through insufficient knowledge or a failure to distinguish the difference, the lack of clarification in terminology alludes to a similarity in outcomes attached to racialized ascriptions, ethnicities, and cultural identities. Consequently, assessments within this subtheme lack the specialized responsiveness that each of these variables require as they operate in varying ways.

\section{Mixed Race}

The concept of multiracial or biracial individuals was denoted in 7 articles viewed in this thesis. In such instances, race mixing is intended to be inclusive of individuals that are believed to be a combination of racialized identifications. However, in its inclusion, racial mixing refortifies the view of race as a byproduct of biology rather than the result of a system of 
identification and erases the malignant history that it denotes (Fields \& Fields, 2012). Racial mixing in its present usage eludes a history in which racial mixing was deemed inferior and grounds for the inhumane treatment of those with a perceived biological impurity (Fields \& Fields, 2012).

In contrast to its historical roots, the mixing of various races in leisure research was often observed as a term of neutrality and even positive acceptance. It is seen in the authors' provision of demographic data:

Nearly all participants, $85.8 \%$, identified themselves as mixed race (a combination race of Asian, European, and African descent) with an additional $9.5 \%$ of students identifying as Black and $4.0 \%$ as White. (Caldwell et al., 2010, p. 209)

It was also noted in demographic variables provided by Winter et al. (1999):

The ethnic distribution of participants was mixed: 58.9 percent Caucasian, 10.5 percent Asian American, 9.5 percent Latino/Hispanic American, 5.3 percent African American, 2.1 percent American Indian, and 7.4 percent multi-racial. (p.220)

Both articles are exemplary of the terminology utilized within this subtheme that included "mixed race", "multi-racial", and "biracial". The employment of these three terms make the assumption that racialized ascriptions are derived from a purity of race rather than the consequence of social construction.

\section{Inconsistent Descriptive Terminology}

Twenty-two articles contained inconsistent descriptive terms in which the author's use of a racialized ascription was paired with the use of an ethnic identity. This subtheme is exemplified in an article written by Henderson (1995) on her personal narrative of developing and teaching a course on diversity: 
I had a problem in class today with the stereotypes and overgeneralizations that were made about African-Americans. I am not sure how to get students away from those generalizations when I feel that the recreation and leisure literature also seems to overgeneralize. I tried to encourage the students to examine these perceived differences between blacks and whites, for example, on the basis of structural and institutional perspectives. I am not sure that my point was well made. (p.9-10)

The author's shifting utilization of terminology of "African American" and "black" were exemplified in all of the literature within this category with various racialized ascriptions and ethnic identities. Interchangeable utilization of terminology signify a lack of consistency in labeling of participants and/or groups of interest, creating difficulty in distinguishing whether the article was based on ethnic identity or a restrictive racialized category.

\section{Intentionality of Race}

This thematic category included 53 classifications focused on the article's purpose behind the utilization of race. As found in Table 4, this included articles focused on race to examine differential experiences or preferences, articles that convey racialized samples as exemplary of racialized group, and articles that viewed race as an identity.

\section{Race as a Denotation of Differential Experiences or Preferences}

Thirty articles were categorized into this subtheme where race was employed as means to locate differences between racialized ethnicities. Authors often viewed race as means to understand variations in leisure, as is seen in student learning tools for understanding leisure behavior as explicated by Robertson (2009):

Emphasis is placed on enhancing the student's understanding of the leisure behavior as experienced by individuals of varying backgrounds relating to such factors as race, 
ethnicity, age, gender, sexual orientation, socio economic status, and ability levels. (p.158)

Race was regarded as an explanatory factor in leisure behavior through which finding differences would lead to greater understanding of constituents. However, diverging leisure behavior was often understood as a matter of difference in life experiences or norms of individuals within their racialized grouping. Such is represented in a study performed by Stodolska et al. (2014) in which the authors examined factors that influence after-school sport involvement in racialized youth:

Thus, the strong need to create bonds with older authority figures may perhaps be due to the absence of positive role models in the lives of some minority children and the fact that they grow up in single-parent households. (p.626)

basketball was discussed by Olushola et al. (2013). This finding is perhaps related to the fact that the level of single-parent families among the African American population is high (32\% as compared to $10 \%$ among non-Hispanic Whites and 14\% among Hispanics) (Blackwell, 2010). Thus, the strong need to create bonds with older authority figures may perhaps be due to the absence of positive role models in the lives of some minority children and the fact that they grow up in single-parent households. While previous research considered how attitudes and atmosphere fostered by coaches affect youth motivation and engagement in sport (Keegan et al., 2010; Ntoumanis, 2005; Pelletier et al., 2001), research that would examine the uniquely personal and parental role coaches play in the lives of minority youth is underdeveloped. We argue that

Figure 13. Minority youth participation in an organized sport program: Needs, motivations, and facilitators (Stodolska et al., 2014).

Factors affecting patterns of leisure were often seen as a function of an individual's racialized ascription and frequently indicated positions that were detrimental and contained a negative association (See Figure 13). Although differing experiences between racialized ethnicities were noted within articles, they lacked further examination of the conditions that promoted difference:

As we have seen, for a white adolescent female from a rural-urban fringe community, access to the city is strongly influenced by parents, while the perception of a black 
adolescent male is that he is highly susceptible to being " pulled over" and harassed by

the police in the suburb. (McMeeking \& Purkayastha, 1995, p.374)

Cumulative Impacts: Although the above discussion highlights the impacts of gender, socioeconomic status, race/ethnicity, and age separately, in reality the four variables interact. A hierarchical ordering exists in terms of what is accessible to the adolescents. At the macro-level, race/ethnicity and socioeconomic status appear to establish the initial boundaries between groups in society. Any constraints that the adolescents might encounter is a function of their group identity, which in turn is compounded by micro-level characteristics of age and sex. As we have seen, for a white adolescent female from a rural-urban fringe community, access to the city is strongly curtailed by parents, while the perception of a black adolescent male is that he is highly susceptible to being "pulled over" and harassed by the police in the suburb.

Another way of examining this interaction is in terms of access to vehicles. For the black adolescents in the city, where vehicle ownership per household is $\mathbf{0 . 9 1}$, the likelihood of their being able to have use of a vehicle once they reach the the legal driving age is arguably less than that of their contemporaries in the suburbs or rural-urban fringe, where vehicle ownership rises to 1.68 and 2.08 respectively (U.S. Bureau of the Census, 1990). Thus for the adolescents in the city, the period of restricted mobility is likely to be longer than for the more affluent adolescents, who, once they reach the age of sixteen, invariably have some limited use of a family car. Furthermore, gender compounds the mobility and accessibility situation of the black urban male through the informal restrictions imposed by neighborhood turf issues.

Figure 14. "I can't have my mom running me everywhere": Adolescents, leisure, and

accessibility (McMeeking \& Purkayastha, 1995).

Within this study, the mentioned experiences had an affect on the leisure behavior of adolescent participants (McMeeking \& Purkayastha, 1995). However, similar to other literature in this subcategory, the absence of greater scrutiny over these opposing leisure experiences caused authors to overlook extensions to systemic conditions (See Figure 14).

Five articles were found to contradict aspects of this subcategory by highlighting differential conditions of discrimination placed upon racialized ethnic groups as is seen in Schmalz \& Mowatt (2014) explication of forms of subtle prejudice that create false views of 
"difference" and conceal latent intolerance. Such articles become exemplars of sufficient comprehension of racialized distinctions that curtails improper evaluations of presupposed fundamental variations in individuals based upon their racialized ascription.

\section{Racialized Sample as Exemplary of Racialized Group}

Within 14 articles assessed, sample populations were seen as essential in understanding the group as a whole as is exemplified in the following:

Scale development can progress with the addition of samples that either are drawn from other workplaces or represent other communities more diverse in race, ethnicity, and other factors in life conditions. (Kelly \& Kelly, 1994, p.272)

The main limitation of the study was the sample. Both the work and general life conditions of these workers in one organization were too homogeneous to test the effects of a full range of conditions in the workplace, family and community, or leisure. The subscales will be further refined, but are adequate for analysis and provide a base for such revision. Scale development can progress with the addition of samples that either are drawn from other workplaces or represent other communities more diverse in race, ethnicity, and other factors in life conditions. Useful additions to the scales will be items more directly measuring self-determination in each domain and also the relative centrality of domains and overall life satisfaction.

Figure 15. Multiple dimensions of meaning in the domains of work, family, and leisure (Kelly \& Kelly, 1994).

Obtaining a variety of participants that differ in their racialized ascriptions was connected to enhanced understanding of the article's topic and often as means to find racialized differences (See Figure 15).

Additionally, many of these articles placed the need for a diverse sample in the forefront of generalizability of the study regardless of if their study was on the topic of race. In analysis of communication, emotional support, and satisfaction in adolescents' leisure with close peers and 
partners, Tuggle et al. (2016) explicated the importance of greater sampling diversity to explore potential differences in experiences:

Future research with more diverse samples of youth may add to understanding whether race or other cultural differences affect leisure activity selection or associations between leisure, supportive communication and relationship satisfaction. (p.391) American adolescents (for exceptions see Bohnert et al., 2008; Larson et al., 2001). We conducted additional tests and found no racial differences for participation in either set of core activities or the balance sports and games activities. African-American youth, however, had a slightly higher score (significantly different) for balance community activities compared to white adolescents and to adolescents of other ethnicities. The lack of theoretical and empirical work addressing

African-American adolescents' leisure behaviors, and the lack of power in the current study to fully test race differences in leisure participation or in the models examining associations among leisure, supportive communication and relationship satisfaction, limit the conclusions that can be drawn about the role race might play in explaining the findings of the current study. Future research with more diverse samples of youth may add to understanding whether race or other cultural differences affect leisure activity selection or associations between leisure, supportive communication and relationship satisfaction.

Figure 16. Young adolescents' shared leisure activities with close friends and dating partners: Associations with supportive communication and relationship satisfaction (Tuggle et al., 2016).

Portrayed in literature in this subcategory was the notion that the explanatory power of their studies was reliant on their ability to make broad statements about diverse groups.

Consequently, the racialized sample was seen as a significant factor in making conclusions about racialized ethnicities; thereby, collapsing the experiences of a multitude of individuals of various racializations and experiences to a sample (See Figure 16).

\section{Race as Identity}

Race was regarded as an identity as was seen within 7 articles in this subcategory. The intention in viewing race in this manner diverted attention away from race as a means of identification and towards race as a sense of self: 
We present two critical components of SJYD, self-awareness and critical consciousness in order to tackle the interrelationships between and the importance of racial/ethnic identity, access to recreational centers as a leisure space, and social justice in the development of marginalized youth. (Pryor \& Outley, 2014, p.278)

The purpose of this paper is to explore the role of social justice youth development (SJYD) through the journey of one young woman's relationship with her local YMCA. Through using visual and narrative methodologies, we provide more insight into the literature of marginalized youth and the use of recreational spaces. We present two critical components of SJYD, selfawareness and critical consciousness in order to tackle the interrelationships between and the importance of racial/ethnic identity, access to recreational centers as a leisure space, and social justice in the development of marginalized youth.

Figure 17: Just spaces: Urban recreation centers as sites for social justice youth development

(Pryor \& Outley, 2014).

"Racial identity" in the sense views race as the fundamental nature of individuals and alludes to a sense of choice in the outcomes based upon their purposed identity (See Figure 17). Within studies of this subtheme, the intentionality of race as an identity shifts differential outcomes as being the result of qualities of the individuals as opposed to consequences of their racialized ascription.

Three articles portrayed an appropriate view of race as an identification rather than a chosen identity. Such rhetoric was a notable divergence in that the authors explained the falsity of race as a foundation of an individual's character as is typically seen "by erroneously portraying identities as discrete categories of identification and investigation" (McDonald, 2009, p.18)

\section{Inadequate Lens of Problem/Solution}

Thirty-eight articles in which evaluations of the problem or solution contained incomplete or erroneous framing were classified under the theme of Inadequate Lens of 
Problem/Solution. This included literature that viewed the problem or solution presented in their articles as a function of the individual, as a result of contemporary shifts, and/or as being connected to outcomes of leisure interventions as is demonstrated in Table 6.

\section{Frame Problem/Solution as Individual Rather Than Systemic}

Twenty-five articles viewed racialized issues as being the result of individual qualities/actions or in need of individual action for resolution. Studies performed within this lens overemphasized personal ability as a corrective remedy for historical and political actions and patterns that unequally marginalized racialized groups:

These allowed students to develop an understanding and appreciation of difference from a broad perspective as well as provided opportunities for them to come to realize that self-appreciation is one of the key ways to eliminate oppression. (Grossman, 1993, p.56) As was seen in many articles, the notion that recognition and appreciation for diversity is considered a countermeasure for marginalization of various racialized ethnicities detracts from the ways in which these conditions were conceived.

In a similar manner, exposure to racialized ethnicities with less power was also viewed as being able to augment "confidence and comfort when serving diverse populations" (VanSickle \& Schaumleffel, 2016, p.47). This exposure was also believed to "equip students with the skills to move beyond acts of charity and to address systemic social inequities" (Smith et al., 2011, p.4). In framing the solution of racism to be the result of individual proficiencies, the studies in this subcategory provide an incomplete assessment of the ways systems operates in favor of individuals based upon their racialized ascription. 
As was shown in Godbey (2000) assessment of the state of leisure studies at the time the article was written, mere effort was needed to change the detrimental outcomes noted in leisure studies:

This was obviously not the result of genetic change. Thus, the good news is that, while human groups differ with regard to intelligence, such differences are not immutable but rather capable of being changed by human endeavor. Such good news is largely lost on those who seek to deny differences among human groups in the name of political correctness. (p.38)

Part of this Puritanism, which seeks to deny real differences among ethnic groups, age groups, genders, races, and other divisions of society, is actually a sort of pessimism about human ability to change. The Japanese, for example, raised the average IQ of school age children dramatically over a period of a few decades (Jones, 1993). This was obviously not the result of genetic change. Thus, the good news is that, while human groups differ with regard to intelligence, such differences are not immutable but rather capable of being changed by human endeavor. Such good news is largely lost on those who seek to deny difference among human groups in the name of political correctness.

Figure 18. The future of leisure studies (Godbey, 2000)

As such, the emphases of articles were placed on individual undertakings as a resolving factor, problematic variable, or, as demonstrated in the aforementioned quote, both (See Figure 18). Consequently, focus was diverted from the source of inequitable circumstances created by a system for which "human endeavor" is incapable of providing a complete solution.

In contrast to the 25 articles within this sub-theme, 7 articles portrayed a positive subthematic exhibition in analyzing institutional and systemic foundations of corrections to discrimination:

Radical healing assumes that systems of oppression shape the everyday lives of Black youth. Theoretical and conceptual frameworks adopted for radical healing studies 
should therefore illuminate the presence and inner workings of those systems. (Theriault, 2019, p.420)

\section{Recommendations for the study of radical healing}

Radical healing assumes that systems of oppression shape the everyday lives of Black youth. Theoretical and conceptual frameworks adopted for radical healing studies should therefore illuminate the presence and inner workings of those systems. Mowatt (2017) presented a detailed overview of several frameworks that highlight systems of oppression, including the veil, double consciousness, symbolic racism, social boundary theory, and the theory of racialization. These frameworks should also be supported by qualitative methods that emphasize the unique voices and experiences of Black young people given the emphasis on youth agency within radical healing. Qualitative youth research is sometimes conducted on behalf of youth, where the voices of program leaders or parents are emphasized at the expense of youth perspectives. This approach may unintentionally deepen the very problem that sparked the need for radical healing programs: that Black childhoods are both unimagined and unimaginable (Dumas \& Nelson, 2016).

Figure 19. Power threats and radical healing in Black youths' leisure (Theriault, 2019).

As is exemplified in the following quote, the nature of these articles differed in that macro level

solutions were deemed as pivotal to remediate differentially applied oppression; thus,

minimizing the root of the problem as being solely individual deficiencies (See Figure 19).

\section{Frame Problem as Being Contemporary}

In order to convey importance behind remediating consequences of racialization, 7

articles were found to present the issue as being contemporary. In making the case for equitable conditions, authors framed needs as being a result of new population shifts:

According to the Population Profile of the United States 1995, non-white individuals (i.e., African Americans, Latin Americans, Asian and Pacific Islanders, American Indians, Eskimos, and Aleuts) make up $25.6 \%$ of the total United States population (US Census Bureau, 1999). These data reflect the need for innovative strategies to recruit and retain underrepresented faculty and students in recreation, parks, and leisure studies curricula. 
(Bedini et al., 2000, p.49)

While slight increases exist in faculty of color, disappointingly little change has been noted among the presence of students of color in recreation, parks, and leisure studies curricula. Bialeschki and Dorward (1998) noted that, "Percentages of people of color were still quite low in all degree [level] areas..." (p. 4). According to a comparison of data from the 1988 and 1998 reports, students of color in recreation, parks, and leisure studies curricula grew slightly from $11 \%$ to $14 \%$ on the baccalaureate level, from $4 \%$ to $11 \%$ on the master's level, but showed no growth on the doctoral level at $4 \%$ each. Although some improvement is evident, the percentage of students of color are not equivalent to the percentage of individuals of color in the general population. According to the Population Profile of the United States 1995, non-white individuals (i.e., African Americans, Latin Americans, Asian and Pacific Islanders, American Indians, Eskimos, and Aleuts) make up $25.6 \%$ of the total United States population (US Census Bureau, 1999). These data reflect the need for innovative strategies to recruit and retain underrepresented faculty and students in recreation, parks, and leisure studies curricula.|

Figure 20. Increasing diversity among students in recreation, parks, and leisure studies curricula: A case study (Bedini et al., 2000).

Rather than the inequity itself, the outcomes created by racialization were portrayed as an issue that required attention due to its relevance in population patterns (See Figure 20). This was often seen in the utilization of Census Bureau information:

The population of the United States (U.S.) is becoming increasingly diverse, with selfdentified racial and ethnic minorities projected to reach about $50 \%$ of the U.S. population by the year 2050 (U.S. Census Bureau, 2001). This increased diversity has brought the importance of developing multicultural competent citizens to the forefront of higher education, with service-learning identified as one of the primary ways higher education can foster good citizenship development (Einfeld \& Collins, 2008). (Smith et al., 2011, p.2) 
The population of the United States (U.S.) is becoming increasingly diverse, with self-identified racial and ethnic minorities projected to reach about $50 \%$ of the U.S. population by the year 2050 (U.S. Census Bureau, 2001). This increased diversity has brought the importance of developing multicultural competent citizens to the forefront of higher education, with service-learning identified as one of the primary ways higher education can foster good citizenship development (Einfeld \& Collins, 2008). In its ability to promote self-reflection, service learning is a unique tool that can help students reflect on multicultural differences toward achieving cultural competence. Within the field of public recreation, the need for learning opportunities for students with people who are "different" than themselves is crucial given the diverse nature of today's society.

Figure 21. The relationship between multicultural service-learning and self-reported multicultural competencies in undergraduate students: A qualitative participatory action study (Smith et al., 2011).

Census Bureau statistics utilized by literature in this subcategory suggest a sense of newness, in that recent changes in diversity have created a novel obstacle in the field of leisure that requires mitigation (See Figure 21). In an effort to be responsive to present-day concerns, the context of historical creation and evolution of current racialized issues are expunged under the view that these problems are "contemporary".

This framing was held in stark contrast to articles that acknowledged the historical foundation of discrimination as being relevant to understanding and resolving issues being faced by racialized ethnicities. The relevance of such problems is forged in the chronicle of injustice as is explained by Mowatt (2009):

In doing so, we must acknowledge that racial histories have created unequal playing fields that will continue until a true level playing field can be created, not one that superficially levels play. (p.522) 
In relation to this, hooks (1994) stated, "once we start talking in the classroom about the body and about how we live in our bodies, we're automatically challenging the way power has orchestrated itself in that particular institutionalized space" (p. 137). In doing so, we must acknowledge that racial histories have created unequal playing fields that will continue until a true level playing field can be created, not one that superficially levels play. As Fields (1982) warned that when "one human being can be a simple extension of the will of another" all relationships henceforth will be problematic (p. 161). For people of color as Fanon (1994) added further, "consciousness of the body is a solely negating activity... [for] the body is surrounded by an atmosphere of certain uncertainty" because placement in society is pre-determined, without consultation or input from its owner (pp. 110-111).

Figure 22. Notes from a leisure son: Expanding an understanding of whiteness in leisure

(Mowatt, 2009).

As is expounded by the author, the field of leisure is not faced with modern conditions due to an influx of racialized groups but rather a constant issue of domination that has been transformed over time to appear novel (See Figure 22).

\section{Frame Solution as Being Leisure Specific}

Within 6 articles, leisure was presented as a means to resolve conditions of oppression.

This was seen in the proposition of leisure as being able to bring about large-scale change. Such is demonstrated by Bialeschki and Walbert (1998) in their assessment of historical leisure experience of women labor workers in the early 1900s:

Recreation, on the surface, may seem far less dangerous to the social order than political movements or unions, but when layered with broader community needs, can be a similarly effective tool for institution-building and social change. (p.99) 
By analyzing the experiences of women textile and tobacco workers at a particular historical moment, we can draw conclusions to further both disciplines of leisure studies and history. First, one might conclude from the use of leisure as a means to another end that leisure does not have to be intrinsic to be individually fulfilling or valuable. Leisure can be relational not only in the interpersonal sense of textile community suppers but on a larger level of race, class, and gender as participants assign meaning to activities based on the history of their communities or choose to include and exclude individuals on the basis of demographic categories. Finally, leisure can reflect social hierarchies as well as challenge them. Recreation, on the surface, may seem far less dangerous to the social order than political movements or unions, but when layered with broader community needs, can be a similarly effective tool for institution-building and social change. Collaborative efforts between historians and leisure studies researchers are imperative if we are to build a body of knowledge inclusive of the many voices from our past. Ultimately, perhaps the greatest contribution is the recognition of the critical need for a leisure-based perspective on history and an historical foundation for leisure. Historical perspectives will situate much of our unFigure 23. "You have to have some fun to go along with your work": The interplay of race, class, gender, and leisure in the Industrial New South (Bialeschki \& Walbert, 1998).

The supposed power of leisure was presented by articles in this subtheme as a feasible option in altering outcomes that were forged systemically (See Figure 23). Leisure spaces, by extension, were also viewed as possessing "potential to facilitate diversified relationships, ease social tensions, and break the bonds of discrimination" thereby "making our cities more livable, and ensuring that public places are inviting and welcoming to all Americans" (Beale, 2013, p.418). Within research of this subtheme, efforts to place leisure at the forefront of eradicating prejudicial conditions illustrate an overestimation of the field's influence and a diversion of attention away from the feasible ways that leisure is able to make a difference.

\section{Research Trends}

Between both decades of literature, literature on race, youth development, and community recreation, increased over two fold in viewing only 26 articles in the 1990's and 59 in the decade beginning in 2009. While the quantity of literary pieces have showed progression 
in the textual circulation of information of race as a topic of interest, the fluctuations of research production concentrated within certain themes provide background to the development of race conceptualizations over time. Although these increases and decreases are relative to the amount of leisure studies publications conceived during the time period, they prove a useful tool in understanding relative changes in discourse. As can be seen in Table 7, the use of race as only a demographic variable in leisure studies publications increased drastically and inclusion of diverse demographics was seen as an intentional and fundamental part of generalizability in studies between the 1990's and the decade beginning in 2009. The categorization of articles that demonstrated an improper use of terminology increased across all three subcategories of the theme. Based on relative percentages of articles produced within each decade, there was also a greater likelihood for the importance of combatting racialized issues to be framed as contemporary.

\section{Socio-Political Discourse}

Societal narratives compiled through both written and oral media within this thesis allowed for greater recognition of the discourse that informed the time period and subsequent texts written within the field of leisure.

$1989-2000$

Rodney King/ L.A. "riots". At the beginning of the 1990s, one of the largest rebellions in American history was brought forth through a series of racialized killings and mistreatment. What is commonly known as the LA Rodney King Riots was publicized by media sources as the result of the acquittal of police officers in a video captured of the beating of Rodney King (NBC Southern California, 1992). Despite both Rodney King and the police offers involved in the brutally violent act expressing that it should not be deemed racially motivated, parts of the city of 
Los Angeles rose up against the oppression and over 5 days looting, arsine, and violence ensued (Lindsay \& Martin, 2017). The media coverage during as well as after the riot described that the whole of L.A. was being severely affected and destroyed, deterring focus away from the road blocks of cops set up around certain cities (Lindsay \& Martin, 2017). Thus, racialized ethnicities with less power were left to burn and tear down their own neighborhoods while police officers watched from afar with little intervention (Lindsay \& Martin, 2017). The media coverage, in naming it the Rodney King Riots created the appearance that the aftermath that ensued was solely about the proclaimed innocence of the officers; thereby, erasing pivotal events such as the judge overturn of the guilty verdict of Latasha Harlin's murderer, the level of underpolicing, and the gentrification of areas with a high majority of people of color (Benjamin, 1991; NBC Southern California, 2012). These were three of numerous grievances that added to the time period of the early 1990's but remained largely out of the discussion when the riots erupted (NBC Southern California, 2012). The examination of the events that took place can be seen within talk shows such as The Oprah Winfrey Show in which people affected by the riots created a resounding narrative of non-violence, the need for people of color to stop playing into the stereotype of ghetto, acceptance of diversity, and a need to focus on the fact that the color of someone's skin matters less than the fact that they are human (Winfrey, 1992). Hence, such shows remained a subduing voice in what would have been interpreted as the built up effect of racism. Instead, in producing episodes such as the anti-racism experiment (Winfrey, 1992), ignorance and intolerance replaced its position in the foreground of discourse. It is epitomized in the follow up interview with an individual attacked during the "riots" that explained that the wrongdoings of a few should not misplace effort on violence and "disliking others" as such behavior is an attempt to "put out the fire with gasoline" (NBC Southern California, 2002). A 
drastic rhetorical difference when held against protestors' calls of, "no justice, no peace" (Benjamin, 1991).

Robert Sandifer / Superpredator craze. Almost two years later, the killing of a young boy Robert Sandifer, nicknamed Yummy, in Chicago was one of the final killings before President Clinton enacted the 1994 Crime Bill in response to the perceived growing crime rates (Clinton, 1994). In Clinton's address, the Bill was believed to "punish hardened young criminals with stronger penalties... expand boot camps, drug courts, and other sanctions to stop first-time offenders from beginning lives of crime" (Clinton, 1994) The scare of the "Superpredator", the term coined by Robert Dilulio, emerged as part of the lingering hysteria due to a predicted surge in youth crime amongst those experiencing a new moral poverty, leaving them devoid of empathy or a value on humanity (DiLulio, 1995). The "Superpredator" fueled the belief that although "the trouble will be greatest in black inner-city neighborhoods, other places are also certain to have burgeoning youth-crime problems that will spill over into upscale central-city districts, inner-ring suburbs, and even the rural heartland” (DiLulio, 1995) In Hillary Clinton's 1996 address, the "Superpredator" became utilized as a means to underscore presidential efforts to reduce crime, drugs, and gangs with increased policing and organized campaigns ("Hillary Clinton Campaign Speech", 1996).

Foreign agreements and immigration. In the 1990's, the North American Free Trade Agreement (NAFTA) altered the trade between countries such as Mexico to "promote conditions of fair competition in the free trade area" (Reams et al.,1994). Although portrayed as being equally advantageous, texts from other countries display an unequal pressure on Mexico to comply with requirements that were not applied to all countries in the agreement and/or frequent partners in U.S. trade; thus, not only preventing manufacturing profit in Mexico but also 
thwarting the already deficient competitive edge and resources in the country (Gonzalez-Baz, 1992). Consequently, NAFTA was shown to be deceitfully stimulating beneficial outcomes for the United States rather than all countries in the agreement. More so, the subsequent economic effects from joblessness as a result of uncompetitive crop prices created an unmatched frequency of migratory patterns of people living in Mexico seeking work in the United States (Carlsen, 2014). In addition, the Save Our State Initiative, also known as Proposition 187, passed, which barred immigrants living in the state of California without legal authorization from receiving public benefits such as public education and public health care ("Proposition 187: Text of Proposed Law", 1994). In a political ad by Pete Wilson, the Proposition is presented as a way to reduce the upsurge in unregulated and illegal entries of people at the border, which created unfair costs on citizens to pay for their livelihood ("Pete Wilson 1994 campaign ad on illegal immigration", 1994). The Proposition claimed the State of California had suffered "economic hardship" and "personal injury" as a result of "illegal aliens" with the proposition sanctioning certain actions for people that could not prove or were suspected of living in the country under an illegal status ("Proposition 187: Text of Proposed Law", 1994).

Foreign affairs effect in America. Foreign affairs permeated into America as is seen in the growing fear of the gang entitled Mara Salvatrucha, also known as MS-13. MS-13 was commonly alleged to have originated in El Salvador, obscuring the reality of America's presence in the El Salvador civil war and the large amount of refugees that came to the United States after its culmination (Wolf, 2017). The denial of political asylum to such refugees forced many to live in conditions of scarcity, where discord and lack of safety in cities resulted in gang formation one of which became MS-13 (Wolf, 2017). MS-13's prominence and the ultimate mass deportation of the late 1990's transplanted the divisive groups forged in the United States back to 
El Salvador where the continued violence ensued but not on American soil (Wheeler, 2020). At the end of the decade, Elián González became another face of political asylum that fueled a battle for custody between family members of Cuba and the United States. His perilous journey to the United States with his mother who died en route to seeking refuge became a divisive symbol that went beyond custody and entered into the sphere of politics (Oppmann, 2017). The decision of whether to reunite him with his father despite a communist regime created widespread public commentary that produced an ultimate uproar when Elián was taken by immigration raid in the night to bring him back to Cuba (Diaz, 2017). Regardless of the concerns voiced by public and Americans from Cuba, "Elián was the first time Cuban and American diplomats were pointed in the same direction, wanting the same thing" (Diaz, 2017).

2009 - 2019

Post-racial America/Obama inauguration and presidency. The commencement of the decade beginning in 2009 can be seen as fueled by the election of Barack Obama as President of the United States in 2008, which was widely viewed at what his successor George W. Bush claimed as "a triumph of the American story" (Romano, 2010). His campaign purported the dissolution of lines of racialized versions of Americans and toward a singular united view of America (Scott, 2018). Thus, the beginning of the decade was perceived as being a "statement about where the American people are on the subject of race" ("Barack Obama - America's first African-American president", 2019). Although he did not display the quantifiable achievements desired for his "ethnic group" by the end of his presidency, Barack Obama continued to be seen as symbol of hope and a message of the power of achievement in attaining a position of power for those with his racialized ascription (Koeske, 2018). This discrepancy between systemic advancement and individual accomplishment is personified in Barack Obama's program My 
Brother's Keeper for which the former president places responsibility on people of color to do better and be better as is seen in his following statement:

"We can help give every child access to quality preschool and help them start learning from an early age, but we can't replace the power of a parent who's reading to that child. We can reform our criminal justice system to ensure that it's not infected with bias. But nothing keeps a young man out of trouble like a father who takes an active role in his son's life" (CNN, 2014)

The obligation was thrust back onto racialized ethnic groups, placing culpability in their deficiency as a group rather than those of the institutions. This same rhetoric of possibility without limits of skin color and in deemphasizing race as "playing too much of a role in how we see one another" as it is the "thing that least defines us" was further displayed by Michelle Obama in her final interview as First Lady in 2016 (CBS Evening News, 2016).

Race as understood in the media. The diminishing of race as a fundamental component of treatment and success of individuals is placed against the landscape of national issues that asserted racism was at the source of concerns such as the water conditions of the city of Flint in Michigan (Martinez, 2016). The effects created by a cost cutting change in water supply in the city can be seen in the death and long-term health consequences of its residents comprised of primarily racialized ethnicities with less favorable societal positions (Denchak, 2018). Although, the height of the media coverage created an explicit outcry against the conditions residents were placed in, the coverage diminished despite the lack of complete remediation of water concerns in the city by the end of 2019 (Smith et al., 2019). The rise and fall of media coverage that assert race as a fundamental factor of behavior is additionally seen in the circulation of what was portrayed as the trend of the "knockout game" in which youth attempt to knockout strangers with 
a single punch (FOX News, 2013; Wiener-Bronner, 2013; NBC News, 2013). Coverage of this "trend" speculated racial motivation and hate crimes, citing that the "knockout game" was performed by only Black youth against unsuspecting White individuals that may be result of an affinity for "pugilism" as a way for social mobility (FOX News, 2013). The result of the upsurge in rhetoric around the game came the belief that police were preparing for the violent acts committed by "urban youth" (NBC News, 2013). Although shown to be falsified myth that resulted in waned reporting, the "knockout game" is representative that race is not the thing that least defines us but rather can be the most defining characteristic of discrimination.

Leisure in the media. Within this decade, there is an obvious condemning for overt racism and inequity, some of which can be viewed within leisure settings. It is seen in the numerous lawsuits filed in both fitness and hotel industries over the discrimination of their employees and constituents (Glusac, 2018; Moore, 2018). These lawsuits often began a revitalization of diversity training within the companies as a result (Glusac, 2018; Moore, 2018). It is also observed in news media coverage of park conditions that leave certain areas overcome with community perception as being unsafe (ABC 7, 2017; NBC New York, 2016). Thus, the need for increased policing and simple additions of lights is used to remedy the observed problematic state of parks and recreation (ABC 7, 2017; NBC New York, 2016).

Acts of racism were observed in two distinct incidents that occurred at pool settings in this decade. A camper group was denied access into a swim club after members of a swimming pool at Valley Club in Pennsylvania complained regarding the racialized ethnic groups that were permitted entrance (Northeast Times, 2012). Although the Valley Club offered the campers back into swim club after the incident received widespread public attention, the outcome of this act of discrimination became a large settlement and public criticism over the continuation of racism in 
public spheres that would hopefully be prevented as a result of the court decision (Northeast Times, 2012). An equally explicit case of discrimination was witnessed through video footage of a police officer's use of force on a young girl of color after the abrupt end to an "out of control" community pool party in Texas (Cole-Frowe \& Fausset, 2015). Although the pool was situated in a community perceived as having "friendly relations among black, white, Hispanic and Asian residents", the footage portrays the officer as only addressing and detaining youth of color, one of which was a young girl in a bathing suit that ultimately received national attention (ColeFrowe \& Fausset, 2015). Along with denials of racial motivated policing, the officer's behavior was singled out as being out of line with the policies and practices of the police department (Keneally, 2015).

Discrimination in educational institutions. Beyond the field of leisure, media coverage condemning the improper treatment of racialized ethnic groups is greatly circulated such as the reporting of Tiana Parker's prevention of coming to school with dreadlocks based upon dress code policy that specified that "hairstyles such as dreadlocks, afros and other faddish styles are unacceptable" (Eger, 2013). Or in the University of Oklahoma, where the chant of fraternity members alluding to lynching and that an "African American" would not be permitted into the frat led to the suspension of students and closure of the fraternity (Moyer, 2015). Such explicit racism were observed at Andrean High School in Indiana, where a high school basketball game led to chanting of deportation, tokenism, and building a wall towards students at a rival school (Hernandez, 2016); thus, resulting in diversity celebrations with "talk about community, solidarity, inclusion and empathy" (McCollum, 2018). In all cases, the coverage alone proved defacing to the institutions; consequently, causing immediate and swift action from board and/or school officials to change policies and resolve issues of discrimination under the guise that they 
were the result of the inappropriate actions of a few and not reflections of the institutions (Eger, 2013, Moyer, 2015; Hernandez, 2016).

Individual bias and prejudice. The notion that the consequences of racialization were by and large due to the result of thought and perceptions can be understood in media segments and reactions to political projections. It can be viewed in the release of Census Data at the beginning of the decade that projected that the population of individuals classified as White would be the minority group in the United States by the year 2044 (Tavernise, 2018). This projection and subsequent studies revealed an increase in prejudicial attitudes and fear when such a finding was presented; thereby, leading to the belief that reframing or even omitting projections could mitigate "the American patchwork to a crude, divisive political formula" (Tavernise, 2018). Focus on prejudicial attitudes can be additionally seen in news pieces such as CNN's story on racial bias in young children that demonstrated internalized negative associations made about people of color at young ages ("Study shows how children view race bias", 2010; “A look at race relations through a child's eyes", 2012). It can be further observed in interviews with religious figures about the root of racism being ignorance and insecurity (Winfrey, 2016); thus, highlighting the perceived individualized nature of racism that must be changed.

Immigration and xenophobia. Rhetoric regarding immigration was circulated and by the end of the decade, coverage regarding reform came to the forefront of news and media. The Remain in Mexico program (Desk, 2019), the repeal of a formerly created program entitled the Deferred Action for Childhood Arrivals (DACA) (Rappaport, 2019), and the condoning of Immigration and Customs Enforcement (ICE) raids with corresponding detention centers were a few among a growing number of political decisions during the decade centered on deterring 
immigration (Vazquez, 2019). Such decisions were publicized under the assertion that they were centered toward removal of criminals and to curtail the growing amount of immigrants coming to America for personal gain (Oprysko, 2019). While news coverage of events such as the elimination of Mexican American Studies to deter advocacy for "ethnic solidarity" began in the beginning of this specified decade (Stephenson, 2018), the uptick in discursive elements regarding treatment of various racialized ethnicities were seen in the mass shooting of a Walmart store in El Paso, Texas (Campbell, 2019). While the shooting was underscored by the shooter's denunciation of "interracial mixing and the "Hispanic invasion of Texas"” (Romo, 2019), political responses were centered on mental health support, gun violence, and the action of a single “monster" (Keith \& Naylor, 2019).

Denunciation of groups deemed non-American reached beyond Latinx groups as can be seen in the ubiquitous anti-Muslim rhetoric during the time period. Condemnation was both overt and violent as demonstrated in threats made to kill members of a mosque in Florida (Bay News 9, 2015). However, such pervasive out-grouping was given greater emphasis with running presidential candidate commentary alluding to barring Muslims from entering the country and shutting down mosques to prevent the perceived radicalism of American hatred (Leon, 2015). As exhibited in ACT for America's local chapters, such discourse lobbied for the American people to "take your country back" (Leon, 2015). Despite efforts to deter discrimination such as school district inclusion of anti-Islamophobia programs (ABC 10 News, 2017), they were met with legal responses under the premise of condoning favoritism (Schroeder, 2019), as well as public criticism as adding to the "Muslim takeover" (ABC 10 News, 2017). 


\section{CHAPTER 4}

\section{DISCUSSION}

Based upon the results presented, the comprised themes elicit an understanding of leisure studies scholarship whose ideological foundation is forged in historical and contextual discourse.

\section{0's Discourse}

\section{0's Socio-Political Discourse}

The discourse of the 1990's was displayed within domestic, immigration, and foreign country policies as well as through media coverage that demonstrated a lack of overt recognition of systemic continuation of hegemony. The discourse of that decade deterred attention away from the topic of racism and race as a whole, making subjects such as gang violence, police use of force, and safety of citizens as the foundation of political decisions. Often focused on singular incidents such as the verdict of Rodney King or the killing of Yummy Sandifer, the discourse aimed responses away from examining intentional racism and the conditions placed upon some based on their racialized ascriptions. In it's place, those occurrences were used within the narrative to formulate the appearance that issues in the community were being dealt with. Agreements such as NAFTA seemingly contrasted the prejudicial rhetoric of Proposition 187 despite their equally pernicious consequences. The fear of the Superpredator diminished findings of reduced crime and fueled mandatory action to prevent to rise of racialized ethnicities deemed as morally deprived. The effect of political asylum denial that attributed to the rise of particular gangs in the United States was replaced with narratives regarding the violence of immigrants that led to their ultimate deportation. Whether by being tough on crime or providing a platform that capitalized on feelings and attitudes such as fear or understanding, the forefront of the discourse 
was the notion that diversity, tolerance, and a desire to protect all regardless of race was necessary.

\section{0's Leisure Literature Discourse}

Based upon textual analysis, leisure studies discourse displayed similar patterns. While many of the articles did not explicitly focus on race as a topic of interest, race was spoken about implicitly. Often, leisure scholars demonstrated faint mentions of race when obvious extensions could have been made. Even when included, leisure studies literature rarely focused solely on race although a large percentage of the literature maintained that race was a significant factor in differential experiences and preferences in leisure. Education articles written on the topical areas of interest focused on social commitment and a need for diversity in order to be impactful; thereby, making systemic issues a matter of individual thought and behavior similar to what was observed in the sopio-political context.

\section{0's Discourse}

\section{0's Socio-Political Discourse}

Discourse within the decade beginning in 2009 can be seen as dichotomized between presenting race as a serious topic of interest or in diluting the outcomes of inequity created by racialization. Amongst a plethora of rhetoric emphasizing the gravity of discriminatory behavior and mobilizing attention to produce remedial action, there included the minimization of pervasive racism by many powerful leaders in that particular decade. Upward mobility within racialized ascriptions was seen as a result of personal effort (i.e., color evasiveness), dissolution of racism was diminished to ignorance and diversity training, and targeted mass killings were made the result of everything but violence aimed blatantly toward a specific racialized ethnic group. Exposure of injustices summoned immediate coverage in both small and large scale 
incidents such as denials of swim club access to the media craze over the fake "knockout game". However, this spotlight ebbed when interest feigned as seen in Flint, Michigan or were framed as exemplary of individual rather than institutional decisions as can be viewed in the justification of ICE raids.

\section{0's Leisure Literature Discourse}

In leisure studies scholarship, the importance of being representative of racialized ethnic groups is seen in the collection of demographic data despite its lack of relation to the article's topic of interest. Therefore, similar to the discourse of the time, there was an insistence on inclusion of all racialized groups and appeal to diverse groups. Although there was a relative stability in article production that focused on differences between racialized ethnic groups, the intentional utilization of diverse demographics for generalizability along with continuation of research on difference inherently asserts that there are distinctions characteristic to one's racialized category. Various racialized ethnic groups were more likely to be seen as marginalized, oppressed, and underprivileged, heeding to a similar stance that inequality is unjust and differentially affects groups. Thus, lending itself to the same dichotomy seen in the discourse at the time, which is one that recognizes but continues to produce narratives that are neither critical nor place race in the center of examination. Discussions of race were upheld by the "contemporary" nature of racialized issues, yielding significance to scholarship through claims of demographic changes and the novelty of the current situations in communities serviced by leisure and recreation. Accordingly, the lack of historical knowledge of racism is similarly seen between the discourse of leisure studies and that of the socio-political context. Additionally, educational articles in Schole asserted an analogous discourse of the importance of contact, 
personal reflection, and diversity appreciation as an important component in leisure courses to affectively meet the differences of the constituents.

While both periods of time dealt with the topic of race in differing ways, various fundamental components remained constant in the discursive patterns between decades. Many of the nuances seen in leisure studies scholarship, such as terminology and the perceived importance of micro rather than systemic changes were observed in the discourse of both decades. Consequently, it can be ascertained based upon these results that leisure studies scholarship was significantly impacted by the socio-political discourse of both decades.

\section{Discourse Progression}

Comprehension of discourse progress between both decades relies on factors beyond the increase in literature produced since the 1990's. Instead, development is illustrated through the articles continued use of tactics of racecraft seen within the aforementioned thematic categorizations.

\section{Faint Mentions}

An increase in production of articles that included faint mentions of race was seen between both decades. While the overall rise of literature in the 2010's that included race is unsurprising considering the discourse on race of the 1990's focused on race in a passive way, these references were often brief and/or incomplete. The utilization of race was included as a way to strengthen the article's theoretical and/or methodological devices or in momentary deviance from the article's topic of focus. It is important to note that in many circumstances, further examination of race was warranted but failed to be included. Accordingly, the extension of leisure studies scholarship replaced meaningful evaluations with silence, disregarding the chronicle of discrimination in preference for transitory references of race. More so, as expounded 
by Mowatt (2018), "silence seems to perpetuate a lack of knowing that is crucial to the structural nature of racism and its racial ideological underpinnings" (p.59). In this view, in its brevity, such mentions are equally illustrative of the field's overall knowledge of and engagement in hegemony.

While an overall increase in literature production from a cursory glance may appear as an advancement, it obscures that there was minimal to no analyses of race in over half of the classifications of produced articles. Similar to the conclusions made by Floyd and Stoldolska (2019), it remains that analytical examinations of race are not central within leisure studies discourse despite perceptions of greater scholarship of the subject. In connection to racecraft, the cognitive and behavioral grounds of racecraft "entrenches racism in a category itself” (Fields \& Fields, p.261). In this view, racism solely requires a belief in race for which the field of leisure has continued to provide inadvertent confirmation. The field's indiscriminate propagation of race indicates a perfunctory practice of heedless consumption of race without provision of the intellectual weight and time required for its use. It follows that race remains in the margins of examinations, receiving scholarly mentions that denote an extensive belief in its falsity but not enough consideration to merit scholarship that is either critical or intentional. Whether by innocence and/or inattentiveness, faint mentions of race signify a lack of ideological consideration that precipitates institutionalized disregard for inequity.

\section{Demographics}

There was two-fold increase in the percentage of articles produced in each time period in which race was used as a demographic variable with minimal to no assessment connecting its use to the article's subject of interest. Additionally, this doubled increase was also observed in studies that recognized diversity of collected sample demographics as essential to understanding 
groups and generalizing results. The growth in the collection and perceived importance of demographics alludes to the acceptance of race as a viable category in understanding individual differences as well as a necessary component in comprehension of unrelated topics of leisure. Leisure studies that utilized such tactics appear to rely upon "artificial inventions, arbitrary divisions in a continuum of human diversity" (Mukhopadhyay, 2016, p.14). Categorizing individuals by their racialized ascription is not derived from variations in "innate human instinct but from specific historical circumstances", a "process by which racist distinctions have been 'naturalized'” (Jackson, 1987, p. 6). Consequently, instead of capturing a true range of human experience, leisure studies scholars capture a value-laden identification that is hardly elucidatory of leisure behavior when unconnected to the evaluations of racism.

Moreover, in order to universalize findings in line with common scientific practices, these identifications were employed to obtain "causal explanations from a statistical frequency" (Fields \& Fields, 2012). Contrary to such scientific practices, racialized classifications have "no explanatory value and serves little, if any, analytical purpose" (Jackson, 1987, p. 6). In associating diverse samples of racialized individuals with conclusive statements about groups, these assessments present conditions and qualities "in reductionist, and overly deterministic ways" under the guise of being representative (Kivel et al., 2009, p. 489). Such overgeneralizations demonstrate the distorted lens through which groups are not only perceived but are prescribed oppressive social practices as a result.

In such cases, the importance of a racialized ascription was misplaced on producing a diversified demographic sampling, which is neither a justification for generalizability nor should it be performed as a habitual practice in research. The significance of racialized identifications remains in it that it is a signal for discrimination, a distinction that was rarely made in the 
assessed articles in either decade. This discrepancy in the utility of employing racialized categories demonstrates leisure scholarship's conjecture that "racial differences produce outcomes rather than that they are the result of social processes"; thereby, enhancing the cognitive grounds through which racecraft operates (Benjamin, 2014, p.684). Hence, the overwhelming focus placed on race as a demographic category over time alludes to a regression of the field into habits of racecraft, revitalizing race as a marker of inherent difference rather than solely a differential application of systemic oppression.

\section{Terminology Use}

Increases in all three categories of improper terminology use was presented between the 1990's and the decade beginning in 2009. Racialized categories were often used synonymously with ethnicities and/or cultures, although both ethnicities and cultures are bound together by more than physical appearances necessary to racialize. Thus, 'culture' and “ 'ethnicity' further lose its original meaning when it is used interchangeably as a convenient synonym for "race"' (Sasidharan, 2002, p.4). This false equivalency alludes that culture and ethnicities were utilized as "biological race in polite language", asserting a sense of "homogeneity" that does not exist but within the unsubstantiated reasoning of race (Fields \& Fields, 2012, p.156). Patterns of behavior are unable to be concluded from racialized ascriptions and ethnicities/cultures are too broad of terms to capture the nuances of both for proper deductions to be made. In extension, the proposition of cultural patterns unique to those based upon their racial classification are indicative of ethnicizing racialized groups or cultural essentialism in which "fixed cultural patterns definitively and permanently shape the psychological characteristics of individuals within a racial group, and differentiate them from members of other racial groups" (Soylu Yalcinkaya, 2017, p.3). In their failure to properly distinguish the differences between variables, 
many articles potentially drew inaccurate conclusions of their groups of interest. Thus, it is increasingly uncertain to rely on the inferences made in such articles when the foundational aspects of their inquiry are both unclear and unreliable. With this in mind, there is an exhibited lack of consistency and knowledge in classifications as "being products of social-cultural and historical representations" as well as an uninformed comprehension of "the dynamic relationship between race- and ethnic-classifications and societal inequality" (Sasidharan, 2002, p.3).

There was an increased use of the concept that individuals can be identified with multiple racial classifications within leisure studies between both decades. This professed mixture of race can be understood as a reification of racial purity by alluding to a genetic foundation of race that does not exist. While in potential attempts to "broaden the social terrain and include previously excluded individuals" (Benjamin, 2014, p.684), leisure studies scholarship that deploys such techniques retains patterns of racecraft in their assessments due to its accentuation of in-born biology. Additionally, it erases oppression that was historically justified through the professed biological essentialism of race for which mixtures of "racial blood" would determine the diminished humanity of those that deemed multi-racial (Fields \& Fields, 2012). A history of death under claims that biological mixing of subordinate and superior races led to an individual of diminished humanity (Fields \& Fields, 2012). In this view, "the aura of progressivism and righteousness that currently surrounds multiracialism is not a cure for racism but a particularly ugly manifestation of it" (Fields \& Fields, 2012, p.107).

The use of inconsistent terminology remained relatively stable between the two time periods. Often this inconsistency allowed racialized ethnic groups to be regarded using their ascription (e.g., Black) as well as their perceived lineage from a specific country (i.e., African American). This was rarely observed in those that are racialized as White, in which they were 
commonly referenced as White or Caucasian. This discrepancy is illustrative of the unexamined falsity of labels in their maintenance of power inequality. In their interchangeable use, such identifiers establish a state of othering in which "some groups remain framed eternally as immigrants" from countries believed to correspond with their racialized ascription in all cases with exception to White; thereby, "falsely imply[ing] that-clear dividing lines exist between geographically defined 'races'" (Mukhopadhyay, 2016, p.14). These inconsistencies allude to the appointment of an out-group status in that various racialized ethnic groups are not solely American but modified in their status such as African Americans or Asian Americans (Mukhopadhyay, 2016). Thereby, articles that were found to employ such tactics suggest a haphazard labeling in which authors may be unaware of the historical and socio-political significance as well as the ramifications of the identifications utilized.

Overall, a lack of development in mere terminology use is observed when referencing racialized ethnicities over time. "Language is one of the most systematic, subtle, and significant vehicles for transmitting racial ideology" (Mukhopadhyay, 2016, p.12); therefore, proliferation of incorrect and shifting language use seen in all three sub-categories are exemplary of an apolitical and ahistorical comprehension circulated in research. Terminology often portrayed both the pseudo reality of genetic race as well as the biological and cultural essentialism of race. Thus, designating distinct confines for where "where human kinship begins and ends", a separationist grouping created as a result of racecraft and in justification of racist ideology (Giles, 2019, p.25). It can be distinguished that "although scientific criteria are incapable of segregating human beings into distinct racial and ethnic classifications, researchers continue to conceptualize race and ethnicity as naturally occurring categories" (Sasidharan, 2002, p.2). As follows, this pattern becomes indicative of more than the mere misconceptions, but rather the 
result of social practices through which information upholds conditions of discrimination through habitual customs of insufficient understanding.

\section{Fixed Versus Fluid Status}

There was an increase in the overall employment of descriptive words that applied a fixed rather that fluid negative status to racialized groups. While there was a reduction in utilization of linguistics that suggested a state of othering, there was an increase in racialized groups with less power being deemed as vulnerable and disadvantaged. Whereas this may outwardly appear to represent progress in leisure studies scholarship, these statuses often conveyed a sense of permanency and were applied with very minimal justification for the conditions that placed racialized groups in a category of mistreatment. In this sense, without providing a rationale for the ways in which these groups are deprived or persecuted, these characteristics become a seemingly accepted description of the group. Moreover, specific racialized ethnic groups were often referenced as minorities; thereby, transforming a system of oppression into an oppressed individual, making a participant a minority regardless of if they are the majority in their own community. In both instances, the perpetuity is not reflective of reality in that variations of experiences can lend an individual to conditions in which they are neither destitute nor marginal. Rather, the perpetuity is demonstrative of power in that one's racialized identification bears a meaning that overshadows deviations in prescribed conditions, where racialized ethnic groups remain as constant subordinate in a system of hegemony.

In constructing boundaries of immutable labels, racialized ethnicities are situated in enduring states of being that cannot be changed. Consequently, research that put these techniques into use accentuated the characteristics of those that are in conditions of marginalization while retracting from the actions of those that create inequitable conditions. Without context, 
utilization of descriptive qualities in research operates through racecraft, inadvertently providing a rationale for injustice as a result of the preservation of the "the superordinate group's position of dominance" (McDonald, 2006, p.661). Racism relies on this process of chronic differentiation for which the power of individuals can be assessed solely by their racialized categories (Kivel, 2005). As can be seen, if a group is in a permanent position in society as an oppressed minority, then the latent inferiority sufficiently justifies racism (Fields \& Fields, 2012).

\section{Race a Marker of Difference}

In line with the findings of Floyd and Stoldolska (2019), this study found minimal progress in the field with regard to the utilization of race as a marker of dissimilarity as was observed in close to one third of the articles assessed within the last decade. In application of race as a key differentiating characteristic, there is a latent assumption that there are only “differences between 'marginalized' (non-white) and dominant groups (white), in terms of leisure experiences, behaviors and attitudes" (Kivel et al., 2009, p.479). Such evaluations thereby become representative of the ability of dominant discourse to present racialized ethnic groups as an "other", reducing them to a subordinate outside status due to their racialization and the standard of Whiteness that it is measured against (Kivel et al., 2009).

In addition, these appraisals were often structured as a component of the individual as opposed to highlighting the conduct of those with power to marginalize. As was expounded by Benjamin (2014), racecraft is observed "in the way scholars formulate questions and the way public discourse makes sense of social disparities, [where] subjugation is posited as an inevitable outcome of inherent racial difference even when the historical record does not support it" (p.684). With such unsystematic evaluations, there exists no possibility for critical inquiry to "recognize leisure inequities as products of broader socio-historical processes rather than 
particular discrete events" (Rose et al., 2018, p.657). Additionally, there is a failure to acknowledge leisure experiences and preferences as being "grounded in broader macro and structural analyses of power and issues of oppression" (Kivel et al., 2009, p.483). In viewing race as a marker of fundamental difference, dominant discourses in leisure studies scholarship conceals the nature of power inequality. In its place, the assumption arises that "physical features function merely as a visible index of an invisible essence that is separate and different from them" (Fields \& Fields, 2012, p.211). This index ultimately lays the groundwork for "the gaze" of racecraft, or the fundamental ways in which "Americans look at themselves and each other" (Giles, 2019, p.25). Given the constant discursive highlighting of dissimilarities, the consequences of this pattern are recognized in its promotion of a disassociated view of others based solely on their racialized ascription. Consequently, unsupported racial differences prove a corroborating force for the ideology of racism that is easily seen, identified, and passed down through the evolution of leisure studies scholarship on race (Fields \& Fields, 2012).

\section{Change as Individual and Contemporary}

There was a relative stability between each time period in leisure studies scholarship's inadequate lens of the problem and/or solution seen through its minimization of systems of dominance. This was established in the misrepresentation of the influence of individual thought and behavior in overturning oppression.

There was an observed rise in literature in the last decade that applied changing demographic patterns often posed as Census fluctuations as a way to substantiate the necessity for leisure to expand its knowledge of and services for racialized ethnic groups. In formulating the problem of inequity to appear novel, research effectively adopted an ahistorical rather than responsive stance. While racialization has changed over time, it "retains its underlying political 
foundation despite the rising numbers of 'other identities' " (Mowatt, 2009, p.515). Demographic patterns, when rooted in an identification system and used to validate action, neglects to acknowledge how "historical context profoundly shapes the racialized present" (Feagin, 2014, p.60). The ideology of racism is neither contemporary nor should its principal element of race be utilized to expunge the history of racecrafting that, despite migratory variations, continues to uphold White hegemony.

Individualized solutions were often viewed as a remediating influence over prevailing inequitable conditions. Whether a function of leisure, providers, or the racialized individual themselves, the predominant assumption was that issues were the result of individual shortcomings. In one respect, this pattern can be seen as color and power evasiveness, which places fault upon those with less auspicious racialized ascriptions for their failure to capitalize on the opportunities that are believed to be provided freely to all (Frakenberg, 1993). Accordingly, resolution to leisure inequality or participatory differences were concluded to have emerged as the result of personal factors such as insufficient "self awareness and critical consciousness" (Pryor \& Outley, 2014, p.274), or a lack of tools to effectively "get off the streets" (Stodolska et al., 2014, p.613). In this line of thought, there is an implicit inference of inherent inadequacy of racialized ethnicities that lay at the crux of their detrimental life circumstances.

Moreover, "the language of equality, sameness and prejudice additionally suggests that if racism exists at all, it is a matter of biased individual attitudes and personal behavior" (McDonald, 2009, p.10). Diversified hiring, exposure, and diversity training are deemed as necessary components in understanding those reasoned as "other". "A liberal, multicultural framework that rests primarily on training society to become more tolerant is deficient insofar as it fails to directly address power inequities" that can not be remediated whilst the principal 
systems of belief and thought are guided by racecraft (Benjamin, 2014, p.685). In this view, these deficient resolutions emphasize the prevailing mental space in which distinctions are “imagined, acted upon, and reimagined", accentuating that fundamental differences do not only exist but should be appreciated (Fields \& Fields, 2012, p.288). Such tactics were also noted in the overestimation of the power of leisure to eradicate circumstances of marginalization with solutions that highlight the potential of leisure and recreation to alleviate "racial tension" or cultivate tolerance. Inflated impressions of leisure capabilities shroud the ways in which leisure can effectively support racialized ethnicities in attainable ways. In either sense, there is an underlying presumption that through correction of the individual or application of beneficial leisure opportunities, injustice can be corrected; thereby, obscuring the "politicized nature of leisure experiences" and the system of racialized identification itself that would allow for a systemic view of race and racism in leisure (Rose et al., 2018, p.654).

Hence, the power of institutions is revealed in its creation of a false illusion that microcosmic changes in leisure or attitudes can alter what historical patterns of systemic racism have produced and currently reproduce. The focal point of race and leisure is diverted away from what actually is and toward what the field would like to think, which is that it is navigating uncharted territory that can be remediated if outlook/behavior is changed and leisure is provided. However, ideology neither relies on beliefs/attitudes nor does its present-day reproductions require an overt adverse stance to sustain its pernicious functioning (Fields \& Fields, 2012). Rather, it requires a prevailing system of thought in which "rituals of deference and dominance" are warranted under the falsity of "race relations", giving individuals the false sense of "how different people must deal with each other" based upon their racial classification (Giles, 2019, 
p.25). It is through leisure publications that these rituals have been reformulated and confirmed in its restricted idealization of how change can be brought about.

\section{Mattering in Discourse}

Leisure studies scholarship, through its proliferation of racecrafting, upholds that the personal significance of individuals in both the world and in leisure is tied to their racialized ascription. While likely the result of unintentional consumption of collective belief and habits, the lack of critical examination of race as it functions in leisure emphasizes the field's underdeveloped and inadvertently harmful position on inequality.

In persistent utilization of racecraft, many studies, regardless of the time period they were produced, employed race as a symbol of one's placement in society. Whether as a minority, a signal of inherent difference, or a permanent status of marginalization, this placement disregarded the process of identification constructed through time to rationalize unjust practices. Race was often used as a supplementary topic of study involving articles on youth development and community recreation. Consequently, it becomes difficult to establish that the field puts forth an urgent concern over the promulgation of institutionalized injustice seen in both community and youth outcomes due to its apparent lack of application in research (importance). Even more, in bolstering acknowledgement, a foundational part of mattering, articles would have yielded a greater amount of content recognizing and addressing the reality of oppression for various racialized ethnic groups as a result of harmful social practices (Conrad-Garrisi \& Pernice-Duca, 2013). In taking a "politically inert" stance, these texts resulted in "blaming proximate and local forces" rather than systemic ones and adopting an insistent "objectivity of disinterest" latent in claims of neutrality (Robbins, 2012, p. 13). In extension of this lack of urgency, there is an implication that there remains an absence of leisure research devoted to social justice that 
integrates the imperative need to remediate discrimination (ego-extension). Accordingly, the evaluated literature is largely devoid of the subcomponents that are demonstrative that various racialized ethnic groups matter.

Contradictory to mattering, "discourse on exclusion could manifest itself in a potentially huge range of genres and texts" (Wodak, 2009, p.318). In youth development and community recreation, marginalization was advanced in omissions of scholarly assessments of "the way that the structural nature of racism destroys the lives of youth of color" (Mowatt 2018, p.61) This exclusion was further rendered in texts frequently displaying "leisure scholars' collective and individual silences on many of the most politicized issues", thereby denoting "an uneasy complicity in accepting and perhaps even replicating systems of injustice” (Rose et al., 2018, p.652). Whether this is the result of "social practices that are essentially depersonalized through institutionalization", the rhetoric often repudiated the profound sense of oppression that thrusts individuals in the periphery (Guess, 2006, p.651).

Overall, it is unfeasible and even unjust to ascertain from these results that leisure studies scholarship is making a well-informed effort to promote mattering for racialized ethnicities that lack systemic agency. The terrain of social justice and mattering is incompatible with the terrain of racecraft as it is inconceivable that marginalization, oppression, and discrimination (i.e., the byproducts of engaging in racecraft) can exist alongside advocacy for the importance, belonging, and overall equality for racialized ethnicities.

\section{Ideological Development in Discourse}

With respect to evolution of leisure studies scholarship, there appears to be a preservation of techniques of racecraft in sustaining racist ideology. There were few noticeable changes imparted over time beyond further inclusion of race within content. As was illustrated, there was 
an increase in literary production in nearly every thematic category. This finding is suggestive that there is a progressively widespread employment of racecraft that confines the field of leisure within its inherent ideology as seen in the pervasive and discernible choices made by leisure studies scholars. Undisputed habits of research remain culprits to a prevalent belief system that has become more sophisticated over time, although made to seem beneficial and progressive. Asserting diversity, inclusion, and a need to provide services to racialized ethnic groups that demonstrate historically low participation in leisure at cursory glance seems benign and even generous. However, without a critical lens, it conceals the existence of racism that justifies systemic mistreatment through presumably uncontroversial thought and language. Therefore, "our zeal in our personal engagement in leisure may cloud our examination of it as a political dimension or a political ideology that serves the dominant society" (Mowatt, 2018, p.672)

Despite the commonly supported conception of race as a social construct, it is important to distinguish that "the socially constructed part of race is not that it is unreal, but that it is invisible in its construction, and that it is being done by people all the time, in action and in understanding" (Fields et al., 2015). While often used as an unconscious retort of progressiveness, once observed, leisure studies scholarship reveals its apolitical and ahistorical foundational knowledge that acts on and reproduces the same adverse social reality of race through its utilization of racecraft. In this respect, leisure studies scholarship displays an inability to conceptualize race beyond its social construction whose meaning is systemically forged through power and hegemony over time (Kivel et al., 2009). More so, the compelling aspect of race within collective consciousness has furthered its utilization as a social fact with the ideological construction of racism conceived as a result. The field of leisure's complicity in ideologies maintaining social injustice is hence revealed in its unexamined utilization of and, 
therefore, evident belief in race.

Within this study, discourse on race revealed a convoluted link between societal ideology and leisure academia that was exposed in a common language and, by natural expansion, behavior and thought connected to racialized ethnicities (Stewart et al., 2008, p.362). Furthermore, this oppressive ideology specified "an idealized vision of end states of society" exhibited in research's relation to aligning discourse with this prescriptive vision; thus, "discourse creates a framework in which the world fits, and our research shapes the world to fit" (Stewart et al., 2008, p.375). As attested to in this thesis, maintenance of racial order continues to be "sustained by an ideological system and by a set of attitudes that legitimate difference and dominance" that is embedded in discourse and its intended outcomes (Van Dijk, 1992, p.192).

Whether or not reflected in the conscious beliefs of researchers and the field itself, it remains that "racial ideologies rely on not knowing and not being reflexive about empirical exemplars of racism" in which "further lack of knowing and blindness to the effects of racism" produces a institutional cycle of imprudent assessments of race and culprits to racist ideology (Mowatt, 2018, p.59). Through its indiscriminate role in discourse, leisure studies scholarship has overlooked that "leisure has not been impacted negatively by racism but instead operates according to the order desired by elites and administrators" (Mowatt, 2018, p.671). As a consequence, leisure studies scholarship is employed as a discursive piece in "the long history of this dominant, white-created racial frame" (Feagin, 2014, p.27). A governing historical narrative that asserts its power to devise the mental landscape through which society traverses and to which leisure studies scholarship has validated with matching ideologies and rhetoric. Although ingrained into the socio-political and historical system, it is a landscape that will continue to reveal the field of leisure's stance on mattering, on power, and on racism. 


\section{CHAPTER 5}

\section{CONCLUSION}

In adding to the fourth wave of leisure research, this thesis complements the literary focus of scholarship on race in assessment of ideology that functions in the field as well as within leisure literature. This project provides a unique perspective in that the concept racecraft, the construct of mattering, and the DHA have seen minimal employment within leisure studies scholarship. Together, they form a depiction of oppression in which the field of leisure further marginalizes racialized ethnic groups particularly through scholarly articles.

In observation of this study's findings, the objective is not to cast a view of the field and leisure studies scholarship as being intrinsically right or wrong, good or bad (Wodak, 2001). Rather, it is the approach of re-attuning the field of leisure to the harmful principles found in discourse that are undoubtedly intertwined with leisure studies. As demonstrated in the prevalence of racecraft in leisure articles, the detriment of the field's conceptualization of race endures within "popular imagination, impoverishes our collective vocabulary, and distorts our scholarly suppositions" (Benjamin, 2014, p.685). Thus, there is an imperative obligation to "reflexively question our own roles in the production of particular knowledge and particular practices of the continuation of domination and subordination of individuals and groups" (Rose et al., 2018, p.660). As was noted in the progression of discourse from the 1990's to the 2010's, the operation of race is not fixed but rather its underlying ideology conforms to the sociopolitical context so as to remain an undisputed and accepted reality. With that, it becomes compulsory to "increase the capacity of our discourses to explicitly recognize their values and ideologies" (Stewart et al., 2008, p.362).

Nevertheless, the repercussions of failing to heed to calls made, not only in this thesis but 
those offered by many leisure scholars before, is that it forms a disjuncture between the societal visions the field presumes it promotes and the ones that are constantly being brought to fruition through continued utilization of racecraft. Such a disjuncture is insidious in that researchers are disillusioned to believe that leisure research is conducted "in ways that provide the most hope for end states such as health, social justice, and well-being” (Stewart et al., 2008, p.366). Rather, its underlying discourse of hegemony fulfills "its potential to reproduce a social order and leave the causes of problems unaddressed", a position of power in its creation of an unintended reality (Stewart et al., 2008, p.363). In this line of thought, "traditional expressions of leisure... as the individual realization of freedom, self-determination and choice" are sustained in lieu of the constructive outcomes that could be conceived from developed reasoning on the relationship between leisure, racism, and race (Rojek, 2001, p.121). In this manner, there is an obvious moral component in viewing the persistent utilization of racecraft and apparent rejection of the former appeals made by leisure scholars. The morality of this void is revealed in the latent assertion that an individual only matters as much as their racialization allows but also that it was brought into the field's awareness through time with little corrective action taken.

\section{Application of Race}

As is shown within this study, while scholarly articles in the field of leisure may feign impartiality in focusing on leisure behavior and preferences along racialized categorizations, "without also examining the ideological and construction of such markers, we can easily miss the discourses of racism that are constructed and structured through leisure" (Kivel 2005, p.25). The conclusions established in this thesis should not be viewed as a proposition of the abolishment of utilizing race within leisure studies publications altogether. Such a denunciation would likely prompt equally adverse consequences of the same ideological lineage (i.e., colorblind racism and 
color evasion). Alternatively, race remains as a social fact that affirms the functioning of prejudice. In reorienting the field to the observance of race as fundamentally racism, racialized identifications become central to uncovering discrimination. Such an ideological reframing adjusts the lens of scholarship to a more deliberate use of racialized ascriptions solely for entering into critical discussion on discrimination and the conduct of those that sustain it. To this end, what is done with the collection of demographics or in specification of racialized categories can mean the difference between marginalization and mattering as well as disassociated versus active stances on hegemony in leisure.

\section{Promoting Mattering}

Advocating for the mattering of racialized groups requires consciousness in research. This mindfulness can be sustained in a variety of ways, most principally of which is a political and historical awareness in leisure studies scholars. This may transpire through "understand[ing] historical relationships between communities of color and social science researchers", which is one laden with mistrust based on a chronicle of grievances (Floyd, 2014, p.381). This relationship extends beyond research in its collaboration with community agencies that are able to further re-impose the ideology of oppression through social practices. Bolstering conditions of mattering would thus advance the political nature of leisure studies' position to solicit remedial action from institutions that have and continue to discriminate racialized ethnic groups.

Dismissals of racialized ethnic groups can be further avoided through a greater breadth of knowledge of historical racism due to its association with researchers' comprehension of contemporary racism (Feagin, 2014). As was described by Fields (1990), "loose thinking on these matters leads to careless language, which in turn promotes misinformation" (p.99). More so, it can generate power inequity by "substitut[ing] negligible terminology and policies with 
sanctified ones" (Mowatt \& Schmalz, 2014, p.355). Examination of leisure if not through the lens of history and racialization fails to see that race is a pervasive and ever-present aspect of life that ultimately confounds leisure with power (Mowatt, 2018). Often, the level of concern required to foster belonging begins with an understanding of the chronicle of injustice and a cognitive vigilance to disrupt further marginalization. A concerted effort is required of the field to deepen understanding of the cycle of deceptive discourse with an even greater resolution to extricate itself from it.

\section{Effective Research and Education}

In taking a more effective approach toward examinations of race in leisure studies scholarship, "researchers should recognize possible ways research, teaching, and engagement practices compromise and undermine efforts to advance social justice” (Floyd, 2014, p.380). Conscious effort is necessary in abstaining from the inclusion of racialized ethnic groups to form monolithic conclusions and images of communities (Kivel et al., 2009). From an academic standpoint, this type of astute practice is partly forged in institutions that are able to educate future practitioners in ways to counter hegemony in research. Consequently, there is an obligation for institutional inquiry on the conceptualizations of race and thus racism being provided to future professionals. Based upon the findings of this study, there is a demand for critical pedagogy in providing a more in-depth and macro view of approaching race and leisure, in particular within community recreation and youth development. This can be promoted by producing a base comprehension of students and scholars in "tracing the historical and geographical roots of such classifications" to ensure a more effective application of categorical variables (Sasidharan, 2002). The field of leisure must invest in creating future scholars and practitioners with a high level of systemic discernment to understand that what racialized ethnic 
groups require is not solely more picnic tables or park lights to successfully engage in leisure but rather individuals with a committed political voice and a working knowledge of the interconnected nature of racism that exists within the social framework of society (Floyd \& Johnson, 2002). Only then, will the field of leisure be able to effectively engage in matters of social justice.

\section{Next Steps}

This thesis is regarded as the first phase of discourse examination for which further expansion will include a greater amount of leisure studies publications. While a critical analysis of leisure studies scholarship discourse was performed within this study, language use in the field of leisure can be examined in a variety of contexts.

In practical extension of discourse historical analyses of leisure, research can be applied to program brochures or agency manuals to provide a more concentrated examination of latent ideology, social practices, and social power as well as its affect on leisure programming. From a governance standpoint, distribution of outdoor recreation are often indicative of environmental racism, where racialized ethnic groups "enter American society at the margins and remain there to varying extents, in environmental decisions affecting community and leisure places" (Floyd \& Johnson, 2002, p.73). Thus, the DHA is able to illuminate the ideology inherent in discourse of government initiatives and policies regarding parks and recreation allocation.

In pedagogy, the Council on Accreditation in Parks, Recreation, and Tourism Programs (COAPRT) standards are exemplary of discursive elements in the field of leisure that maintain institutionalized discrimination. In its most recent revised standards, accreditation was partially based on the need for curriculum that teaches students programmatic processes that take into account and welcome diversity (COAPRT, 2014). It additionally cites diverse hiring strategies 
based on factors such as race as a requirement for accreditation (COAPRT, 2014). While minimal in its reference to race, these standards indicate a void in institutions where attempts to remediate injustice are merely symbolic. Such standards become fruitless when held against the distribution of faculty members in leisure studies that demonstrates continued exclusion of faculty of color (Mowatt et al., 2016). The discourse of such texts reveals the pervasive extent of racecrafting and racist ideology in the field so much so that the programmatic requirements lack the proper viewpoint to produce substantive change and accountability in institutions. Overall, racism in leisure discourse endures because the field "continue[s] to verify it, and thus continue[s] to need a social vocabulary that will allow us to make sense ... of what we ourselves choose to do now" (Fields, 1990, p.118). Therefore, regardless of its utilization, discourse examination is a viable approach in reintegrating power and discrimination into the field of leisure's purview.

At the field's current juncture, this thesis supports the urgent need to reorient leisure discourse and the resulting political positioning on race to bring about future viability within academia (Rose et al., 2018). As explicated by Henderson (2010), the continuation of leisure studies as a field is predicated upon the knowledge of leisure researchers and practitioners of "how leisure fits into the broader society" (p.396). As such, the field cannot continue to look forward without looking back historically, without looking systemically, and without looking internally both as a field and as researchers to understand the ideological, oppressive worldviews that it continues to reuse and reinvent. 


\section{References}

ABC 7 (2017, December 29). Cameras being placed at selected Santa Ana parks to help deter crime. Retrieved from https://abc7.com/2836484/

ABC 10 News. (2017, April 26). SDUSD launches effort against Islamophobia. Retrieved from https://www.10news.com/news/san-diego-schools-launches-effort-against-islamophobia

Allaby, M., \& Shannon, C. S. (2019). “I just want to keep in touch”: Adolescents' experiences with leisure-related smartphone use. Journal of Leisure Research, 1-19.

Allison, M. (2000). Leisure, diversity and social justice. Journal of Leisure Research, 32(1), 2-6.

Allison, M. T. (1999). Organizational barriers to diversity in the workplace. Journal of Leisure Research, 31(1), 78-101.

A look at race relations through a child's eyes [Video file]. (2012, April 2). Retrieved from https://www.youtube.com/watch?v=GPVNJgfDwpw

Arai, S., \& Kivel, B. (2009). Critical race theory and social justice perspectives on whiteness, difference(s) and (anti)racism: A fourth wave of race research in leisure studies. Journal of Leisure Research, 41(4), 459-472. doi: 10.1080/00222216.2009.11950185

Bailey, A. W., \& Fernando, I. K. (2012). Routine and project-based leisure, happiness, and meaning in life. Journal of Leisure Research, 44(2), 139-154.

Bailey, A. W., Kang, H. K., \& Schmidt, C. (2016). Leisure routine and positive attitudes: agegraded comparisons of the path to happiness. Journal of Leisure Research, 48(3), 189209.

Barack Obama - America's first African-American president [Video file]. (2019, April 12). Retrieved from https://www.biography.com/video/barack-obama-americas-first-africanamerican-president-5106755981 
Bay News 9. (2015, November 15). St. Petersburg mosque receives threatening voicemail. Retrieved from https://www.mynews13.com/fl/orlando/news/2015/11/15/ st_pete_mosque_recei

Beale, S. (2013). Contested waters: A social history of swimming pools in America. Journal of Leisure Research, 45(3), 415-418. doi: 10.1080/00222216.2013.11950293

Bedini, L. A., \& Anonymous (1996). Integrative book reviews. Journal of Leisure Research, 28(4), 312-321.

Bedini, L. A., Stone, C. F., \& Phoenix, T. L. (2000). Increasing diversity among students in recreation, parks, and leisure studies curricula: A case study. SCHOLE: A Journal of Leisure Studies and Recreation Education, 15(1), 47-62.

Benjamin, P. (1992, May 1). Rodney King verdict sparks LA riots: from the archive, 1 May 1992. Retrieved from https://www.theguardian.com/theguardian/2013/may/01/la-riotsrodney-king-race

Benjamin, R. (2014). Conjuring difference, concealing inequality: A brief tour of Racecraft. Theory and Society, 43(6), 683-688. doi: 10.1007/s11186-014-9238-z

Bialeschki, M. D., \& Walbert, K. L. (1998). "You have to have some fun to go along with your work": The interplay of race, class, gender, and leisure in the industrial New South. Journal of Leisure Research, 30(1), 79-100.

Blanco, J., \& Robinett, J. (2014). Leisure helps get the job done: Intersections of hegemonic masculinity and stress among college-aged males. Journal of Leisure Research, 46(4), $361-374$.

Caldwell, L. L., \& Darling, N. (1999). Leisure context, parental control, and resistance to peer 
pressure as predictors of adolescent partying and substance use: An ecological perspective. Journal of Leisure Research, 31(1), 57-77.

Caldwell, L. L., Patrick, M. E., Smith, E. A., Palen, L. A., \& Wegner, L. (2010). Influencing adolescent leisure motivation: intervention effects of health wise South Africa. Journal of Leisure Research, 42(2), 203-220.

Campbell, A. F. (2019, August 9). The El Paso shooter told police that he was targeting Mexicans. Retrieved from https://www.vox.com/2019/8/6/20756750/el-paso-shootertargeted-latinx-walmart

Carlsen, L. (2013, November 24). What we've learned From NAFTA. Retrieved from https://www.nytimes.com/roomfordebate/2013/11/24/what-weve-learned-fromnafta/under-nafta-mexico-suffered-and-the-united-states-felt-its-pain

CBS Evening News (2016, December 15). Michelle Obama discusses race and labels with Oprah. Retrieved from https://www.youtube.com/watch?v=SkdHn8DxigM

Chun, S., \& Lee, Y. (2010). The role of leisure in the experience of posttraumatic growth for people with spinal cord injury. Journal of Leisure Research, 42(3), 393-415.

Clark, B. S., \& Anderson, D. M. (2014). Not yet a woman, not yet a mom: The leisure experiences of pregnant adolescents. Journal of Leisure Research, 46(5), 509-524.

Clinton, W. J. (1994, September 10). The President's radio address on September 10, 1994. Retrieved from https://clinton.presidentiallibraries.us/items/show/12940

CNN. (2014, February 28). Transcript: Obama announces 'my brother's keeper' - CNNPolitics. Retrieved from https://www.cnn.com/2014/02/27/politics/obama-brothers-keepertranscript/index.html

COAPRT. (2014). Guidelines for learning outcomes for therapeutic recreation education. 
Retrieved from http://www.nrpa.org/uploadedFiles/nrpa.org/Professional_Development/ Accreditation/COAPRT/TR\%20Guidelines\%20for\%20Learning\%20Outcomes_11-3011.pdf

Cole-Frowe, C., \& Fausset, R. (2015, June 8). Jarring image of police's use of force at Texas pool party. Retrieved from https://www.nytimes.com/2015/06/09/us/mckinney-tex-poolparty-dispute-leads-to-police-officer-suspension.html

Conrad-Garrisi, D. L., \& Pernice-Duca, F. (2013). The relationship between sense of mattering, stigma, and recovery: An empirical study of clubhouse participants in the U.S. Midwest. International Journal of Self Help and Self Care, 7(1), 41-57.

Denchak, M. (2018, November 8). Flint water crisis: Everything you need to know. Retrieved from https://www.nrdc.org/stories/flint-water-crisis-everything-you-need-know

Desk, F. (2019, September 12). Changing policies, plans: Toughened enforcement pushes asylum seekers to stay in Mexico. Retrieved from https://news.azpm.org/p/news-topicalborder/2019/9/12/158013-changing-policies-plans-toughened-enforcement-pushesasylum-seekers-to-stay-in-mexico/

Diaz, C. D. (2017, May 17). The political battle over Cuban rafter boy Elián González is the focus of new documentary film. Retrieved from https://www.univision.com/univisionnews/culture/the-political-battle-over-cuban-rafter-boy-elian-gonzalez-is-the-focus-ofnew-documentary-film

DiLulio, J. (1995, November 27). The coming of the super-predator. Retrieved from https://www.washingtonexaminer.com/weekly-standard/the-coming-of-the-superpredators

Dixon, A. L., Scheidegger, C., \& McWhirter, J. J. (2009). Adolescent gender variations 
in perceived mattering, anxiety, and depression. Journal of Counseling and

Development, 87, 302-310. doi:10.1002/j.1556-6678.2009.tb00111.x

Durham, A. (2015). ___While Black. Cultural Studies $\leftrightarrow$ Critical Methodologies, 15(4), 253-259.

Edwards, M. B., \& Matarrita-Cascante, D. (2011). Rurality in leisure research: A review of four major journals. Journal of Leisure Research, 43(4), 447-474.

Eger, A. (2013, September 10). Tulsa charter school's board votes to rescind controversial hairstyle rule. Retrieved from https://www.tulsaworld.com/news/local/education/tulsacharter-school-s-board-votes-to-rescind-controversial-hairstyle/article_93a1ade8-bf9f5dcd-b342-a0738aaa9327.html

Fairclough, N. (2003). Analyzing discourse. London: Routledge.

Feagin, J. R. (2000). Racist America: Roots, current realities, and future reparations (2nd ed.). New York, NY: Routledge.

Feagin, J. R. (2014). Racist America : Roots, current realities, and future reparations (3rd ed.). New York, NY: Routledge.

Fernandez, M., \& Witt, P. A. (2013). Attracting Hispanics to an African American recreation center: Examining attitudes and historical factors. Journal of Leisure Research, 45(4), 423-444.

Fields, B. J. (1990). Slavery, race and ideology in the United States of America. New Left Review, 181(1), 95-118.

Fields, B. J., Fields, K., \& Farbman, J. (2015). How race is conjured. Jacobin, June, 29.

Fields, K. E., \& Fields, B. J. (2012). Racecraft: The soul of inequality in American life. Verso Trade.

Floyd, M. (1998). Getting beyond marginality and ethnicity: The challenge for race and ethnic 
studies in leisure research. Journal of Leisure Research, 30(1), 3-22.

Floyd, M. (2007). Research on race and ethnicity in leisure: Anticipating the fourth wave. Leisure/Loisir, 31(1), 245-254.

Floyd, M. (2014). Social justice as an integrating force for leisure research. Leisure Sciences, 36(4), 379-387.

Floyd, M. F., \& Johnson, C. Y. (2002). Coming to terms with environmental justice in outdoor recreation: A conceptual discussion with research implications. Leisure Sciences, 24(1), $59-77$.

Floyd, M., \& Stodolska, M. (2019). Scholarship on race and ethnicity: Assessing contributions to leisure theory and practice. The Journal Of Park And Recreation Administration, 37(1), 80-94. doi: 10.18666/jpra-2019-8339

FOX News. (2013, November 21). 'Knockout' game part of epidemic of senseless violence. Retrieved from https://www.foxnews.com/health/knockout-game-part-of-epidemic-ofsenseless-violence

France, M. K., \& Finney, S. J. (2009). What matters in the measurement of mattering?. Measurement and Evaluation in Counseling and Development,42(2), 104120. doi: $10.1177 / 0748175609336863$

Frankenberg, R. (1993). White women, race matters: The social construction of whiteness. U of Minnesota Press.

Freysinger, V. J., Fox, K. M., Henderson, K. A., \& Bedini, L. (1994). Book and resource review: Addressing multiculturalism in recreation and leisure education. SCHOLE: A Journal of Leisure Studies and Recreation Education, 9(1), 79-89.

García, R. (2013). Social justice and leisure: The usefulness and uselessness of research. Journal 
of Leisure Research, 45(1), 7-22.

Giles, H. (2019). Toward a theory of justicecraft: language, narratives, and justice in restorative community conversations. Contemporary Justice Review, 22(3), 257-279.

Giddens, A. (1984). The constitution of society: Outline of the theory of structuration. Univ of California Press.

Glover, T. D. (2015). Leisure research for social impact. Journal of Leisure Research, 47(1), 114.

Glover, T. D. (2007). Ugly on the diamonds: An examination of white privilege in youth baseball. Leisure Sciences, 29(2), 195-208.

Glusac, E. (2018, August 1). Hotels grapple with racial bias. Retrieved from https://www.nytimes.com/2018/08/01/travel/hotels-diversity-training.html

Godbey, G. (2000). The future of leisure studies. Journal of Leisure Research, 32(1), 37-41.

Gonzalez-Baz, E. (1992). A Mexican perspective on the North American Free Trade Agreement and the environment. Canada-United States Law Journal, 18(23), 235-240.

Goodale, T. L. (1993). Educating for social responsibility-Aspirations and obstacles. SCHOLE: A Journal of Leisure Studies and Recreation Education, 7(1), 81-91.

Grossman, A. H. (1993). Ten percent of those we teach and they serve: A case study of incorporating gay and lesbian studies into the curriculum. SCHOLE: A Journal of Leisure Studies and Recreation Education, 8(1), 51-60.

Hall, S. \& DuGay, P. (1996). Questions of cultural identity. London: Sage Publications.

Harrolle, M. G., Floyd, M. F., Casper, J. M., Kelley, K. E., \& Bruton, C. M. (2013). Physical activity constraints among Latinos: Identifying clusters and acculturation differences. Journal of Leisure Research, 45(1), 74-90. 
Henderson, K. A. (1993). A feminist analysis of selected professional recreation literature about girls/women from 1907-1990. Journal of Leisure Research, 25(2), 165-181.

Henderson, K. A. (1995). Leisure in a diverse society: Designing a course. SCHOLE: A Journal of Leisure Studies and Recreation Education, 10(1), 1-15.

Henderson, K. A. (2010). Leisure studies in the 21st century: The sky is falling?. Leisure Sciences, 32(4), 391-400.

Hernandez, D. (2016, March 2). White students keep using anti-Latino 'Trump' chants at high school basketball games. Retrieved from https://www.vice.com/en_us/article/ 7xa7az/white-students-keep-using-anti-latino-trump-chants-at-high-school-basketballgames

Hillary Clinton campaign speech [Video file]. (1996, January 25). Retrieved from https://www.c-span.org/video/?69606-1/hillary-clinton-campaign-speech

Hodge, C., Bocarro, J. N., Henderson, K. A., Zabriskie, R., Parcel, T. L., \& Kanters, M. A. (2015). Family leisure: An integrative review of research from select journals. Journal of Leisure Research, 47(5), 577-600.

Huang, W. J., Norman, W. C., Ramshaw, G. P., \& Haller, W. J. (2015). Transnational leisure experience of second-generation immigrants: The case of Chinese-Americans. Journal of Leisure Research, 47(1), 102-124.

Hultsman, J. (1995). Adding a diversity component to a recreation and tourism curriculum. SCHOLE: A Journal of Leisure Studies and Recreation Education, 10(1), 1728.

Hultsman, W. (1993). The influence of others as a barrier to recreation participation among early 
adolescents. Journal Of Leisure Research, 25(2), 150-164. doi:

$10.1080 / 00222216.1993 .11969915$

Hurly, J., \& Walker, G. J. (2019). Nature in our lives: Examining the human need for nature relatedness as a basic psychological need. Journal of Leisure Research, 50(4), 290-310.

Hutson, G., Montgomery, D., \& Caneday, L. (2010). Perceptions of outdoor recreation professionals toward place meanings in natural environments: A Q-method inquiry. Journal of Leisure Research, 42(3), 417-442.

Ito, E., Walker, G. J., \& Liang, H. (2014). A systematic review of non-Western and crosscultural/national leisure research. Journal of Leisure Research, 46(2), 226-239.

Iwasaki, Y., Messina, E., Shank, J., \& Coyle, C. (2015). Role of leisure in meaning-making for community-dwelling adults with mental illness: Inspiration for engaged life. Journal of Leisure Research, 47(5), 538-555.

Jackson, P. (1987). The idea of 'race' and the geography of racism. Race and Racism: Essays in Social Geography, 3-21.

Jacobson, S., \& Samdahl, D. M. (1998). Leisure in the lives of old lesbians: Experiences with and responses to discrimination. Journal of Leisure Research, 30(2), 233-255.

Jarrett, R. L., Bahar, O. S., McPherson, E., \& Williams, D. A. (2013). No child left inside: The built environment and caregiver strategies to promote child physical activity. Journal of Leisure Research, 45(4), 485-513.

Johnson, C. W. (2015). Twenty-plus years of exclusion in the Boy Scouts of America: A simulated debate on inclusion in public and private recreation agencies. SCHOLE: A Journal of Leisure Studies and Recreation Education, 30(2), 70-77.

Johnson, J. (2012). Mattering, marginality, and black feminism: Moving to empower Black 
women. The Vermont Connection, 33(10), 77-85.

Johnson, W. (2014). Brute ideology. Dissent, 61(4), 127-132.

Josselson, R. (1994). Identity and relatedness in the life cycle. In Identity and development: an interdisciplinary approach, Thousand Oaks: Sage, pp. 81-102.

Keith, T., \& Naylor, B. (2019, August 5). 'Hate has no place' in America, Trump says after El Paso And Dayton Shootings. Retrieved from http://www.npr.org/2019/08/05/748190808/trump-calls-for-strong-background-checksfollowing-el-paso-and-dayton-shootings.

Kelly, J. R., \& Kelly, J. R. (1994). Multiple dimensions of meaning in the domains of work, family, and leisure. Journal of Leisure Research, 26(3), 250-274.

Keneally, M. (2015, June 9). McKinney police officer Eric Casebolt resigns in wake of pool video. Retrieved from https://abcnews.go.com/US/mckinney-police-officer-eric-caseboltresigns-wake-pool/story?id=31649084

Kim, J., Dattilo, J., \& Heo, J. (2011). Taekwondo participation as serious leisure for life satisfaction and health. Journal of Leisure Research, 43(4), 545-559.

King, C. (2005). Cautionary notes on whiteness and sport studies. Sociology of Sport Journal, 22(3), 397-408.

Kivel, B.D. (2000). Leisure experience and identity: What difference does difference make?. Journal of Leisure Research, 32(1), 79-81.

Kivel, B. D. (2005). Examining racism, power, and White hegemony in Stodolska's conditioned attitude model of individual discriminatory behavior. Leisure Sciences, 27(1), 21-27. doi: 10.1080/01490400590885926

Kivel, B. D., \& Johnson, C. W. (2009). Consuming media, making men: Using collective 
memory work to understand leisure and the construction of masculinity. Journal of Leisure Research, 41(1), 110-134.

Kivel, B., Johnson, C., \& Scraton, S. (2009). (Re)theorizing leisure, experience and race. Journal Of Leisure Research, 41(4), 473-493. doi: $10.1080 / 00222216.2009 .11950186$

Koeske, Z. (2018, June 6). Obama as symbol of hope, possibility for blacks, key to racial legacy, scholars say. Retrieved from https://www.chicagotribune.com/news/ct-sta-king-obamalegacy-st-0116-20170113-story.html

Koller, V. (2011). Analysing lesbian identity in discourse. Discourse Approaches to Politics, Society and Culture (DAPSAC), 119.

Lange, J. K. (1994). Debate on diversity [Letter to the editor]. National Parks, 6-7.

Larson, L., Whiting, J. W., Green, G. T., \& Bowker, J. M. (2014). Physical activity levels and preferences of ethnically diverse visitors to Georgia state parks. Journal of Leisure Research, 46(5), 540-562.

Le, T., Le, Q., \& Short, M. (2009). Critical discourse analysis: An interdisciplinary perspective.

Lee, K. J., Scott, D., Floyd, M. F., \& Edwards, M. B. (2016). Social stratification in fishing participation in the United States: a multiple hierarchy stratification perspective. Journal of Leisure Research, 48(3), 245-263.

Leon, H. (2015, December 8). Visiting an anti-Muslim hate group at the peak of America's islamophobia. Retrieved from https://www.vice.com/en_us/article/gqm3g7/visiting-ananti-muslim-hate-group-at-the-peak-of-americas-of-islamaphobia-511

Lim, W. M. (2019). Spectator sports and its role in the social marketing of national unity: Insights from a multiracial country. Journal of Leisure Research, 50(3), 260-284. 
Lin, M., \& Graefe, A. R. (2019). Roller-skating into the big city: A case study of migrant workers' informal leisure activity in Guangzhou, China. Journal of Leisure Research, 50(3), 181-200.

Lindsay, D., \& Martin, T. (Directors). (2017). L.A. 92 [Video File]. Retrieved from http://www.netflix.com

Link, B. G., \& Phelan, J. C. (2001). Conceptualizing stigma. Annual review of Sociology, 27(1), 363-385.

Lundberg, N. R., Taniguchi, S., McCormick, B. P., \& Tibbs, C. (2011). Identity negotiating: Redefining stigmatized identities through adaptive sports and recreation participation among individuals with a disability. Journal of Leisure Research, 43(2), 205-225.

Lyman, S. M. (1990). Civilization: Contents, Discontents, and Malcontents and Other Essays (c). University of Arkansas Press.

Parsons, A. A., Besenyi, G. M., Kaczynski, A. T., Wilhelm Stanis, S. A., Blake, C. E., \& BarrAnderson, D. J. (2015). Investigating issues of environmental injustice in neighborhoods surrounding parks. Journal of Leisure Research, 47(2), 285-303.

Mainland, M., Shaw, S., \& Prier, A. (2015). Fearing fat: exploring the discursive links between childhood obesity, parenting, and leisure. Journal of Leisure Research, 47(2), 202-219.

Marshall, S. K. (2001). Do I matter? Construct validation of adolescents perceived mattering to parents and friends. Journal of Adolescence, 24(4), 473-490. doi:10.1006/jado.2001.0384

Martinez, M. (2016, January 28). Flint, Michigan: Neglected because city is black, poor? Retrieved from https://www.cnn.com/2016/01/26/us/flint-michigan-water-crisis-racepoverty/index.html

McCollum, C. (2018, March 4). Andrean focuses on diversity for its February Formation Day. 
Retrieved from https://www.nwitimes.com/news/education/andrean-focuses-on-diversityfor-its-february-formation-day/article_65e2fe83-6ccc-5c99-9111-ef42fb63dd22.html

McDonald, D., \& McAvoy, L. (1997). Native Americans and leisure: State of the research and future directions. Journal of Leisure Research, 29(2), 145-166.

McDonald, M. G. (2009). Dialogues on whiteness, leisure and (anti) racism. Journal of Leisure Research, 41(1), 5-21.

McKeown, J. K. (2015). “I will not be wearing heels tonight!” A feminist exploration of singlehood, dating, and leisure. Journal of Leisure Research, 47(4), 485-500.

McMeeking, D., \& Purkayastha, B. (1995). "I can't have my mom running me everywhere": Adolescents, leisure, and accessibility. Journal of Leisure Research, 27(4), 360-378.

Mirehie, M., \& Gibson, H. J. (2019). Women's participation in snow-sports and sense of wellbeing: a positive psychology approach. Journal of Leisure Research, 1-19.

Moore, A., \& Henderson, K. (2018). "Like precious gold": Recreation in the lives of low-income committed couples. Journal of Leisure Research, 49(1), 46-69.

Moore, K. (2018, September 25). Woman files race discrimination complaint against LA Fitness. Retrieved from https://www.wwltv.com/article/news/local/woman-files-racediscrimination-complaint-against-la-fitness/289-598061171

Morning, A. (2013). The 21st century is not the 19th- Karen E. Fields and Barbara J. Fields, racecraft. The soul of inequality in American life (London \& New York: Verso Books, 2012). European Journal of Sociology/Archives Européennes de Sociologie, 54(3), 525530.

Motamedi, M., Caldwell, L. L., Weybright, E. H., Jones, D., Wegner, L., \& Smith, E. A. (2020). 
Doing a leisure activity because there is nothing else to do: Related outcomes and intervention effects for adolescents. Journal of Leisure Research, 51(1), 1-15.

Mowatt, R. (2009). Notes from a leisure son: Expanding an understanding of whiteness in leisure. Journal of Leisure Research, 41(4), 511-528.

Mowatt, R. (2018). A people's history of leisure studies: Leisure, the tool of racecraft. Leisure Sciences, 40(7), 663-674. doi: 10.1080/01490400.2018.1534622

Mowatt, R. (2018). The case of the 12-year-old boy: Or, the silence of and relevance to leisure research. Leisure Sciences, 40(1-2), 54-70.

Mowatt, R., Johnson, C. W., Roberts, N. S., \& Kivel, B. D. (2016). "Embarrassingly White" Faculty racial disparities in American recreation, park, and tourism programs. SCHOLE: A Journal of Leisure Studies and Recreation Education, 31(1), 37-55.

Mowatt, R., \& Schmalz, D. (2014). The conspicuous nature of power. Journal of Leisure Research, 46(3), 353-358. doi: 10.1080/00222216.2014.11950331

Moyer, J. W. (2015, March 9). University of Oklahoma fraternity closed after racist chant. Retrieved from https://www.washingtonpost.com/news/morningmix/wp/2015/03/09/university-of-oklahoma-fraternity-suspended-after-racist-chant/

Mukhopadhyay, C. C. (2016). Getting rid of the word "caucasian". Privilege: A Reader, 21. NBC New York. (2016, August 9). Tale of 2 parks: Differing crime rates at parks. Retrieved from https://www.nbcnewyork.com/news/local/4-investigates_-why-some-city-parks-areseeing-more-crime_new-york/1194421/

NBC News. (2013, November 25). 'Knockout game': Teenagers attack unsuspecting strangers for fun. Retrieved from http://investigations.nbcnews.com/_news/2013/11/25/21599448knockout-game-teenagers-attack-unsuspecting-strangers-for-fun 
NBC Southern California. (2002). 2002 Reginald Denny interview: Revenge and the LA 4.

Retrieved from https://www.nbclosangeles.com/on-

air/reginald_denny_on_revenge_and_the_la_4_los_angeles/2037298/

NBC Southern California. (1992, April 29). April 29, 1992: LAPD preparations at parker center. Retrieved from https://www.nbclosangeles.com/onair/april_29_1992_lapd_preparations_at_parker_center_los_angeles/1951487/

NBC Southern California. (2012, May 10). LA Riots rooted deeper than verdicts. Retrieved from https://www.nbclosangeles.com/local/la_riots_rooted_deeper_than_verdicts_los_ angeles/2037300/

Northeast Times. (2012, August 23). \$1.4 million settlement in Valley Club swim case.

Retrieved from https://northeasttimes.com/2012/08/22/1-4-million-settlement-in-valleyclub-swim-case/

Oppmann, P. (2017, August 23). Cuba's Elian Gonzalez is all grown up. Retrieved from https://www.cnn.com/2017/08/15/world/cuba-elian-gonzalez-update/index.html

Oprysko, C. (2019, July 12). Trump claims upcoming ICE raids will focus on criminals. Retrieved from https://www.politico.com/story/2019/07/12/trump-ice-raids-criminals1413295

Payne, L. L., \& Janke, M. C. (2019). Introduction to the special issue: Contemporary trends and issues. Journal of Leisure Research, 50(4), 285-289.

Payne, L. L., Schmalz, D. L., \& Janke, M. C. (2018). The reemergence and revitalized focus of JLR. Journal of Leisure Research, 49(1), 1-7.

Pete Wilson 1994 campaign ad on illegal immigration [Video file]. (1994), Retrieved from https://www.youtube.com/watch?v=lLIzzs2HHgY\&feature=youtu.be 
Philipp, S. (2000). Race and the pursuit of happiness. Journal of Leisure Research, 32(1), 121124.

Pohl, S. L., Borrie, W. T., \& Patterson, M. E. (2000). Women, wilderness, and everyday life: A documentation of the connection between wilderness recreation and women's everyday lives. Journal of Leisure Research, 32(4), 415-434.

Powers, S. L., Lee, K. J., Pitas, N. A., Graefe, A. R., \& Mowen, A. J. (2019). Understanding access and use of municipal parks and recreation through an intersectionality perspective. Journal of Leisure Research, 1-20.

Proposition 187: Text of Proposed Law. (1994). Retrieved from https://www.kpbs.org/documents/2014/oct/24/proposition-187-text-proposed-law/

Pryor, B. N. K., \& Outley, C. W. (2014). Just spaces: Urban recreation centers as sites for social justice youth development. Journal of Leisure Research, 46(3), 272-290.

Rappaport, N. (2019, December 29). Removal of DACA recipients has begun: It didn't take a crystal ball to see DACA would not end well. Retrieved from https://thehill.com/opinion/immigration/476151-removal-of-daca-recipients-has-begun-itdidnt-take-a-crystal-ball-to-see

Rayle, A. D. (2005). Adolescent gender differences in mattering and wellness. Journal of Adolescence,28(6), 753-763. doi:10.1016/j.adolescence.2004.10.009

Reams, B. D., Schultz, J. S., \& United States. (1994). The North American Free Trade Agreement (NAFTA): Documents and materials including a legislative history of the North American Free Trade Agreement Implementation Act, Public Law 103-182. Buffalo, N.Y: W.S. Hein.

Reisigl, M., \& Wodak, R. (2017). The discourse-historical approach (DHA). In R. Wodak, \& 
M. Meyers, Methods for Critical Discourse Analysis (pp. 87-121). London: Sage (2nd revised edition).

Riley, B., Skalko, T., McChesney, J., \& Glascoff, M. (1998). Learn and serve: integrating elements of social learning theory and cross cultural exposure in professional preparation. SCHOLE: A Journal of Leisure Studies and Recreation Education, 13(1), $55-68$.

Riggins, R. D. (1993). Liberal education and professional studies at the undergraduate level: Still circling Moose Jaw. SCHOLE: A Journal of Leisure Studies and Recreation Education, 7(1), 5-16.

Robertson, B. J. (1999). Leisure and family: Perspectives of male adolescents who engage in delinquent activity as leisure. Journal of Leisure Research, 31(4), 335-358.

Robertson, B. J. (2009). Reflective self study: A tool for understanding leisure behavior. SCHOLE: A Journal of Leisure Studies and Recreation Education, 24(1), 155161.

Rojek, C. (2001). Leisure and life politics. Leisure Sciences, 23(2), 115-125.

Romano, A. (2010, March 18). Bush on Obama: 'A Triumph of the American story'. Retrieved from https://www.newsweek.com/bush-obama-triumph-american-story-217848

Romo, V. (2019, October 10). El Paso Walmart shooting suspect pleads not guilty. Retrieved from https://www.npr.org/2019/10/10/769013051/el-paso-walmart-shooting-suspectpleads-not-guilty

Rose, J., Harmon, J., \& Dunlap, R. (2018). Becoming political: An expanding role for critical leisure studies. Leisure Sciences, 40(7), 649-662.

Salkind, N. J. (2010). Demographics. In Encyclopedia of Research Design. Thousand Oaks, CA: 
SAGE Publications, Inc.

Sasidharan, V. (2002). Special issue introduction: Understanding recreation and the environment within the context of culture. Leisure Sciences, 24(1), 1-11.

Schlossberg, N. (1989). Marginality and mattering: Key issues in building community. New Directions for Student Services, 48, 5-15.

Schmalz, D., \& Mowatt, R. (2014). The unsettling nature of prejudice. Journal of Leisure Research, 46(3), 245-251. doi: 10.1080/00222216.2014.11950324

Schrag, P. (2010, September). Unwanted: Immigration and nativism in America. Retrieved from https://www.americanimmigrationcouncil.org/sites/default/files/research/Immigration_an d_Natvism_091310.pdf

Schroeder, L. (2019, March 28). San Diego Unified reaches settlement in anti-Islamophobia initiative lawsuit. Retrieved from https://www.sandiegouniontribune.com/news/ education/story/2019-03-27/sd-me-sdunified-islamophobia

Scott, D. (2000). Tic, toe, the game is locked and nobody else can play!. Journal of Leisure Research, 32(1), 133-137.

Scott, E. (2018, November 30). Analysis | Obama's evolution from downplaying identity politics to acknowledging the prevalence of tribalism. Retrieved from https://www.washingtonpost.com/politics/2018/11/30/obamas-evolution-downplayingidentity-politics-acknowledging-prevalence-tribalism/

Shannon, C. S. (2016). Exploring factors influencing girls' continued participation in competitive dance. Journal of Leisure Research, 48(4), 284-306.

Sharaievska, I., Kono, S., \& Mirehie, M. S. (2019). Are we speaking the same language? The 
experiences of international students and scholars in North American higher education. SCHOLE: A Journal of Leisure Studies and Recreation Education, 34(2), 120131.

Shinew, K. J., Stodolska, M., Floyd, M., Hibbler, D., Allison, M., Johnson, C., \& Santos, C. (2006). Race and ethnicity in leisure behavior: Where have we been and where do we need to go? Leisure Sciences, 28(4), 403-408. doi: 10.1080/01490400600745902

Shores, K. A. (2010). The Politics of Park Design. Galen Cranz. Journal of Leisure Research, 42(1), 177-180. doi: 10.1080/00222216.2010.11950200

Simpkins, S. D., Vest, A. E., Delgado, M. Y., \& Price, C. D. (2012). Do school friends participate in similar extracurricular activities?: Examining the moderating role of race/ethnicity and age. Journal of Leisure Research, 44(3), 332-352.

Sing, C. S. (2011). The ideological construction of European identities: A critical discourse analysis of the linguistic representation of the old vs. new Europe debate. In Critical discourse studies in context and cognition (pp. 143-170). John Benjamins.

Smith, A. B., Johnson, C. W., Powell, G. M., \& Oliver, J. P. (2011). The relationship between multicultural service-learning and self-reported multicultural competencies in undergraduate students: A qualitative participatory action study. SCHOLE: A Journal of Leisure Studies and Recreation Education, 26(2), 1-13.

Smith, C., Santucci, D., Xu, S., Cox, A., \& Henderson, K. A. (2012). “I love my job, but....” A narrative analysis of women's perceptions of their careers in parks and recreation. Journal of Leisure Research, 44(1), 52-69.

Smith, M., Bosman, J., \& Davey, M. (2019, April 25). Flint's water crisis started 5 years ago. 
It's not over. Retrieved from https://www.nytimes.com/2019/04/25/us/flint-watercrisis.html

Snelgrove, R. (2015). Youth with chronic illness forming identities through leisure. Journal of Leisure Research, 47(1), 154-173.

Soylu Yalcinkaya, N., Estrada-Villalta, S., \& Adams, G. (2017). The (biological or cultural) essence of essentialism: Implications for policy support among dominant and subordinated groups. Frontiers in psychology, 8, 900.

Stebleton, M. J., Soria, K. M., \& Huesman Jr, R. L. (2014). First-generation students' sense of belonging, mental health, and use of counseling services at public research universities. Journal of College Counseling, 17(1), 6-20.

Steck, L.W., Heckert, D. M. \& Heckert, D. A. (2003). The salience of racial identity among African American and White students. Race and Society, 6, 57-73.

Stephenson, H. (2018, January 31). TUSD board majority sidesteps effort to resurrect aspects of Mexican American studies. Retrieved from https://tucson.com/news/local/tusd-boardmajority-sidesteps-effort-to-resurrect-aspects-of-mexican/article_620f0e1b-6b09-57c3ae4c-342130d3b612.html

Stewart, W. P., Parry, D. C., \& Glover, T. D. (2008). Writing leisure: Values and ideologies of research. Journal of Leisure Research, 40(3), 360-384.

Study shows how children view race bias [Video file]. (2010, May 18). Retrieved from https://www.youtube.com/watch?v=EQACkg5i4AY

Stodolska, M. (1998). Assimilation and leisure constraints: Dynamics of constraints on leisure in immigrant populations. Journal of Leisure Research, 30(4), 521-551.

Stodolska, M. (2000). Looking beyond the invisible: Can research on leisure of ethnic and racial 
minorities contribute to leisure theory?. Journal of Leisure Research, 32(1), 156-160.

Stodolska, M., Sharaievska, I., Tainsky, S., \& Ryan, A. (2014). Minority youth participation in an organized sport program: Needs, motivations, and facilitators. Journal of Leisure Research, 46(5), 612-634.

Tavernise, S. (2018, November 22). Why the announcement of a looming White minority makes demographers nervous. Retrieved from https://www.nytimes.com/2018/11/22/us/white-americans-minority-population.html

Taylor, D. E. (1999). Central Park as a model for social control: urban parks, social class and leisure behavior in nineteenth-century America. Journal of Leisure Research, 31(4), 420477.

Theriault, D. (2014). Organized leisure experiences of LBGTQ youth: Resistance and oppression. Journal of Leisure Research, 46(4), 448-461.

Theriault, D. (2019). Power threats and radical healing in Black youths' leisure. Journal of Leisure Research, 50(5), 413-424.

Tirone, S., \& Goodberry, A. (2011). Leisure, biculturalism, and second-generation Canadians. Journal of Leisure Research, 43(3), 427-444.

Trussell, D. E. (2014). Dancing in the margins: Reflections on social justice and researcher identities. Journal of Leisure Research, 46(3), 342-352.

Tucker, C., Dixon, A., \& Griddine, K. (2010). Academically successful African American male urban high school students' experiences of mattering to others at school. Professional School Counseling, 14(2), 135-145.

Tuggle, F. J., Kerpelman, J., \& Pittman, J. (2016). Young adolescents' shared leisure activities 
with close friends and dating partners: Associations with supportive communication and relationship satisfaction. Journal of Leisure Research, 48(5), 374-394.

Van Dijk, T. A. (1992). Denying racism: Elite discourse and racism. Discourse and Society, 3(1), 87-118.

Van Dijk, T. A. (2011). Discourse, knowledge, power and politics. Discourse Approaches to Politics, Society and Culture (DAPSAC), 27.

VanSickle, J., \& Schaumleffel, N. A. (2016). Developing recreation, leisure, and sport professional competencies through practitioner/academic service engagement partnerships. SCHOLE: A Journal of Leisure Studies and Recreation Education, 31(2), $37-55$.

Vazquez, M. (2019, August 9). Trump defends ICE raid strategy. Retrieved from https://www.cnn.com/2019/08/09/politics/trump-defends-ice-raid-strategy/index.html

Video of Rodney King beaten by police released [Video file]. (1991, March 7). Retrieved from https://abcnews.go.com/Archives/video/march-1991-rodney-king-videotape-9758031

Walker, G. J., \& Fenton, L. (2011). Institutional concentration of leisure research: A follow-up to and extension of Jackson (2004). Journal of Leisure Research, 43(4), 475-490.

Wankel, L. M., \& Berger, B. G. (1990). The psychological and social benefits of sport and physical activity. Journal of leisure research, 22(2), 167-182.

Watson, J. C. (2017). Examining the relationship between self-esteem, mattering, school connectedness, and wellness among middle school students. Professional School Counseling, 21(1). doi: 10.5330/1096-2409-21.1.108

Weiler, B., Martin, V. Y., Canosa, A., \& Cutter-Mackenzie, A. (2018). Generation Y and 
protected areas: A scoping study of research, theory, and future directions. Journal of Leisure Research, 49(3-5), 277-297.

West, P. (1989). Urban regional parks and Black minorities: Subculture, marginality, and interracial relations in park use in the Detroit metropolitan area. Leisure Sciences, 11, 1128.

Wheeler, W. (2020, January 10). How the US helped create El Salvador's bloody gang war. Retrieved from https://www.theguardian.com/news/2020/jan/10/how-the-us-helpedcreate-el-salvadors-bloody-gang-war

Wiegman, R. (1995). American anatomies: Theorizing race and gender. Durham: Duke University.

Wiener-Bronner, D. (2013, November 26). How the 'knockout' game let media outlets flex their muscles. Retrieved from https://www.theatlantic.com/national/archive/2013/11/ knockout-games-media-coverage/355544/

Winfrey, O. (1992). The LA riots. The Oprah Winfrey show. London: Channel 4.

Winfrey, O. (1992). The anti-racism experiment. Retrieved from https://www.youtube.com/watch?time_continue=228\&v=0YOTxammRTw

Winfrey, O. (2016, October 16). The conversation we should have about race $\mid$ SuperSoul ... Retrieved from https://www.youtube.com/watch?v=AO36zrR3wa0

Winter, P. L., Palucki, L. J., \& Burkhardt, R. L. (1999). Anticipated responses to a fee program: The key is trust. Journal of Leisure Research, 31(3), 207-226.

Witmer, L., Bocarro, J. N., \& Henderson, K. (2011). Adolescent girls' perception of health within a leisure context. Journal of Leisure Research, 43(3), 334-354.

Wodak, R. (2001). The discourse-historical approach. Methods of Critical Discourse Analysis, 1, 
63-94.

Wodak, R. (2009). The semiotics of racism: A critical discourse-historical analysis. Discourse, of Course: An Overview of Research in Discourse Studies, 311-326.

Wodak, R., \& Reisigl, M. (2003). 19 Discourse and Racism. The Handbook of Discourse Analysis, 18, 372.

Wolf, S. (2017, October 5). Distorting the MS-13 threat. Retrieved from https://nacla.org/news/2017/10/06/distorting-ms-13-threat

Wright, E. R., Gronfein, W., \& Owens, T. J. (2000). Deinstitutionalization, social rejection, and the self-esteem of former mental patients. Journal of Health and Social Behavior, 41, 68-90.

Wu, H. C. J., \& Van Egeren, L. A. (2010). Voluntary participation and parents' reasons for enrollment in after-school programs: Contributions of race/ethnicity, program quality, and program policies. Journal of Leisure Research, 42(4), 591-620.

Yudell, M. (2014). Race unmasked: Biology and race in the twentieth century. Columbia University Press. 


\section{APPENDIX A}

Table 1

Thematic Descriptions

$\begin{array}{lll}\text { Themes } & \text { Description } & \text { Sub-Themes }\end{array}$

Faint mentions of race

Racialization in the negative

Improper terminology use

Intentionality of race
Race was neither a central component of the text nor were attempts made by the author(s) to elaborate extensively on how race functioned within the scope of their study.

Racialized ethnicities were regarded in a negative manner and/or were given descriptors with little to no justification for their utilization.

Race was conceptualized as being correspondent with ethnicity and/or culture and/or as a byproduct of race purity.

Race was used a category to highlight intrinsic differentiation between racialized ethnic groups
Periphery mentions

Demographic variable with no assessment

Stigma comparison

"Minority"

Condition of othering

Engagement in dangerous activities

Condition of deprivation and persecution

Race, ethnicity, and culture used interchangeably

\section{Mixed race}

Inconsistent descriptive terminology

Race as a denotation of differential experiences or preferences

Racialized sample as exemplary of 
and/or to make broad statements about diverse groups based upon racialized ascriptions.

Evaluations of the problem or solution contained incomplete or erroneous framing of inequity and/or prejudicial conditions. racialized group

Race as identity

Frame problem/solution as individual rather than systemic

Frame problem as being contemporary

Frame solution as being leisure specific

Table 2

Sub-Themes $n$ Article Title


19 Henderson, K. A. (1993). A feminist analysis of selected professional recreation literature about girls/women from 1907-1990. Journal of Leisure Research, 25(2), 165-181.

Taylor, D. E. (1999). Central Park as a model for social control: urban parks, social class and leisure behavior in nineteenth-century America. Journal of Leisure Research, 31(4), 420-477.

Riggins, R. D. (1993). Liberal education and professional studies at the undergraduate level: Still circling Moose Jaw. SCHOLE: A Journal of Leisure Studies and Recreation Education, 7(1), 5-16.

Goodale, T. L. (1993). Educating for social responsibility-Aspirations and obstacles. Schole: A Journal of Leisure Studies and Recreation Education, 7(1), 81-91.

Smith, C., Santucci, D., Xu, S., Cox, A., \& Henderson, K. A. (2012). “I love my job, but...:” A narrative analysis of women's perceptions of their careers in parks and recreation. Journal of Leisure Research, 44(1), 52-69.

Lin, M., \& Graefe, A. R. (2019). Roller-skating into the big city: A case study of migrant workers' informal leisure activity in Guangzhou, China. Journal of Leisure Research, 50(3), 181-200.

Bailey, A. W., \& Fernando, I. K. (2012). Routine and project-based leisure, happiness, and meaning in life. Journal of Leisure Research, 44(2), 139-154.

Payne, L. L., \& Janke, M. C. (2019). Introduction to the special issue: Contemporary trends and issues. Journal of Leisure Research, 50(4), 285-289.

Shores, K. A. (2010). The politics of park design. Galen Cranz. Journal of Leisure Research, 42(1), 177-180. doi: 10.1080/00222216.2010.11950200

McKeown, J. K. (2015). “I will not be wearing heels tonight!” A feminist exploration of singlehood, dating, and leisure. Journal of Leisure Research, 47(4), 485-500. 
Demographic variable with no
Ito, E., Walker, G. J., \& Liang, H. (2014). A systematic review of non-Western and crosscultural/national leisure research. Journal of Leisure Research, 46(2), 226-239.

Walker, G. J., \& Fenton, L. (2011). Institutional concentration of leisure research: A follow-up to and extension of Jackson (2004). Journal of Leisure Research, 43(4), 475-490.

Huang, W. J., Norman, W. C., Ramshaw, G. P., \& Haller, W. J. (2015). Transnational leisure experience of second-generation immigrants: The case of Chinese-Americans. Journal of Leisure Research, 47(1), 102-124.

Mainland, M., Shaw, S., \& Prier, A. (2015). Fearing fat: exploring the discursive links between childhood obesity, parenting, and leisure. Journal of Leisure Research, 47(2), 202-219.

Johnson, C. W. (2015). Twenty-plus years of exclusion in the Boy Scouts of America: A simulated debate on inclusion in public and private recreation agencies. SCHOLE: A Journal of Leisure Studies and Recreation Education, 30(2), 70-77.

Sharaievska, I., Kono, S., \& Mirehie, M. S. (2019). Are we Speaking the same language? The experiences of international students and scholars in North American higher education. SCHOLE: A Journal of Leisure Studies and Recreation Education, 34(2), 120-131.

Theriault, D. (2014). Organized leisure experiences of LBGTQ youth: Resistance and oppression. Journal of Leisure Research, 46(4), 448-461.

Robertson, B. J. (2009). Reflective self study: A tool for understanding leisure behavior. SCHOLE: A Journal of Leisure Studies and Recreation Education, 24(1), 155-161.

Harrolle, M. G., Floyd, M. F., Casper, J. M., Kelley, K. E., \& Bruton, C. M. (2013). Physical activity constraints among Latinos: Identifying clusters and acculturation differences. Journal of Leisure Research, 45(1), 74-90.

Pohl, S. L., Borrie, W. T., \& Patterson, M. E. (2000). Women, wilderness, and everyday life: A documentation of the connection between wilderness recreation and women's everyday 
Caldwell, L. L., \& Darling, N. (1999). Leisure context, parental control, and resistance to peer pressure as predictors of adolescent partying and substance use: An ecological perspective. Journal of Leisure Research, 31(1), 57-77.

Robertson, B. J. (1999). Leisure and family: Perspectives of male adolescents who engage in delinquent activity as leisure. Journal of Leisure Research, 31(4), 335-358.

Jacobson, S., \& Samdahl, D. M. (1998). Leisure in the lives of old lesbians: Experiences with and responses to discrimination. Journal of Leisure Research, 30(2), 233-255.

Moore, A. C., \& Henderson, K. A. (2018). "Like precious gold": Recreation in the lives of lowincome committed couples. Journal of Leisure Research, 49(1), 46-69.

Hutson, G., Montgomery, D., \& Caneday, L. (2010). Perceptions of outdoor recreation professionals toward place meanings in natural environments: A Q-method inquiry. Journal of Leisure Research, 42(3), 417-442.

Lundberg, N. R., Taniguchi, S., McCormick, B. P., \& Tibbs, C. (2011). Identity negotiating: Redefining stigmatized identities through adaptive sports and recreation participation among individuals with a disability. Journal of Leisure Research, 43(2), 205-225.

Kivel, B. D., \& Johnson, C. W. (2009). Consuming media, making men: Using collective memory work to understand leisure and the construction of masculinity. Journal of Leisure Research, 41(1), 110-134.

Kim, J., Dattilo, J., \& Heo, J. (2011). Taekwondo participation as serious leisure for life satisfaction and health. Journal of Leisure Research, 43(4), 545-559.

Tuggle, F. J., Kerpelman, J., \& Pittman, J. (2016). Young adolescents' shared leisure activities with 
close friends and dating partners: Associations with supportive communication and relationship satisfaction. Journal of Leisure Research, 48(5), 374-394.

Bailey, A. W., Kang, H. K., \& Schmidt, C. (2016). Leisure routine and positive attitudes: agegraded comparisons of the path to happiness. Journal of leisure research, 48(3), 189-209.

Chun, S., \& Lee, Y. (2010). The role of leisure in the experience of posttraumatic growth for people with spinal cord injury. Journal of Leisure Research, 42(3), 393-415.

Witmer, L., Bocarro, J. N., \& Henderson, K. (2011). Adolescent girls' perception of health within a leisure context. Journal of Leisure Research, 43(3), 334-354.

Allaby, M., \& Shannon, C. S. (2019). “I just want to keep in touch": Adolescents' experiences with leisure-related smartphone use. Journal of Leisure Research, 1-19.

Blanco, J., \& Robinett, J. (2014). Leisure helps get the job done: Intersections of hegemonic masculinity and stress among college-aged males. Journal of Leisure Research, 46(4), 361-374.

Iwasaki, Y., Messina, E., Shank, J., \& Coyle, C. (2015). Role of leisure in meaning-making for community-dwelling adults with mental illness: Inspiration for engaged life. Journal of Leisure Research, 47(5), 538-555.

Caldwell, L. L., Patrick, M. E., Smith, E. A., Palen, L. A., \& Wegner, L. (2010). Influencing adolescent leisure motivation: intervention effects of health wise South Africa. Journal of Leisure Research, 42(2), 203-220.

Shannon, C. S. (2016). Exploring factors influencing girls' continued participation in competitive dance. Journal of Leisure Research, 48(4), 284-306.

Bailey, A. W., Kang, H. K., \& Schmidt, C. (2016). Leisure routine and positive attitudes: agegraded comparisons of the path to happiness. Journal of Leisure Research, 48(3), 189-209.

Mirehie, M., \& Gibson, H. J. (2019). Women's participation in snow-sports and sense of well- 
Only mention in comparison to stigma being: a positive psychology approach. Journal of Leisure Research, 1-19.

Allaby, M., \& Shannon, C. S. (2019). "I just want to keep in touch”: Adolescents' experiences with leisure-related smartphone use. Journal of Leisure Research, 1-19.

4 Jacobson, S., \& Samdahl, D. M. (1998). Leisure in the lives of old lesbians: Experiences with and responses to discrimination. Journal of Leisure Research, 30(2), 233-255.

Grossman, A. H. (1993). Ten percent of those we teach and they serve: A case study of incorporating gay and lesbian studies into the curriculum. Schole: A Journal of Leisure Studies and Recreation Education, 8(1), 51-60.

Snelgrove, R. (2015). Youth with chronic illness forming identities through leisure. Journal of Leisure Research, 47(1), 154-173.

Tirone, S., \& Goodberry, A. (2011). Leisure, biculturalism, and second-generation Canadians. Journal of Leisure Research, 43(3), 427-444.

Table 3

Articles on Race Classified as a Racialization in the Negative

$\begin{array}{lll}\text { Sub-Themes } & \text { Article Title }\end{array}$


"Minority"

Allison, M. T. (1999). Organizational barriers to diversity in the workplace. Journal of Leisure Research, 31(1), 78-101.

Godbey, G. (2000). The future of leisure studies. Journal of Leisure Research, 32(1), 37-41.

Stodolska, M. (1998). Assimilation and leisure constraints: Dynamics of constraints on leisure in immigrant populations. Journal of Leisure Research, 30(4), 521-551.

Scott, D. (2000). Tic, toe, the game is locked and nobody else can play!. Journal of Leisure Research, 32(1), 133-137.

Hultsman, J. (1995). Adding a diversity component to a recreation and tourism curriculum. SCHOLE: A Journal of Leisure Studies and Recreation Education, 10(1), 17-28.

Grossman, A. H. (1993). Ten percent of those we teach and they serve: A case study of incorporating gay and lesbian studies into the curriculum. Schole: A Journal of Leisure Studies and Recreation Education, 8(1), 51-60.

Wu, H. C. J., \& Van Egeren, L. A. (2010). Voluntary participation and parents' reasons for enrollment in after-school programs: Contributions of race/ethnicity, program quality, and program policies. Journal of Leisure Research, 42(4), 591-620.

Stodolska, M., Sharaievska, I., Tainsky, S., \& Ryan, A. (2014). Minority youth participation in an organized sport program: Needs, motivations, and facilitators. Journal of Leisure Research, 46(5), 612-634.

Edwards, M. B., \& Matarrita-Cascante, D. (2011). Rurality in leisure research: A review of four major journals. Journal of Leisure Research, 43(4), 447-474.

Simpkins, S. D., Vest, A. E., Delgado, M. Y., \& Price, C. D. (2012). Do school friends participate in similar extracurricular activities?: Examining the moderating role of race/ethnicity and 
age. Journal of Leisure Research, 44(3), 332-352.

Parsons, A. A., Besenyi, G. M., Kaczynski, A. T., Wilhelm Stanis, S. A., Blake, C. E., \& BarrAnderson, D. J. (2015). Investigating issues of environmental injustice in neighborhoods surrounding parks. Journal of Leisure Research, 47(2), 285-303.

Hodge, C., Bocarro, J. N., Henderson, K. A., Zabriskie, R., Parcel, T. L., \& Kanters, M. A. (2015). Family leisure: An integrative review of research from select journals. Journal of Leisure Research, 47(5), 577-600.

Jarrett, R. L., Bahar, O. S., McPherson, E., \& Williams, D. A. (2013). No child left inside: The built environment and caregiver strategies to promote child physical activity. Journal of Leisure Research, 45(4), 485-513.

Clark, B. S., \& Anderson, D. M. (2014). Not yet a woman, not yet a mom: The leisure experiences of pregnant adolescents. Journal of Leisure Research, 46(5), 509-524.

García, R. (2013). Social justice and leisure: The usefulness and uselessness of research. Journal of Leisure Research, 45(1), 7-22.

Shores, K. A. (2010). The Politics of Park Design. Galen Cranz. Journal of Leisure Research, 42(1), 177-180. doi: 10.1080/00222216.2010.11950200

Ito, E., Walker, G. J., \& Liang, H. (2014). A systematic review of non-Western and crosscultural/national leisure research. Journal of Leisure Research, 46(2), 226-239.

Powers, S. L., Lee, K. J., Pitas, N. A., Graefe, A. R., \& Mowen, A. J. (2019). Understanding access and use of municipal parks and recreation through an intersectionality perspective. Journal of Leisure Research, 1-20.

Smith, A. B., Johnson, C. W., Powell, G. M., \& Oliver, J. P. (2011). The relationship between multicultural service-learning and self-reported multicultural competencies in undergraduate students: A qualitative participatory action study. Schole: A Journal of Leisure Studies and 
Recreation Education, 26(2), 1-13.

Fernandez, M., \& Witt, P. A. (2013). Attracting Hispanics to an African American recreation center: Examining attitudes and historical factors. Journal of Leisure Research, 45(4), 423-444.

Larson, L., Whiting, J. W., Green, G. T., \& Bowker, J. M. (2014). Physical activity levels and preferences of ethnically diverse visitors to Georgia state parks. Journal of Leisure Research, 46(5), 540-562.

Lee, K. J., Scott, D., Floyd, M. F., \& Edwards, M. B. (2016). Social stratification in fishing participation in the United States: a multiple hierarchy stratification perspective. Journal of Leisure Research, 48(3), 245-263.

Clark, B. S., \& Anderson, D. M. (2014). Not yet a woman, not yet a mom: The leisure experiences of pregnant adolescents. Journal of Leisure Research, 46(5), 509-524.

Bailey, A. W., Kang, H. K., \& Schmidt, C. (2016). Leisure routine and positive attitudes: agegraded comparisons of the path to happiness. Journal of Leisure Research, 48(3), 189-209.

Tirone, S., \& Goodberry, A. (2011). Leisure, biculturalism, and second-generation Canadians. Journal of Leisure Research, 43(3), 427-444.

McDonald, D., \& McAvoy, L. (1997). Native Americans and leisure: State of the research and future directions. Journal of Leisure Research, 29(2), 145-166.

Harrolle, M. G., Floyd, M. F., Casper, J. M., Kelley, K. E., \& Bruton, C. M. (2013). Physical activity constraints among Latinos: Identifying clusters and acculturation differences. Journal of Leisure Research, 45(1), 74-90.

Positive sub-thematic exhibition
1 Mowatt, R. A., Johnson, C. W., Roberts, N. S., \& Kivel, B. D. (2016). "Embarrassingly White" Faculty racial disparities in American recreation, park, and tourism programs. SCHOLE: A Journal of Leisure Studies and Recreation Education, 31(1), 37-55. 
Condition of othering

Positive sub-thematic exhibition

Engagement in dangerous activities

Positive sub-thematic exhibition
Allison, M. T. (1999). Organizational barriers to diversity in the workplace. Journal of Leisure Research, 31(1), 78-101.

Freysinger, V. J., Fox, K. M., Henderson, K. A., \& Bedini, L. (1994). Book and Resource Review: Addressing Multiculturalism in Recreation and Leisure Education. SCHOLE: A Journal of Leisure Studies and Recreation Education, 9(1), 79-89.

Hodge, C., Bocarro, J. N., Henderson, K. A., Zabriskie, R., Parcel, T. L., \& Kanters, M. A. (2015). Family leisure: An integrative review of research from select journals. Journal of Leisure Research, 47(5), 577-600.

2 McDonald, M. G. (2009). Dialogues on whiteness, leisure and (anti) racism. Journal of Leisure Research, 41(1), 5-21.

Mowatt, R. A., Johnson, C. W., Roberts, N. S., \& Kivel, B. D. (2016). "Embarrassingly White" Faculty racial disparities in American recreation, park, and tourism programs. SCHOLE: A Journal of Leisure Studies and Recreation Education, 31(1), 37-55.

2 Wu, H. C. J., \& Van Egeren, L. A. (2010). Voluntary participation and parents' reasons for enrollment in after-school programs: Contributions of race/ethnicity, program quality, and program policies. Journal of Leisure Research, 42(4), 591-620.

Stodolska, M., Sharaievska, I., Tainsky, S., \& Ryan, A. (2014). Minority youth participation in an organized sport program: Needs, motivations, and facilitators. Journal of Leisure Research, 46(5), 612-634.

Mowatt, R. A., Johnson, C. W., Roberts, N. S., \& Kivel, B. D. (2016). "Embarrassingly White" Faculty racial disparities in American recreation, park, and tourism programs. SCHOLE: A Journal of Leisure Studies and Recreation Education, 31(1), 37-55. 
Condition of

deprivation and

persecution
McDonald, M. G. (2009). Dialogues on whiteness, leisure and (anti) racism. Journal of Leisure Research, 41(1), 5-21.

Mowatt, R. A., \& Schmalz, D. L. (2014). The conspicuous nature of power: Conclusion to the special issue. Journal of Leisure Research, 46(3), 353-358.

9 Godbey, G. (2000). The future of leisure studies. Journal of Leisure Research, 32(1), 37-41.

Hodge, C., Bocarro, J. N., Henderson, K. A., Zabriskie, R., Parcel, T. L., \& Kanters, M. A. (2015). Family leisure: An integrative review of research from select journals. Journal of Leisure Research, 47(5), 577-600.

Powers, S. L., Lee, K. J., Pitas, N. A., Graefe, A. R., \& Mowen, A. J. (2019). Understanding access and use of municipal parks and recreation through an intersectionality perspective. Journal of Leisure Research, 1-20.

Smith, A. B., Johnson, C. W., Powell, G. M., \& Oliver, J. P. (2011). The relationship between multicultural service-learning and self-reported multicultural competencies in undergraduate students: A qualitative participatory action study. Schole: A Journal of Leisure Studies and Recreation Education, 26(2), 1-13.

Edwards, M. B., \& Matarrita-Cascante, D. (2011). Rurality in leisure research: A review of four major journals. Journal of Leisure Research, 43(4), 447-474.

Hultsman, J. (1995). Adding a diversity component to a recreation and tourism curriculum. SCHOLE: A Journal of Leisure Studies and Recreation Education, 10(1), 17-28.

Wu, H. C. J., \& Van Egeren, L. A. (2010). Voluntary participation and parents' reasons for enrollment in after-school programs: Contributions of race/ethnicity, program quality, and program policies. Journal of Leisure Research, 42(4), 591-620.

Stodolska, M., Sharaievska, I., Tainsky, S., \& Ryan, A. (2014). Minority youth participation in an organized sport program: Needs, motivations, and facilitators. Journal of Leisure Research, 46(5), 
612-634.

Shores, K. A. (2010). The politics of park design. Galen Cranz. Journal of Leisure Research, 42(1), 177-180. doi: 10.1080/00222216.2010.11950200

Positive sub-thematic exhibition
2 Mowatt, R. A., \& Schmalz, D. L. (2014). The conspicuous nature of power: Conclusion to the special issue. Journal of Leisure Research, 46(3), 353-358.

Theriault, D. (2019). Power threats and radical healing in Black youths' leisure. Journal of Leisure Research, 50(5), 413-424.

Table 4

Articles on Race Classified as an Improper Terminology Use 
Race, ethnicity, and culture are used interchangeably
36 Allison, M. T. (1999). Organizational barriers to diversity in the workplace. Journal of Leisure Research, 31(1), 78-101.

Winter, P. L., Palucki, L. J., \& Burkhardt, R. L. (1999). Anticipated responses to a fee program: The key is trust. Journal of Leisure Research, 31(3), 207-226.

McMeeking, D., \& Purkayastha, B. (1995). "I can't have my mom running me everywhere": Adolescents, leisure, and accessibility. Journal of Leisure Research, 27(4), 360-378.

Stodolska, M. (1998). Assimilation and leisure constraints: Dynamics of constraints on leisure in immigrant populations. Journal of Leisure Research, 30(4), 521-551.

Wankel, L. M., \& Berger, B. G. (1990). The psychological and social benefits of sport and physical activity. Journal of Leisure Research, 22(2), 167-182.

Hultsman, J. (1995). Adding a diversity component to a recreation and tourism curriculum. SCHOLE: A Journal of Leisure Studies and Recreation Education, 10(1), 17-28.

Bedini, L. A., Stone, C. F., \& Phoenix, T. L. (2000). Increasing diversity among students in recreation, parks, and leisure studies curricula: A case study. SCHOLE: A Journal of Leisure Studies and Recreation Education, 15(1), 47-62.

Riley, B., Skalko, T., McChesney, J., \& Glascoff, M. (1998). Learn and serve: integrating elements of social learning theory and cross cultural exposure in professional preparation. SCHOLE: A Journal of Leisure Studies and Recreation Education, 13(1), 55-68.

Moore, A. C., \& Henderson, K. A. (2018). "Like precious gold": Recreation in the lives of lowincome committed couples. Journal of Leisure Research, 49(1), 46-69.

Wu, H. C. J., \& Van Egeren, L. A. (2010). Voluntary participation and parents' reasons for enrollment in after-school programs: Contributions of race/ethnicity, program quality, and program 
policies. Journal of Leisure Research, 42(4), 591-620.

Hutson, G., Montgomery, D., \& Caneday, L. (2010). Perceptions of outdoor recreation professionals toward place meanings in natural environments: A Q-method inquiry. Journal of Leisure Research, 42(3), 417-442.

Lundberg, N. R., Taniguchi, S., McCormick, B. P., \& Tibbs, C. (2011). Identity negotiating: Redefining stigmatized identities through adaptive sports and recreation participation among individuals with a disability. Journal of Leisure Research, 43(2), 205-225.

Stodolska, M., Sharaievska, I., Tainsky, S., \& Ryan, A. (2014). Minority youth participation in an organized sport program: Needs, motivations, and facilitators. Journal of Leisure Research, 46(5), 612-634.

Edwards, M. B., \& Matarrita-Cascante, D. (2011). Rurality in leisure research: A review of four major journals. Journal of Leisure Research, 43(4), 447-474.

Simpkins, S. D., Vest, A. E., Delgado, M. Y., \& Price, C. D. (2012). Do school friends participate in similar extracurricular activities?: Examining the moderating role of race/ethnicity and age. Journal of Leisure Research, 44(3), 332-352.

Parsons, A. A., Besenyi, G. M., Kaczynski, A. T., Wilhelm Stanis, S. A., Blake, C. E., \& BarrAnderson, D. J. (2015). Investigating issues of environmental injustice in neighborhoods surrounding parks. Journal of Leisure Research, 47(2), 285-303.

Weiler, B., Martin, V. Y., Canosa, A., \& Cutter-Mackenzie, A. (2018). Generation Y and protected areas: A scoping study of research, theory, and future directions. Journal of Leisure

Research, 49(3-5), 277-297.

Tuggle, F. J., Kerpelman, J., \& Pittman, J. (2016). Young adolescents' shared leisure activities with close friends and dating partners: Associations with supportive communication and relationship satisfaction. Journal of Leisure Research, 48(5), 374-394.

Jarrett, R. L., Bahar, O. S., McPherson, E., \& Williams, D. A. (2013). No child left inside: The built 
environment and caregiver strategies to promote child physical activity. Journal of Leisure Research, 45(4), 485-513.

Clark, B. S., \& Anderson, D. M. (2014). Not yet a woman, not yet a mom: The leisure experiences of pregnant adolescents. Journal of Leisure Research, 46(5), 509-524.

García, R. (2013). Social justice and leisure: The usefulness and uselessness of research. Journal of Leisure Research, 45(1), 7-22.

Payne, L. L., Schmalz, D. L., \& Janke, M. C. (2018). The reemergence and revitalized focus of JLR. Journal of Leisure Research, 49(1), 1-7.

Bailey, A. W., Kang, H. K., \& Schmidt, C. (2016). Leisure routine and positive attitudes: agegraded comparisons of the path to happiness. Journal of leisure research, 48(3), 189-209.

Witmer, L., Bocarro, J. N., \& Henderson, K. (2011). Adolescent girls' perception of health within a leisure context. Journal of Leisure Research, 43(3), 334-354.

Powers, S. L., Lee, K. J., Pitas, N. A., Graefe, A. R., \& Mowen, A. J. (2019). Understanding access and use of municipal parks and recreation through an intersectionality perspective. Journal of Leisure Research, 1-20.

Blanco, J., \& Robinett, J. (2014). Leisure helps get the job done: Intersections of hegemonic masculinity and stress among college-aged males. Journal of Leisure Research, 46(4), 361-374.

Pryor, B. N. K., \& Outley, C. W. (2014). Just spaces: Urban recreation centers as sites for social justice youth development. Journal of Leisure Research, 46(3), 272-290.

Fernandez, M., \& Witt, P. A. (2013). Attracting Hispanics to an African American recreation center: Examining attitudes and historical factors. Journal of Leisure Research, 45(4), 423-444.

Larson, L., Whiting, J. W., Green, G. T., \& Bowker, J. M. (2014). Physical activity levels and preferences of ethnically diverse visitors to Georgia state parks. Journal of Leisure Research, 46(5), 
$540-562$.

Iwasaki, Y., Messina, E., Shank, J., \& Coyle, C. (2015). Role of leisure in meaning-making for community-dwelling adults with mental illness: Inspiration for engaged life. Journal of Leisure Research, 47(5), 538-555.

Caldwell, L. L., Patrick, M. E., Smith, E. A., Palen, L. A., \& Wegner, L. (2010). Influencing adolescent leisure motivation: intervention effects of health wise South Africa. Journal of Leisure Research, 42(2), 203-220.

Lee, K. J., Scott, D., Floyd, M. F., \& Edwards, M. B. (2016). Social stratification in fishing participation in the United States: a multiple hierarchy stratification perspective. Journal of Leisure Research, 48(3), 245-26

Clark, B. S., \& Anderson, D. M. (2014). Not yet a woman, not yet a mom: The leisure experiences of pregnant adolescents. Journal of Leisure Research, 46(5), 509-524.

Bailey, A. W., Kang, H. K., \& Schmidt, C. (2016). Leisure routine and positive attitudes: agegraded comparisons of the path to happiness. Journal of leisure research, 48(3), 189-209.

Allaby, M., \& Shannon, C. S. (2019). “I just want to keep in touch": Adolescents' experiences with leisure-related smartphone use. Journal of Leisure Research, 1-19.

McDonald, D., \& McAvoy, L. (1997). Native Americans and leisure: State of the research and future directions. Journal of Leisure Research, 29(2), 145-166.

8 Winter, P. L., Palucki, L. J., \& Burkhardt, R. L. (1999). Anticipated responses to a fee program: The key is trust. Journal of Leisure Research, 31(3), 207-226.

Wu, H. C. J., \& Van Egeren, L. A. (2010). Voluntary participation and parents' reasons for enrollment in after-school programs: Contributions of race/ethnicity, program quality, and program policies. Journal of Leisure Research, 42(4), 591-620. 
Inconsistent descriptive terminology
Edwards, M. B., \& Matarrita-Cascante, D. (2011). Rurality in leisure research: A review of four major journals. Journal of Leisure Research, 43(4), 447-474.

Simpkins, S. D., Vest, A. E., Delgado, M. Y., \& Price, C. D. (2012). Do school friends participate in similar extracurricular activities?: Examining the moderating role of race/ethnicity and age. Journal of Leisure Research, 44(3), 332-352.

Hodge, C., Bocarro, J. N., Henderson, K. A., Zabriskie, R., Parcel, T. L., \& Kanters, M. A. (2015). Family leisure: An integrative review of research from select journals. Journal of Leisure Research, 47(5), 577-600.

Blanco, J., \& Robinett, J. (2014). Leisure helps get the job done: Intersections of hegemonic masculinity and stress among college-aged males. Journal of Leisure Research, 46(4), 361-374.

Caldwell, L. L., Patrick, M. E., Smith, E. A., Palen, L. A., \& Wegner, L. (2010). Influencing adolescent leisure motivation: intervention effects of health wise South Africa. Journal of Leisure Research, 42(2), 203-220.

Bialeschki, M. D., \& Walbert, K. L. (1998). "You have to have some fun to go along with your work": The Interplay of Race, Class, Gender, and Leisure in the Industrial New South. Journal of Leisure Research, 30(1), 79-100.

Allison, M. T. (1999). Organizational barriers to diversity in the workplace. Journal of Leisure Research, 31(1), 78-101.

Stodolska, M. (1998). Assimilation and leisure constraints: Dynamics of constraints on leisure in immigrant populations. Journal of Leisure Research, 30(4), 521-551.

Bedini, L. A., Stone, C. F., \& Phoenix, T. L. (2000). Increasing diversity among students in recreation, parks, and leisure studies curricula: A case study. SCHOLE: A Journal of Leisure Studies and Recreation Education, 15(1), 47-62.

Riley, B., Skalko, T., McChesney, J., \& Glascoff, M. (1998). Learn and serve: integrating elements 
of social learning theory and cross cultural exposure in professional preparation. SCHOLE: A Journal of Leisure Studies and Recreation Education, 13(1), 55-68.

Freysinger, V. J., Fox, K. M., Henderson, K. A., \& Bedini, L. (1994). Book and resource review: Addressing multiculturalism in recreation and leisure education. SCHOLE: A Journal of Leisure Studies and Recreation Education, 9(1), 79-89.

Henderson, K. A. (1995). Leisure in a diverse society: Designing a course. Schole: A Journal of Leisure Studies and Recreation Education, 10(1), 1-15.

Snelgrove, R. (2015). Youth with chronic illness forming identities through leisure. Journal of Leisure Research, 47(1), 154-173.

Simpkins, S. D., Vest, A. E., Delgado, M. Y., \& Price, C. D. (2012). Do school friends participate in similar extracurricular activities?: Examining the moderating role of race/ethnicity and age. Journal of Leisure Research, 44(3), 332-352.

Kim, J., Dattilo, J., \& Heo, J. (2011). Taekwondo participation as serious leisure for life satisfaction and health. Journal of Leisure Research, 43(4), 545-559.

Tuggle, F. J., Kerpelman, J., \& Pittman, J. (2016). Young adolescents' shared leisure activities with close friends and dating partners: Associations with supportive communication and relationship satisfaction. Journal of Leisure Research, 48(5), 374-394.

Jarrett, R. L., Bahar, O. S., McPherson, E., \& Williams, D. A. (2013). No child left inside: The built environment and caregiver strategies to promote child physical activity. Journal of Leisure Research, 45(4), 485-513.

Clark, B. S., \& Anderson, D. M. (2014). Not yet a woman, not yet a mom: The leisure experiences of pregnant adolescents. Journal of Leisure Research, 46(5), 509-524.

Beale, S. (2013). Contested waters: A social history of swimming pools in America. Journal of Leisure Research, 45(3), 415-418. doi: 10.1080/00222216.2013.11950293 
García, R. (2013). Social justice and leisure: The usefulness and uselessness of research. Journal of Leisure Research, 45(1), 7-22.

Glover, T. D. (2015). Leisure research for social impact. Journal of Leisure Research, 47(1), 1-14.

Chun, S., \& Lee, Y. (2010). The role of leisure in the experience of posttraumatic growth for people with spinal cord injury. Journal of Leisure Research, 42(3), 393-415.

Witmer, L., Bocarro, J. N., \& Henderson, K. (2011). Adolescent girls' perception of health within a leisure context. Journal of Leisure Research, 43(3), 334-354.

Powers, S. L., Lee, K. J., Pitas, N. A., Graefe, A. R., \& Mowen, A. J. (2019). Understanding access and use of municipal parks and recreation through an intersectionality perspective. Journal of Leisure Research, 1-20.

Smith, A. B., Johnson, C. W., Powell, G. M., \& Oliver, J. P. (2011). The relationship between multicultural service-learning and self-reported multicultural competencies in undergraduate students: A qualitative participatory action study. Schole: A Journal of Leisure Studies and Recreation Education, 26(2), 1-13.

Caldwell, L. L., Patrick, M. E., Smith, E. A., Palen, L. A., \& Wegner, L. (2010). Influencing adolescent leisure motivation: intervention effects of health wise South Africa. Journal of Leisure Research, 42(2), 203-220.

Clark, B. S., \& Anderson, D. M. (2014). Not yet a woman, not yet a mom: The leisure experiences of pregnant adolescents. Journal of Leisure Research, 46(5), 509-524.

McDonald, D., \& McAvoy, L. (1997). Native Americans and leisure: State of the research and future directions. Journal of Leisure Research, 29(2), 145-166.

Harrolle, M. G., Floyd, M. F., Casper, J. M., Kelley, K. E., \& Bruton, C. M. (2013). Physical activity constraints among Latinos: Identifying clusters and acculturation differences. Journal of 
Leisure Research, 45(1), 74-90.

Positive sub-thematic exhibition
1 Theriault, D. (2019). Power threats and radical healing in Black youths' leisure. Journal of Leisure Research, 50(5), 413-424.

Table 5

Articles on Race Classified on the Intentionality of Race

Sub-Themes 
Race as a denotation of differential experiences or preferences
31 Bialeschki, M. D., \& Walbert, K. L. (1998). "You have to have some fun to go along with your work": The interplay of race, class, gender, and leisure in the industrial New South. Journal of Leisure Research, 30(1), 79-100.

Pohl, S. L., Borrie, W. T., \& Patterson, M. E. (2000). Women, wilderness, and everyday life: A documentation of the connection between wilderness recreation and women's everyday lives. Journal of Leisure Research, 32(4), 415-434.

Hultsman, W. Z. (1993). The influence of others as a barrier to recreation participation among early adolescents. Journal of Leisure Research, 25(2), 150-164.

Allison, M. T. (1999). Organizational barriers to diversity in the workplace. Journal of Leisure Research, 31(1), 78-101.

Winter, P. L., Palucki, L. J., \& Burkhardt, R. L. (1999). Anticipated responses to a fee program: The key is trust. Journal of Leisure Research, 31(3), 207-226.

Kelly, J. R., \& Kelly, J. R. (1994). Multiple dimensions of meaning in the domains of work, family, and leisure. Journal of Leisure Research, 26(3), 250-274.

McMeeking, D., \& Purkayastha, B. (1995). "I can't have my mom running me everywhere": Adolescents, leisure, and accessibility. Journal of Leisure Research, 27(4), 360-378.

Godbey, G. (2000). The future of leisure studies. Journal of Leisure Research, 32(1), 37-41.

Stodolska, M. (1998). Assimilation and leisure constraints: Dynamics of constraints on leisure in immigrant populations. Journal of Leisure Research, 30(4), 521-551.

Hultsman, J. (1995). Adding a diversity component to a recreation and tourism curriculum. SCHOLE: A Journal of Leisure Studies and Recreation Education, 10(1), 17-28. 
Freysinger, V. J., Fox, K. M., Henderson, K. A., \& Bedini, L. (1994). Book and resource review: Addressing multiculturalism in recreation and leisure education. SCHOLE: A Journal of Leisure Studies and Recreation Education, 9(1), 79-89.

Riggins, R. D. (1993). Liberal education and professional studies at the undergraduate level: Still circling Moose Jaw. SCHOLE: A Journal of Leisure Studies and Recreation Education, 7(1), 5-16.

Wu, H. C. J., \& Van Egeren, L. A. (2010). Voluntary participation and parents' reasons for enrollment in after-school programs: Contributions of race/ethnicity, program quality, and program policies. Journal of Leisure Research, 42(4), 591-620.

Stodolska, M., Sharaievska, I., Tainsky, S., \& Ryan, A. (2014). Minority youth participation in an organized sport program: Needs, motivations, and facilitators. Journal of Leisure Research, 46(5), 612-634.

Simpkins, S. D., Vest, A. E., Delgado, M. Y., \& Price, C. D. (2012). Do school friends participate in similar extracurricular activities?: Examining the moderating role of race/ethnicity and age. Journal of Leisure Research, 44(3), 332-352.

Weiler, B., Martin, V. Y., Canosa, A., \& Cutter-Mackenzie, A. (2018). Generation Y and protected areas: A scoping study of research, theory, and future directions. Journal of Leisure Research, 49(3-5), 277-297.

Hodge, C., Bocarro, J. N., Henderson, K. A., Zabriskie, R., Parcel, T. L., \& Kanters, M. A. (2015). Family leisure: An integrative review of research from select journals. Journal of Leisure Research, 47(5), 577-600.

Tuggle, F. J., Kerpelman, J., \& Pittman, J. (2016). Young adolescents' shared leisure activities with close friends and dating partners: Associations with supportive communication and relationship satisfaction. Journal of Leisure Research, 48(5), 374-394.

Jarrett, R. L., Bahar, O. S., McPherson, E., \& Williams, D. A. (2013). No child left inside: The built environment and caregiver strategies to promote child physical activity. Journal of Leisure 
Research, 45(4), 485-513.

Clark, B. S., \& Anderson, D. M. (2014). Not yet a woman, not yet a mom: The leisure experiences of pregnant adolescents. Journal of Leisure Research, 46(5), 509-524.

Powers, S. L., Lee, K. J., Pitas, N. A., Graefe, A. R., \& Mowen, A. J. (2019). Understanding access and use of municipal parks and recreation through an intersectionality perspective. Journal of Leisure Research, 1-20.

Allaby, M., \& Shannon, C. S. (2019). "I just want to keep in touch": Adolescents' experiences with leisure-related smartphone use. Journal of Leisure Research, 1-19.

VanSickle, J., \& Schaumleffel, N. A. (2016). Developing recreation, leisure, and sport professional competencies through practitioner/academic service engagement partnerships. Schole: A Journal of Leisure Studies and Recreation Education, 31(2), 37-55.

Edwards, M. B., \& Matarrita-Cascante, D. (2011). Rurality in leisure research: A review of four major journals. Journal of Leisure Research, 43(4), 447-474.

Larson, L., Whiting, J. W., Green, G. T., \& Bowker, J. M. (2014). Physical activity levels and preferences of ethnically diverse visitors to Georgia state parks. Journal of Leisure Research, 46(5), 540-562.

Hurly, J., \& Walker, G. J. (2019). Nature in our lives: Examining the human need for nature relatedness as a basic psychological need. Journal of Leisure Research, 50(4), 290-310.

Lee, K. J., Scott, D., Floyd, M. F., \& Edwards, M. B. (2016). Social stratification in fishing participation in the United States: a multiple hierarchy stratification perspective. Journal of Leisure Research, 48(3), 245-263.

Clark, B. S., \& Anderson, D. M. (2014). Not yet a woman, not yet a mom: The leisure experiences of pregnant adolescents. Journal of Leisure Research, 46(5), 509-524. 
Positive sub-thematic exhibition

Racialized sample as exemplary of racialized group
Mirehie, M., \& Gibson, H. J. (2019). Women's participation in snow-sports and sense of wellbeing: a positive psychology approach. Journal of Leisure Research, 1-19.

Robertson, B. J. (2009). Reflective self study: A tool for understanding leisure behavior. SCHOLE: A Journal of Leisure Studies and Recreation Education, 24(1), 155-161.

McDonald, D., \& McAvoy, L. (1997). Native Americans and leisure: State of the research and future directions. Journal of Leisure Research, 29(2), 145-166.

Theriault, D. (2019). Power threats and radical healing in Black youths' leisure. Journal of Leisure Research, 50(5), 413-424.

Mowatt, R. A. (2009). Notes from a leisure son: Expanding an understanding of whiteness in leisure. Journal of Leisure Research, 41(4), 511-528.

McDonald, M. G. (2009). Dialogues on whiteness, leisure and (anti) racism. Journal of Leisure Research, 41(1), 5-21.

Schmalz, D. L., \& Mowatt, R. A. (2014). The unsettling nature of prejudice: An introduction to the special issue. Journal of Leisure Research, 46(3), 245-251.

Mowatt, R. A., Johnson, C. W., Roberts, N. S., \& Kivel, B. D. (2016). "Embarrassingly White" Faculty racial disparities in American recreation, park, and tourism programs. SCHOLE: A Journal of Leisure Studies and Recreation Education, 31(1), 37-55.

14 Pohl, S. L., Borrie, W. T., \& Patterson, M. E. (2000). Women, wilderness, and everyday life: A documentation of the connection between wilderness recreation and women's everyday lives. Journal of Leisure Research, 32(4), 415-434.

Kelly, J. R., \& Kelly, J. R. (1994). Multiple dimensions of meaning in the domains of work, family, and leisure. Journal of Leisure Research, 26(3), 250-274. 
Stodolska, M., Sharaievska, I., Tainsky, S., \& Ryan, A. (2014). Minority youth participation in an organized sport program: Needs, motivations, and facilitators. Journal of Leisure Research, 46(5), 612-634.

Kim, J., Dattilo, J., \& Heo, J. (2011). Taekwondo participation as serious leisure for life satisfaction and health. Journal of Leisure Research, 43(4), 545-559.

Hodge, C., Bocarro, J. N., Henderson, K. A., Zabriskie, R., Parcel, T. L., \& Kanters, M. A. (2015). Family leisure: An integrative review of research from select journals. Journal of Leisure Research, 47(5), 577-600.

Tuggle, F. J., Kerpelman, J., \& Pittman, J. (2016). Young adolescents' shared leisure activities with close friends and dating partners: Associations with supportive communication and relationship satisfaction. Journal of Leisure Research, 48(5), 374-394.

Bailey, A. W., Kang, H. K., \& Schmidt, C. (2016). Leisure routine and positive attitudes: agegraded comparisons of the path to happiness. Journal of Leisure Research, 48(3), 189-209.

Ito, E., Walker, G. J., \& Liang, H. (2014). A systematic review of non-Western and crosscultural/national leisure research. Journal of Leisure Research, 46(2), 226-239.

Allaby, M., \& Shannon, C. S. (2019). "I just want to keep in touch": Adolescents' experiences with leisure-related smartphone use. Journal of Leisure Research, 1-19.

Blanco, J., \& Robinett, J. (2014). Leisure helps get the job done: Intersections of hegemonic masculinity and stress among college-aged males. Journal of Leisure Research, 46(4), 361-374. 
Race as identity

Positive sub-thematic exhibition
7 Bialeschki, M. D., \& Walbert, K. L. (1998). "You have to have some fun to go along with your work": The interplay of race, class, gender, and leisure in the industrial New South. Journal of leisure Research, 30(1), 79-100.

Snelgrove, R. (2015). Youth with chronic illness forming identities through leisure. Journal of Leisure Research, 47(1), 154-173.

Powers, S. L., Lee, K. J., Pitas, N. A., Graefe, A. R., \& Mowen, A. J. (2019). Understanding access and use of municipal parks and recreation through an intersectionality perspective. Journal of Leisure Research, 1-20.

Smith, A. B., Johnson, C. W., Powell, G. M., \& Oliver, J. P. (2011). The relationship between multicultural service-learning and self-reported multicultural competencies in undergraduate students: A qualitative participatory action study. Schole: A Journal of Leisure Studies and Recreation Education, 26(2), 1-13.

Bedini, L. A., \& Anonymous (1996). Integrative Book Reviews. Journal of Leisure research, 28(4), 312-321.

McMeeking, D., \& Purkayastha, B. (1995). "I can't have my mom running me everywhere": Adolescents, leisure, and accessibility. Journal of Leisure Research, 27(4), 360-378.

Pryor, B. N. K., \& Outley, C. W. (2014). Just spaces: Urban recreation centers as sites for social justice youth development. Journal of Leisure Research, 46(3), 272-290.

McDonald, M. G. (2009). Dialogues on whiteness, leisure and (anti) racism. Journal of Leisure Research, 41(1), 5-21.

Trussell, D. E. (2014). Dancing in the margins: Reflections on social justice and researcher identities. Journal of Leisure Research, 46(3), 342-352.

Mowatt, R. A. (2009). Notes from a leisure son: Expanding an understanding of whiteness in leisure. Journal of Leisure Research, 41(4), 511-528. 
Table 6

Articles on Race Classified as Inadequate Lens of Problem/Solution

Sub-Themes $n$ Article Title

Frame racialized problem/solution as individual rather than systemic
Hultsman, J. (1995). Adding a diversity component to a recreation and tourism curriculum. SCHOLE: A Journal of Leisure Studies and Recreation Education, 10(1), 17-28.

Bedini, L. A., Stone, C. F., \& Phoenix, T. L. (2000). Increasing diversity among students in recreation, parks, and leisure studies curricula: A case study. SCHOLE: A Journal of Leisure Studies and Recreation Education, 15(1), 47-62.

Riley, B., Skalko, T., McChesney, J., \& Glascoff, M. (1998). Learn and serve: Integrating elements of social learning theory and cross cultural exposure in professional preparation. SCHOLE: A Journal of Leisure Studies and Recreation Education, 13(1), 55-68.

Freysinger, V. J., Fox, K. M., Henderson, K. A., \& Bedini, L. (1994). Book and resource review: Addressing multiculturalism in recreation and leisure education. SCHOLE: A Journal of Leisure Studies and Recreation Education, 9(1), 79-89.

Grossman, A. H. (1993). Ten percent of those we teach and they serve: A case study of incorporating gay and lesbian studies into the curriculum. Schole: A Journal of Leisure Studies and Recreation Education, 8(1), 51-60.

Henderson, K. A. (1995). Leisure in a diverse society: Designing a course. Schole: A Journal of Leisure Studies and Recreation Education, 10(1), 1-15.

Stodolska, M., Sharaievska, I., Tainsky, S., \& Ryan, A. (2014). Minority youth participation in an organized sport program: Needs, motivations, and facilitators. Journal of Leisure Research, 46(5), 612-634.

Lim, W. M. (2019). Spectator sports and its role in the social marketing of national unity: Insights 
from a multiracial country. Journal of Leisure Research, 50(3), 260-284.

Weiler, B., Martin, V. Y., Canosa, A., \& Cutter-Mackenzie, A. (2018). Generation Y and protected areas: A scoping study of research, theory, and future directions. Journal of Leisure Research, 49(3-5), 277-297.

Bailey, A. W., \& Fernando, I. K. (2012). Routine and project-based leisure, happiness, and meaning in life. Journal of Leisure Research, 44(2), 139-154.

Beale, S. (2013). Contested waters: A social history of swimming pools in America. Journal of Leisure Research, 45(3), 415-418. doi: 10.1080/00222216.2013.11950293

Payne, L. L., Schmalz, D. L., \& Janke, M. C. (2018). The reemergence and revitalized focus of JLR. Journal of Leisure Research, 49(1), 1-7.

Shores, K. A. (2010). The politics of park design. Galen Cranz. Journal of Leisure Research, 42(1), 177-180. doi: 10.1080/00222216.2010.11950200

Bailey, A. W., Kang, H. K., \& Schmidt, C. (2016). Leisure routine and positive attitudes: agegraded comparisons of the path to happiness. Journal of Leisure Research, 48(3), 189-209.

Witmer, L., Bocarro, J. N., \& Henderson, K. (2011). Adolescent girls' perception of health within a leisure context. Journal of Leisure Research, 43(3), 334-354.

VanSickle, J., \& Schaumleffel, N. A. (2016). Developing recreation, leisure, and sport professional competencies through practitioner/academic service engagement partnerships. Schole: A Journal of Leisure Studies and Recreation Education, 31(2), 37-55.

Smith, A. B., Johnson, C. W., Powell, G. M., \& Oliver, J. P. (2011). The relationship between multicultural service-learning and self-reported multicultural competencies in undergraduate students: A qualitative participatory action study. Schole: A Journal of Leisure Studies and Recreation Education, 26(2), 1-13. 
Positive sub-thematic exhibition
Bedini, L. A., \& Anonymous (1996). Integrative Book Reviews. Journal of Leisure research, 28(4), 312-321.

McMeeking, D., \& Purkayastha, B. (1995). "I can't have my mom running me everywhere": Adolescents, leisure, and accessibility. Journal of Leisure Research, 27(4), 360-378.

Godbey, G. (2000). The future of leisure studies. Journal of Leisure Research, 32(1), 37-41.

Pryor, B. N. K., \& Outley, C. W. (2014). Just spaces: Urban recreation centers as sites for social justice youth development. Journal of Leisure Research, 46(3), 272-290.

Hurly, J., \& Walker, G. J. (2019). Nature in our lives: Examining the human need for nature relatedness as a basic psychological need. Journal of Leisure Research, 50(4), 290-310.

Lee, K. J., Scott, D., Floyd, M. F., \& Edwards, M. B. (2016). Social stratification in fishing participation in the United States: a multiple hierarchy stratification perspective. Journal of Leisure Research, 48(3), 245-263.

Mirehie, M., \& Gibson, H. J. (2019). Women's participation in snow-sports and sense of wellbeing: a positive psychology approach. Journal of Leisure Research, 1-19.

Tirone, S., \& Goodberry, A. (2011). Leisure, biculturalism, and second-generation Canadians. Journal of Leisure Research, 43(3), 427-444.

Theriault, D. (2019). Power threats and radical healing in Black youths' leisure. Journal of Leisure Research, 50(5), 413-424.

Mowatt, R. A. (2009). Notes from a leisure son: Expanding an understanding of whiteness in leisure. Journal of Leisure Research, 41(4), 511-528.

McDonald, M. G. (2009). Dialogues on whiteness, leisure and (anti) racism. Journal of Leisure Research, 41(1), 5-21. 
Frame problem as being contemporary
Schmalz, D. L., \& Mowatt, R. A. (2014). The unsettling nature of prejudice: An introduction to the special issue. Journal of Leisure Research, 46(3), 245-251.

Trussell, D. E. (2014). Dancing in the margins: Reflections on social justice and researcher identities. Journal of Leisure Research, 46(3), 342-352.

Mowatt, R. A., Johnson, C. W., Roberts, N. S., \& Kivel, B. D. (2016). "Embarrassingly White" Faculty racial disparities in American recreation, park, and tourism programs. SCHOLE: A Journal of Leisure Studies and Recreation Education, 31(1), 37-55.

Mowatt, R. A., \& Schmalz, D. L. (2014). The conspicuous nature of power: Conclusion to the special issue. Journal of Leisure Research, 46(3), 353-358.

7 Bedini, L. A., Stone, C. F., \& Phoenix, T. L. (2000). Increasing diversity among students in recreation, parks, and leisure studies curricula: A case study. SCHOLE: A Journal of Leisure Studies and Recreation Education, 15(1), 47-62.

Wu, H. C. J., \& Van Egeren, L. A. (2010). Voluntary participation and parents' reasons for enrollment in after-school programs: Contributions of race/ethnicity, program quality, and program policies. Journal of Leisure Research, 42(4), 591-620.

Hodge, C., Bocarro, J. N., Henderson, K. A., Zabriskie, R., Parcel, T. L., \& Kanters, M. A. (2015). Family leisure: An integrative review of research from select journals. Journal of Leisure Research, 47(5), 577-600.

Payne, L. L., Schmalz, D. L., \& Janke, M. C. (2018). The reemergence and revitalized focus of JLR. Journal of Leisure Research, 49(1), 1-7.

Smith, A. B., Johnson, C. W., Powell, G. M., \& Oliver, J. P. (2011). The relationship between multicultural service-learning and self-reported multicultural competencies in undergraduate students: A qualitative participatory action study. Schole: A Journal of Leisure Studies and Recreation Education, 26(2), 1-13. 
Positive sub-thematic exhibition

Frame solution as being leisure specific
Pryor, B. N. K., \& Outley, C. W. (2014). Just spaces: Urban recreation centers as sites for social justice youth development. Journal of Leisure Research, 46(3), 272-290.

Fernandez, M., \& Witt, P. A. (2013). Attracting Hispanics to an African American recreation center: Examining attitudes and historical factors. Journal of Leisure Research, 45(4), 423-444.

4 Mowatt, R. A. (2009). Notes from a leisure son: Expanding an understanding of whiteness in leisure. Journal of Leisure Research, 41(4), 511-528.

McDonald, M. G. (2009). Dialogues on whiteness, leisure and (anti) racism. Journal of Leisure Research, 4l(1), 5-21.

Mowatt, R. A., Johnson, C. W., Roberts, N. S., \& Kivel, B. D. (2016). "Embarrassingly White" Faculty racial disparities in American recreation, park, and tourism programs. SCHOLE: A Journal of Leisure Studies and Recreation Education, 31(1), 37-55.

Mowatt, R. A., \& Schmalz, D. L. (2014). The conspicuous nature of power: Conclusion to the special issue. Journal of Leisure Research, 46(3), 353-358.

7 Bialeschki, M. D., \& Walbert, K. L. (1998). "You have to have some fun to go along with your work": The interplay of race, class, gender, and leisure in the industrial New South. Journal of Leisure Research, 30(1), 79-100.

Lim, W. M. (2019). Spectator sports and its role in the social marketing of national unity: Insights from a multiracial country. Journal of Leisure Research, 50(3), 260-284.

Bailey, A. W., \& Fernando, I. K. (2012). Routine and project-based leisure, happiness, and meaning in life. Journal of Leisure Research, 44(2), 139-154.

Beale, S. (2013). Contested waters: A social history of swimming pools in America. Journal of Leisure Research, 45(3), 415-418. doi: 10.1080/00222216.2013.11950293 
Bedini, L. A., \& Anonymous (1996). Integrative book reviews. Journal of Leisure Research, 28(4), 312-321.

Positive sub-thematic exhibition
Pryor, B. N. K., \& Outley, C. W. (2014). Just spaces: Urban recreation centers as sites for social justice youth development. Journal of Leisure Research, 46(3), 272-290.

1 Theriault, D. (2019). Power threats and radical healing in Black youths' leisure. Journal of Leisure Research, 50(5), 413-424. 
Table 7

Article Themes Based on Decade

\begin{tabular}{|c|c|c|c|c|}
\hline \multirow[b]{2}{*}{ Themes/Sub-Themes } & \multicolumn{2}{|c|}{$1990 \mathrm{~s}$} & \multicolumn{2}{|c|}{$2010 \mathrm{~s}$} \\
\hline & $n$ & $n / \mathrm{N}$ & $n$ & $n / \mathrm{N}$ \\
\hline
\end{tabular}

Faint mentions of race

Periphery mentions

Demographic variable with no assessment

Stigma comparison

4

2

7

"Minority"

Condition of othering

Engagement in dangerous activities

Condition of deprivation and persecution

\section{Improper terminology use}

Race, ethnicity, and culture used interchangeably

Mixed race

Inconsistent descriptive terminology
9

1

$15.4 \%$

$15.4 \%$

$7.7 \%$

$38.5 \%$

$26.9 \%$

$7.7 \%$

$0 \%$

$7.7 \%$

$42.3 \%$

15

17

2

$28.8 \%$

$3.4 \%$

$57.6 \%$

$35.6 \%$

$1.7 \%$

$3.4 \%$

$13.6 \%$

$54.2 \%$

$45.8 \%$

$10.2 \%$

$3.8 \%$

$30.8 \%$
27

6

17
$28.8 \%$ 


\section{Intentionality of race}

Race as a denotation of differential experiences or preferences

Racialized sample as exemplary of racialized group

Race as identity

2

$7.7 \%$

12

$20.3 \%$

$11.5 \%$

4

$6.8 \%$

$65.4 \%$

$59.3 \%$

\section{Wrong lens of problem/solution}

Frame problem/solution as individual rather than systemic

Frame problem as being contemporary

Frame solution as being leisure specific 


\section{APPENDIX B}

The research was further delimited to addressing what the literature suggested about women and did not address women in comparison to changes occurring in the editorial and organizational philosophies of the National Recreation Association and its predecessor and successor organizations. In addition, the description of social roles was primarily about Euro-American women. The role of people of color in the recreation movement was largely invisible in the literature and little could be determined about the role of women of color based on the material reviewed. Class issues were more apparent in the analysis because the early focus of the playground and recreation movement was on bringing a quality of life to working class adults and their families (Sessoms, 1984). Class distinctions were not necessarily specified in the literature, but latent meanings concerning class status were noted in the interpretation of the analysis when possible.

Figure 1. A feminist analysis of selected professional recreation literature about girls/women

from 1907-1990 (Henderson, 1993). 
attempts to develop the parks. For example, the following issues and constraints had to be addressed in the process of designing and developing the urban parks: (a) land use conflicts, (b) traffic, noise, congestion, (c) large numbers of users, (d) incompatibility of working class and middle class values and behavior, (e) labor relations, (f) city politics, (g) economic conditions, and (h) social lifestyles. Parks like Central Park were not built in uninhabited open space. Often unemployed and working class whites and blacks lived in spaces chosen for these parks. Notwithstanding, these areas were perceived as urban wastelands standing in the way of efforts to "improve" and develop the city. Differing land use perspectives between the middle and working class resulted in poor people being evicted as their communities were cleared to make way for the parks. For example, Down-

Figure 2. Central Park as a model for social control: urban parks, social class and leisure behavior in nineteenth-century America (Taylor, 1999). 


\section{Data Collection}

From a pool of 101 Phase I participants recruited from five mental health agencies in a northeastern Unites States city, 40 individuals were invited to a Phase II qualitative study, which this current paper is based on. A purposeful sampling was used to ensure the diversity of participants. First, cultural backgrounds were considered; thus, we attempted to recruit ten adults (five men, five women) from each of four ethnic/racial subsets (i.e., African American, Asian American, Latino, and Caucasian). Second, we considered other personal variables (e.g., age, types of mental illness) and responses to standardized measures (e.g., active living, leisure) during Phase I to recruit as diverse participants as possible (e.g., those with low to high leisure participation levels).

Figure 3. Role of leisure in meaning-making for community-dwelling adults with mental illness: Inspiration for engaged life (Iwasaki et al., 2015). 


\section{Study Participants}

A pool of potential interviewees was generated through posting a call for subjects using recommendations from members of the field of recreation management, from women who recreated in wilderness, from acquaintances of the interviewer, and from responses to posters placed at local outfitting organizations, outdoor equipment shops, and recreation facilities (e.g. climbing walls). Aiming for a stratified and diverse sample of women, the original pool of approximately 45 women was reduced to 24 . Stratification of this pool aimed for diversity (racial, sexual orientation, age, ability level, marital and family status, and socioeconomic status) and women who have a moderate to great amount of wilderness experience (self-defined by the interviewee, but at least one year). While it was important to the researchers to attain a diverse sample, the only sociodemographic characteristic that was asked of the interviewees was age. Paramount to this study was refraining

Figure 4. Women, wilderness, and everyday life: A documentation of the connection between

wilderness recreation and women's everyday lives (Pohl et al., 2000). 
According to Allport (1958), a minority group is one which suffers from unjustified negative attitudes and actions from the dominant group, ranging from mild denigration to scapegoating. Most of the major differences between gay and lesbian people and members of other minority groups, i.e., ethnic and racial groups, arise from the fact that the gay or lesbian person becomes aware of being a member of the group during adolescence rather than at birth. Most gay and lesbian people, however, demonstrate characteristics that have been identified in other minority groups such as obsessive concern with stigma, denial of membership in the minority group, withdrawal, and passivity (Martin, 1982a).

Figure 5. Ten percent of those we teach and they serve: A case study of incorporating gay and lesbian studies into the curriculum (Grossman, 1993). 
The literature suggests ASPs have their greatest impacts on low-income youth, who tend to be disproportionately low-achieving and from racial/ethnic minority groups (Marsh, 1992; Marsh \& Kleitman, 2002). The impact of ASP involvement may be stronger on low-income youth because their home and neighborhood environments are often less enriching and more dangerous than those of middle-income youth (Robinson \& Fenwick, 2007; Simpkins, 2003). However, most studies examining ASP participation have concluded that low-income minority youth have lower participation rates than their white counterparts and that their time outside of school is often highly unproductive (e.g., Fulbright-Anderson, Lawrence, Sutton, Susi, \& Kubisch, 2005; Harvard Family Research Project, 2007; Pedersen \& Seidman, 2005; Rothstein, 2004; Shann, 2002), indicating a need to identify pathways to enrollment in ASPs for these groups.

Figure 6. Voluntary participation and parents' reasons for enrollment in after-school programs:

Contributions of race/ethnicity, program quality, and program policies (Wu \& Van Egeren, 2010). 
The political potency and controversy surrounding diversity issues in today's society makes it difficult for agencies to know how to create appropriate and meaningful responses to diversity. Social and political discussions of diversity efforts and programs have become increasingly value-loaded and value-laden. Terms and phrases such as "political correctness," "quotas," "reverse discrimination," and "affirmative action programs" take on levels of symbolic and political meaning in the workplace that can, by their very nature, create barriers in the form of resentment and non-responsiveness toward "people of difference." Individuals who are thought to benefit from such programs are frequently stereotyped and diminished in capability. This leads to increased resentment at all levels of the organization.

Figure 7. Organizational barriers to diversity in the workplace (Allison, 1999). 
Alternatively, it is important to note that there are some segments of the population that experience vulnerability beyond that of time famine and busyness. These individuals and families are economically distressed, chronically ill, or otherwise disadvantaged, and leisure is often a luxury they cannot afford (in terms of both time and financial resources). They may face a double- or triple-jeopardy situation in that they have limited access to health care, employment, and leisure. This can create a cycle of family distress, and one that Moore and Henderson (this issue) examined in their article on recreation among low-income couples. In their book, Decentring Work: Critical Perspectives on Leisure, Social Policy, and Human Development, Mair, Arai, and Reid (2011) advocate for populations that are more vulnerable and lack access and ability to engage in leisure and receation due to a number of factors such as incarceration, income distress, illness/disease, ethnicity/race, culture, and so on.

Figure 8. The reemergence and revitalized focus of JLR (Payne et al., 2018). 
Specifically, articles found in this review demonstrated the tendency to generalize from largely White male population samples. One problematic aspect of the lack of attention to representation across a population is the implied assumption that a universal rural condition exists across sociodemographic groups. Therefore, we cannot be sure that conclusions related to the perceived benefits of rural residence and rural population preferences for leisure activities, particularly outdoor recreation, were not biased by samples that were overrepresented by White males. Considering theoretical developments and practice recommendations within the leisure and recreation field that may have resulted from these generalizations, this oversight is not minor. As indicated by the few articles that examined rural women, racial and ethnic minorities, low-income populations, and other marginalized groups, there seemed to be significant differences in the experiences of members of these groups compared to those from majority populations. To provide a deeper understanding of rurality, future research should appropriately consider the different social conditions experienced by different sociodemographic groups and the effect of these conditions on leisure and recreation.

Figure 9. Rurality in leisure research: A review of four major journals (Edwards \& Matarrita-

Cascante, 2011). 
A counter-narrative noted discussions that included young people as being enriched with backgrounds and perspectives needing to be tapped. The use of the term "minority" could be linked with her assessment of linguistics, as it has less quantifiable representation, rather a position of perpetual inferiority. One can ask, "When is the minority ever the majority in the U.S.?" Throughout this manuscript the term "faculty of color" is used instead of "minority" as it might be more empowering and inclusive of both racial and ethnic classifications.| Stanley's (2007) research is remarkable as it actually uses the feedback from reviewers responsible for manuscripts submitted by faculty of color to highlight Figure 10. "Embarrassingly White" faculty racial disparities in American recreation, park, and tourism programs (Mowatt et al., 2016). 
any problems." Other parents enrolled their children at the MRC, but not without some reservations. Laura, a Hispanic mother, shared the apprehension she felt at the beginning,

I'd never feel comfortable to take my kids there because of all the Black people. And they are probably like "who are you?" I don't know how they are going to treat me, really. And I don't know them. I guess I just don't want to have to deal with it.

Although several parents reflected this view point, other parents made a distinction between the negative behaviors and the African American race. Carolina, the Hispanic mother

Figure 11. Attracting Hispanics to an African American recreation center: Examining attitudes and historical factors (Fernandez \& Witt, 2013). 
marginalization of pregnant adolescents (Wiemann, Rickert, Berenson, \& Volk, 2005). Interestingly, of the 925 low-income African-American, Mexican-American, and Caucasian pregnant adolescents aged 18 years or younger Wiemann et al. interviewed regarding feelings of stigma during pregnancy, more Caucasian participants (45.3\%) reported being stigmatized compared to $41 \%$ of African-Americans and $32.7 \%$ of Mexican-Americans. While Wiemann et al. did not examine why White girls felt more stigmatized than Black and Mexican-American girls, one may speculate this is the case due to research finding that teen pregnancy is a greater cultural norm in low socioeconomic Black communities (Mollborn, 2010). Regardless of race, there is no denying pregnant teens have the potential to be forced to the margins as research has found pregnant adolescents lack social interaction with peers and often are not involved in extracurricular activities (Whitehead, 2001).

Figure 12. Not yet a woman, not yet a mom: The leisure experiences of pregnant adolescents (Clark \& Anderson, 2014). 
basketball was discussed by Olushola et al. (2013). This finding is perhaps related to the fact that the level of single-parent families among the African American population is high (32\% as compared to $10 \%$ among non-Hispanic Whites and 14\% among Hispanics) (Blackwell, 2010). Thus, the strong need to create bonds with older authority figures may perhaps be due to the absence of positive role models in the lives of some minority children and the fact that they grow up in single-parent households. While previous research considered how attitudes and atmosphere fostered by coaches affect youth motivation and engagement in sport (Keegan et al., 2010; Ntoumanis, 2005; Pelletier et al., 2001), research that would examine the uniquely personal and parental role coaches play in the lives of minority youth is underdeveloped. We argue that Figure 13. Minority youth participation in an organized sport program: Needs, motivations, and facilitators (Stodolska et al., 2014). 
Cumulative Impacts: Although the above discussion highlights the impacts of gender, socioeconomic status, race/ethnicity, and age separately, in reality the four variables interact. A hierarchical ordering exists in terms of what is accessible to the adolescents. At the macro-level, race/ethnicity and socioeconomic status appear to establish the initial boundaries between groups in society. Any constraints that the adolescents might encounter is a function of their group identity, which in turn is compounded by micro-level characteristics of age and sex. As we have seen, for a white adolescent female from a rural-urban fringe community, access to the city is strongly curtailed by parents, while the perception of a black adolescent male is that he is highly susceptible to being "pulled over" and harassed by the police in the suburb.

Another way of examining this interaction is in terms of access to vehicles. For the black adolescents in the city, where vehicle ownership per household is 0.91 , the likelihood of their being able to have use of a vehicle once they reach the the legal driving age is arguably less than that of their contemporaries in the suburbs or rural-urban fringe, where vehicle ownership rises to 1.68 and 2.08 respectively (U.S. Bureau of the Census, 1990). Thus for the adolescents in the city, the period of restricted mobility is likely to be longer than for the more affluent adolescents, who, once they reach the age of sixteen, invariably have some limited use of a family car. Furthermore, gender compounds the mobility and accessibility situation of the black urban male through the informal restrictions imposed by neighborhood turf issues.

Figure 14. "I can't have my mom running me everywhere": Adolescents, leisure, and accessibility

(McMeeking \& Purkayastha, 1995). 
The main limitation of the study was the sample. Both the work and general life conditions of these workers in one organization were too homogeneous to test the effects of a full range of conditions in the workplace, family and community, or leisure. The subscales will be further refined, but are adequate for analysis and provide a base for such revision. Scale development can progress with the addition of samples that either are drawn from other workplaces or represent other communities more diverse in race, ethnicity, and other factors in life conditions. Useful additions to the scales will be items more directly measuring self-determination in each domain and also the relative centrality of domains and overall life satisfaction.

Figure 15. Multiple dimensions of meaning in the domains of work, family, and leisure (Kelly \&

Kelly, 1994). 
American adolescents (for exceptions see Bohnert et al., 2008; Larson et al., 2001). We conducted additional tests and found no racial differences for participation in either set of core activities or the balance sports and games activities. African-American youth, however, had a slightly higher score (significantly different) for balance community activities compared to white adolescents and to adolescents of other ethnicities. The lack of theoretical and empirical work addressing

African-American adolescents' leisure behaviors, and the lack of power in the current study to fully test race differences in leisure participation or in the models examining associations among leisure, supportive communication and relationship satisfaction, limit the conclusions that can be drawn about the role race might play in explaining the findings of the current study. Future research with more diverse samples of youth may add to understanding whether race or other cultural differences affect leisure activity selection or associations between leisure, supportive communication and relationship satisfaction.

Figure 16. Young adolescents' shared leisure activities with close friends and dating partners:

Associations with supportive communication and relationship satisfaction (Tuggle et al., 2016). 
The purpose of this paper is to explore the role of social justice youth development (SJYD) through the journey of one young woman's relationship with her local YMCA. Through using visual and narrative methodologies, we provide more insight into the literature of marginalized youth and the use of recreational spaces. We present two critical components of SJYD, selfawareness and critical consciousness in order to tackle the interrelationships between and the importance of racial/ethnic identity, access to recreational centers as a leisure space, and social justice in the development of marginalized youth.

Figure 17: Just spaces: Urban recreation centers as sites for social justice youth development (Pryor \& Outley, 2014). 
Part of this Puritanism, which seeks to deny real differences among ethnic groups, age groups, genders, races, and other divisions of society, is actually a sort of pessimism about human ability to change. The Japanese, for example, raised the average IQ of school age children dramatically over a period of a few decades (Jones, 1993). This was obviously not the result of genetic change. Thus, the good news is that, while human groups differ with regard to intelligence, such differences are not immutable but rather capable of being changed by human endeavor. Such good news is largely lost on those who seek to deny difference among human groups in the name of political correctness.

Figure 18. The future of leisure studies (Godbey, 2000). 


\section{Recommendations for the study of radical healing}

Radical healing assumes that systems of oppression shape the everyday lives of Black youth. Theoretical and conceptual frameworks adopted for radical healing studies should therefore illuminate the presence and inner workings of those systems. Mowatt (2017) presented a detailed overview of several frameworks that highlight systems of oppression, including the veil, double consciousness, symbolic racism, social boundary theory, and the theory of racialization. These frameworks should also be supported by qualitative methods that emphasize the unique voices and experiences of Black young people given the emphasis on youth agency within radical healing. Qualitative youth research is sometimes conducted on behalf of youth, where the voices of program leaders or parents are emphasized at the expense of youth perspectives. This approach may unintentionally deepen the very problem that sparked the need for radical healing programs: that Black childhoods are both unimagined and unimaginable (Dumas \& Nelson, 2016).

Figure 19. Power threats and radical healing in Black youths' leisure (Theriault, 2019). 
While slight increases exist in faculty of color, disappointingly little change has been noted among the presence of students of color in recreation, parks, and leisure studies curricula. Bialeschki and Dorward (1998) noted that, "Percentages of people of color were still quite low in all degree [level] areas..." (p. 4). According to a comparison of data from the 1988 and 1998 reports, students of color in recreation, parks, and leisure studies curricula grew slightly from $11 \%$ to $14 \%$ on the baccalaureate level, from $4 \%$ to $11 \%$ on the master's level, but showed no growth on the doctoral level at $4 \%$ each. Although some improvement is evident, the percentage of students of color are not equivalent to the percentage of individuals of color in the general population. According to the Population Profile of the United States 1995, non-white individuals (i.e., African Americans, Latin Americans, Asian and Pacific Islanders, American Indians, Eskimos, and Aleuts) make up $25.6 \%$ of the total United States population (US Census Bureau, 1999). These data reflect the need for innovative strategies to recruit and retain underrepresented faculty and students in recreation, parks, and leisure studies curricula.|

Figure 20. Increasing diversity among students in recreation, parks, and leisure studies curricula: A case study (Bedini et al., 2000). 
The population of the United States (U.S.) is becoming increasingly diverse, with self-identified racial and ethnic minorities projected to reach about $50 \%$ of the U.S. population by the year 2050 (U.S. Census Bureau, 2001). This increased diversity has brought the importance of developing multicultural competent citizens to the forefront of higher education, with service-learning identified as one of the primary ways higher education can foster good citizenship development (Einfeld \& Collins, 2008). In its ability to promote self-reflection, service learning is a unique tool that can help students reflect on multicultural differences toward achieving cultural competence. Within the field of public recreation, the need for learning opportunities for students with people who are "different" than themselves is crucial given the diverse nature of today's society.

Figure 21. The relationship between multicultural service-learning and self-reported multicultural competencies in undergraduate students: A qualitative participatory action study (Smith et al., 2011). 
In relation to this, hooks (1994) stated, "once we start talking in the classroom about the body and about how we live in our bodies, we're automatically challenging the way power has orchestrated itself in that particular institutionalized space" (p. 137). In doing so, we must acknowledge that racial histories have created unequal playing fields that will continue until a true level playing field can be created, not one that superficially levels play. As Fields (1982) warned that when "one human being can be a simple extension of the will of another" all relationships henceforth will be problematic (p. 161). For people of color as Fanon (1994) added further, "consciousness of the body is a solely negating activity... [for] the body is surrounded by an atmosphere of certain uncertainty" because placement in society is pre-determined, without consultation or input from its owner (pp. 110-111).

Figure 22. Notes from a leisure son: Expanding an understanding of whiteness in leisure (Mowatt, 2009). 
By analyzing the experiences of women textile and tobacco workers at a particular historical moment, we can draw conclusions to further both disciplines of leisure studies and history. First, one might conclude from the use of leisure as a means to another end that leisure does not have to be intrinsic to be individually fulfilling or valuable. Leisure can be relational not only in the interpersonal sense of textile community suppers but on a larger level of race, class, and gender as participants assign meaning to activities based on the history of their communities or choose to include and exclude individuals on the basis of demographic categories. Finally, leisure can reflect social hierarchies as well as challenge them. Recreation, on the surface, may seem far less dangerous to the social order than political movements or unions, but when layered with broader community needs, can be a similarly effective tool for institution-building and social change. Collaborative efforts between historians and leisure studies researchers are imperative if we are to build a body of knowledge inclusive of the many voices from our past. Ultimately, perhaps the greatest contribution is the recognition of the critical need for a leisure-based perspective on history and an historical foundation for leisure. Historical perspectives will situate much of our un-

Figure 23. "You have to have some fun to go along with your work": The interplay of race, class, gender, and leisure in the Industrial New South (Bialeschki \& Walbert, 1998). 